CHIVERS D.J. \& HLADIK C.M. (1980) - Morphology of the gastrointestinal tract in primates: Comparisons with other mammals in relation to diet. Journal of Morphology, 166 : 337-386.

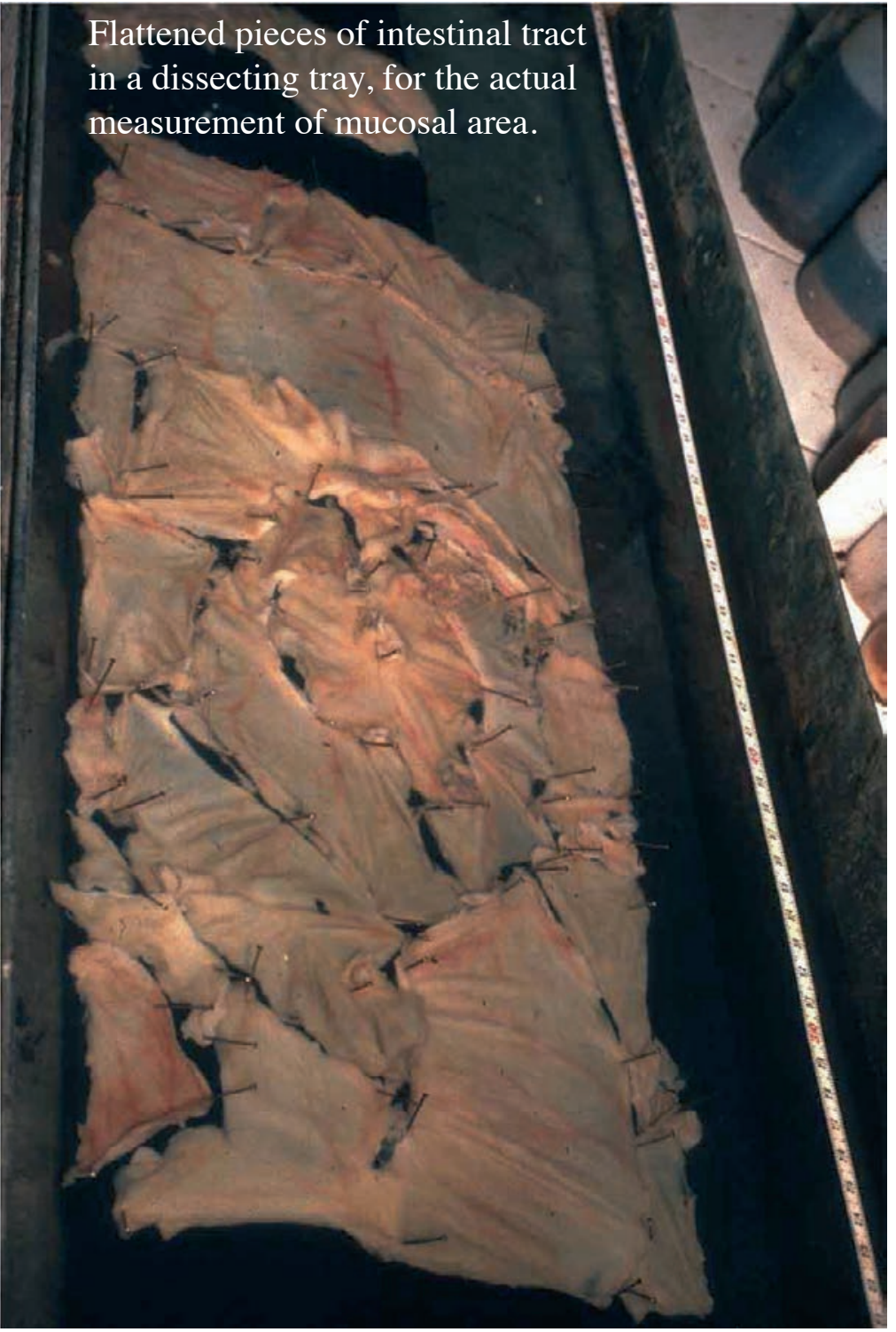

\title{
Morphology of the Gastrointestinal Tract in Primates: Comparisons With Other Mammals in Relation to Diet
}

DAVID J. CHIVERS AND C.M. HLADIK

Sub-Department of Veterinary Anatomy, University of Cambridge, Tennis Court Road, France

ABSTRACT Three categories of dietary adaptation are recognized-faunivory, frugivory, and folivory - according to the distinctive structural and biochemical features of animal matter, fruit, and leaves respectively, and the predominance of only one in the diets of most species.

Mammals subsisting mainly on animal matter have a simple stomach and colon and a long small intestine, whereas folivorous species have a complex stomach and/or an enlarged caecum and colon; mammals eating mostly fruit have an intermediate morphology, according to the nature of the fruit and their tendency to supplement this diet with either animal matter or leaves. The tendency to supplement this diet with either animal matter or leaves. The
frugivorous group are mostly primates: 50 of the 78 mammalian species, and 117 of the 180 individuals included in this analysis are primates.

Coefficients of gut differentiation, the ratio of stomach and large intestine to small intestine (by area, weight, and volume), are low in faunivores and high in folivores; the continuous spread of coefficients reflects the different degrees of adaptation to these two dietary extremes.

Interspecific comparisons are developed by allowing for allometric factors. In faunivores, in which fermentation is minimal, the volume of stomach and large intestine is related to actual body size, whereas these chambers are more voluminous in larger frugivores and mid-gut fermenting folivores; fore-gut fermenters show a marked decrease in capacity with increasing body size. Surface areas for absorption are related to metabolic body size, directly so rugivores; area for absorption is relatively less in lar arger folivores, especially those with large stomachs.

Indices of gut specialization are derived from these regressions by nonlinear transformation, with references to the main functional features of capacity for fermentation and surface area for absorption.

These are directly comparable with the dietary index, derived from quantitative feeding data displayed on a three-dimensional graph, with all species within a crescentic path from $100 \%$ faunivory through $55-80 \%$ frugivory to $100 \%$ folivory, perhaps illustrating, at least for primates, the evolutionary path from primitive insectivorous forms through three major ecological grades.

Recent field studies of primates have produced major advances in our understanding of their feeding behaviour and diet (CluttonBrock, '77; Chivers and Herbert, '78; Hladik, '75). The introduction of quantitative assessments of diet in these field studies allows precise comparisons between food intake and the morphology of the gastro-intestinal tract. Detailed descriptions of gut morphology in mammals (Mitchell, '05; Bolk et at,'
Grassé, '55; Hill, '58) have also lacked effective quantification. The first quantitative effort at comparing gut morphology with diet (Cuvier, 1805) produced no obvious correlations. nan ('12), however, working with areas rathe than lengths, demonstrated a correlation between structure and diet (in corelation bebut but data are not presented so that his conclube verified. Preliminary efforts at 
67) showed interesting relationships among primates, but data on diet were still inadequate.

Our aims in this paper are 1) to describe various features of gut morphology with greater precision and quantification, 2) to present data from our field and laboratory tudies, 3) to account for allometric factors in the disusion of interspecifie differences, and 4) to compare these data on morphology with what is pow known about the feeding ecolog what is now known about th

of data on primates with those on domestic and other mammals is use ful, because it allows a group of elosely-related species with considerable dietary flexibility to be contrasted with others which have become highly specialized for markedly different diet. While the structure of the gastro-intestinal tract is fairly homogeneous among the different orders of mammals, there have been parallel developments of different parts of the gut in various evolutionary lineages, These reflect adaptations to different foods, which can be classified into three major groups, accordin to structure and biochemical composition, and the resulting digestive requirement-

1) "Animal matter," including invertebrates, fish, and other small vertebrates from the secondary production of the ecosystem, which provide sources of protein and fat that are easily digested and, therefore, require a relative short and simple

2) "Fruits," ineluding unripe (e. or flowers and ripe (fleshy) parts, and ripe (neshy parts, seeds, and tubersmostly the reproductive parts or plants which are food containing shortechain sugars that are hydrolysed rapidly in tracts of large intestinal area for rapid absorption and inmediate use.

3) "Leaves," including young and mature leaves, grasses, stems, as well as barks and gums - the vegetative parts of plants - which are foods usually containing protein and longchain sugars that require fermentation in a enlarged stomach or large intestine.

According to the predominant items consumed, three categories of dietary adaptatio may be recognized, and in this paper they are referred to hereafter as faunivore, frugivore, and folivore respectively (recognition of insectivore, carnivore, and herbivore, with their taxonomic and other connotations, contribute little to this analysis). These categories represent a gradation, for a generalized mammat, from fonds that are relatively difficult to col- available in limited quantity (fruit), to those that are widely abundant but relatively difficult to digest (leaves). Hence the need for marked differentiation of feeding strateg $y$ ani gut morphology. A classification in terms of three dietary grades (Hladik, '78a), with ap propriate subdivisions, allows ity, and seems to represen tion, and seoss to different types of food.

COMPARATIVE ANATOMY OF THE GASTRO INTESTINAL TRACT

The structure of the wall of the gastro-in testinal tract follows a pattern common to al vertebrates: the inner lining of mucous mem brane is separated by connective tissue from ane is separated by connective tissue from an outer cylinder of at least two layers of fects divisions into stomach, small intestin dects divisions into stomach, small intestime duodenum, jejunum, ileum), and large intestine (caecum and colon). Brief reference wil made to various configurations of the mucosa and underlying connective tissue, which apparently assist digestion mechanically, by mixing or slowing the passage of food or by increasing the surface area for digestion an trae (sacculations), villi

In this section we shall try to identify those structures relating to each of the three main lietary adaptation che vious knowlede with new inter are me from in water and positioned to show the main eatures clearly; a complete reconstruction, impossible by photograph, is achieved by mov ing parts of the tract while drawing, and adjusting the dimensions of each region afte dissection and ineasurement.

\section{Faunivores}

The basic pattern of gut structure among aunivores consists of a simple globular stomach, tortuous small intestine, short conical caecum, and simple smooth-walled colon. Thi pattern is exhibited by primates feeding mainly on invertebrates, such as Arctocebus (Fig. 1), Loris, and Tarsius. In other mammals there may be structural specialization in one direc tion or another. The smallest mammalian gut known is found in the insectivorous bat, Rhin opome; its tract is only four-fifths of body length (Grassé, '55). Simplification of the gut is extreme in haemophagous bats, such Desmone, with the reductions are clearly specializations, rathe than representing the primitive condition. Specializations of faunivores may also in volve the stomach. Some ant-eating edentates also lack a caecum and the gut is only seven times body length, but the

a "muscular tooth" compensating for the lack of oral teeth (Grassé, '55). A similar muscular specialization is found in pholidotes, such as the termite-eating pangolin, Manis (Fig supplemented by a keratinized area in the pylorus and by the presence of small stones.

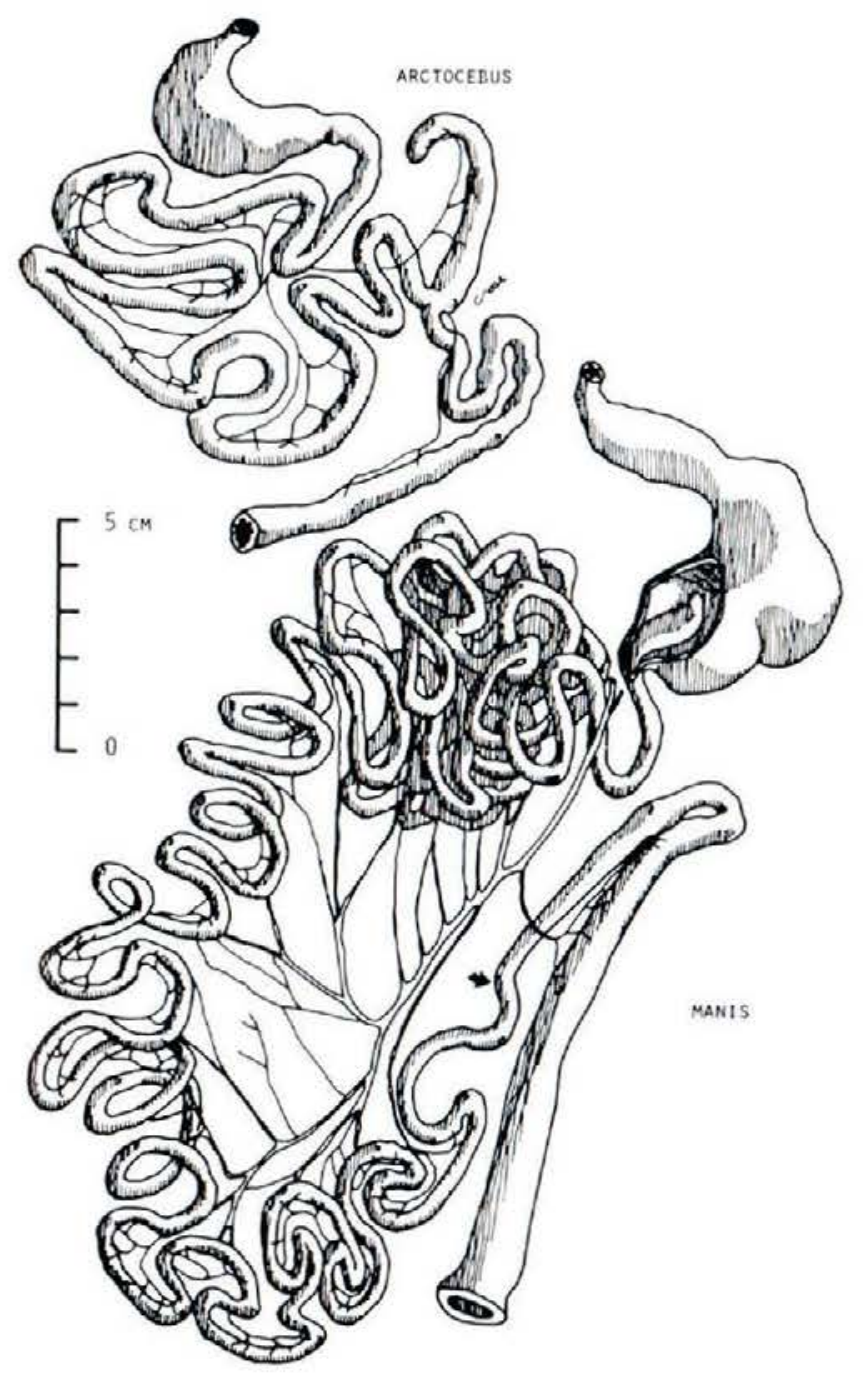

Fig. 1. Gastro-intestinal tracts of faunivores, drawn by C.M.H., with accurate scaling of proportions, main features. The angwantibo, Arctocebus colabarensis (specimen $\mathrm{FC}$, see table 5) is one different morphologica in terms of morphology. The pangolin, Manis giguntea (specimen MR, juvenile) is presented below with an open stomach to show the muscular "tooth;" the arrow marks the junction of ileum and colon, determined from microscopic examination of the mucosal wall: the extreme length of the small intestine did not allow it to be 
In cetaceans the stomach has three main compartments (Harrison et al., '70). The first and largest is covered by folds of thick, keratinized epithelium, the second by spirally arranged folds of thick, glandular epithelium (making a direct channel along the lesser curvature), and the third, tubular compartment has a simple pyloric mucosa and strons sphincters at both ends, e.g., the porpoise sphincters at both ends, ing from a dilated duodenum, is very lon ing from a dilated duodenum, is very long very the disecting micros tope by the abrupt tre the dissecting microseope by sition from villi to crypts.

In the Insectivora the simple stomach is followed by a very short small intestine and, usually, no caecum - as illustrated by Poto mogale (Fig. 3), which is adapted for feeding on freshwater fish and crustaceans. In Sorex the tract is only 2.6 times body length, and some faeces are reingested to permit a second opportunity for digestion. This phenomenon of reflection (Crowcroft, '52) helps to explain the reduction in gut size as a physiological/behav ioral specialization. In one species of Tenrec, which eats foods other than insects, the tract may be seven times body length. Tree shrews, Tupaia, which also supplement their invertebrate diet with fruit, have a slightly larger colon than other insectivores and a smal caecum (Grassé '55). Some rodents subsist on a diet composed entirely of insects or other animal prey. In the African murid Lophuroanys, for prample, specialization to such a includes a change in the distribution of a diet includes a change in the distribu

glands (Genest-Villard, 1968). Other mammals, such as some feeding on vertebrates, show no obvious specialization. In fissipedes, for example, the stomach is simple, the small intestine four to six times body length, the caecum small or absent, and the colon reduced, as shown in the Viverridae by the African linsang Poiana (Fig. 3) and the mongoose Atilax, and in the Felidae by the golden cat Profelis (Fig. 4). The shape, inter nal features, and relative sizes of fundus and pylorus vary slightly among such mammals, as described by Ellenberger and Baum (' 21 and illustrated here by the domestic dog, Canis (Fig. 5)

\section{Frugivores}

This group contains most primates, but none of them subsists entirely on fruit. All frugivores supplement their diets with varyin amounts of insects and/or leaves, but have $\mathrm{no}$ distinctive structural specialization in the gut, although its morphology may show considerable variation between species.

Some Carnivora also have this mixed diet, but retain the structural features of faunivores, e.g., the palm civet Nandinia feeds heavily on fruit (Charles-Dominique, '78), but has no caecum and a reduced colon (Fig. 6). Myoxid rodents also have no caecum (Grassé, '55), and their predation on birds, as a supplement to seeds and fruit, places them on the border between faunivos vores. In the stomachs of cricetine and frugifund in their dimengions, cardial gland region vary in their dimensions, separated by a fold of varying shape (Carleton, 73). In frugivorous bats the stomach is relatively complex, with a distinct cardial region, a long pyloric diver"culum folded back on itself, and a lateral "caecum"; the true caecum is present in several genera (Grassé, '55)

Among artiodactyls, the pigs have a stomach that is clearly divided into zones, and in some cases into compartments; they have an especially long small intestine, a large caecum, and a relatively complex colon, so that the whole tract is about 20 times body length. These elaborations relate to the inclusion of roots and other vegetative parts of plants in their diet.

Gut structure is more homogeneous among frugivorous primates (Figs. 7, 8, 9). The stomach is essentially simple and globular in structure (Hill, '58). Marmosets show some elongation of the fundus, whereas those of cebids are more specialized with a globular fundus, conical body, and cylindrical pylorus, Alouatta, which also eats many leaves $(40 \%$ of diet ta, which also eats many leaves (40\% of diet by weight, Hlo eats many leaves greatest complexity, with a capacious globular sac, narrowing towards the bent tubular pylorus, which is guarded by strong pillars, rugae radiate from the cardia and run longitudinally within the body. Ateles, which is one of the most frugivorous and swallows many stones, has an enlarged J-shaped stomach. Old World primates, other than colobine monkeys, have a single smooth-walled sac, among the apes it is more globular and man-like in gibbons, even more globular in gorillas, and more elongated in chimpanzees and orangutans (Hill, '58).

The duodenum is commonly C-shaped, in contrast to the elongated U-shape of other mammals; in some cebids and all catarrhines it is retroperitoneal. The caecum is large in frugivorous prosimians, short and wide in marmosets, and hook-shaped in cebids; in catarrhines the base is globular, the body short and capacious, and the apex blunt and conical, with a terminal vermiform appendix in hom. inoids (Hill '58).

The colon is simple and straight in cebid such as Saimiri there is a transverse colon in Cebus and Aotus, and a right colon as well in Callicebus, Cacajao, and Pithecio. Further elongation (and foldingtoecurs in callitrichids, elongation (and folding occurs in callitrichids. Taenia coli (reduction of longitudinal muscle

into bands) are lacking in Saimiri, Cehus, and most prosimians, but there may be one or two in Nycticebus, Perodicticus (Fig 6), Lemur. and callitrichids, and cebids and most catarrhines otherwise have three, except for gibbons with four (Hill, '58). The ant ror gibin the transerse colon is comm in prop mine (Fir. 6): this part of the colon prosilong and be this part of the long apeus colonstercible leaf content in the diet and its potential for fermentation.

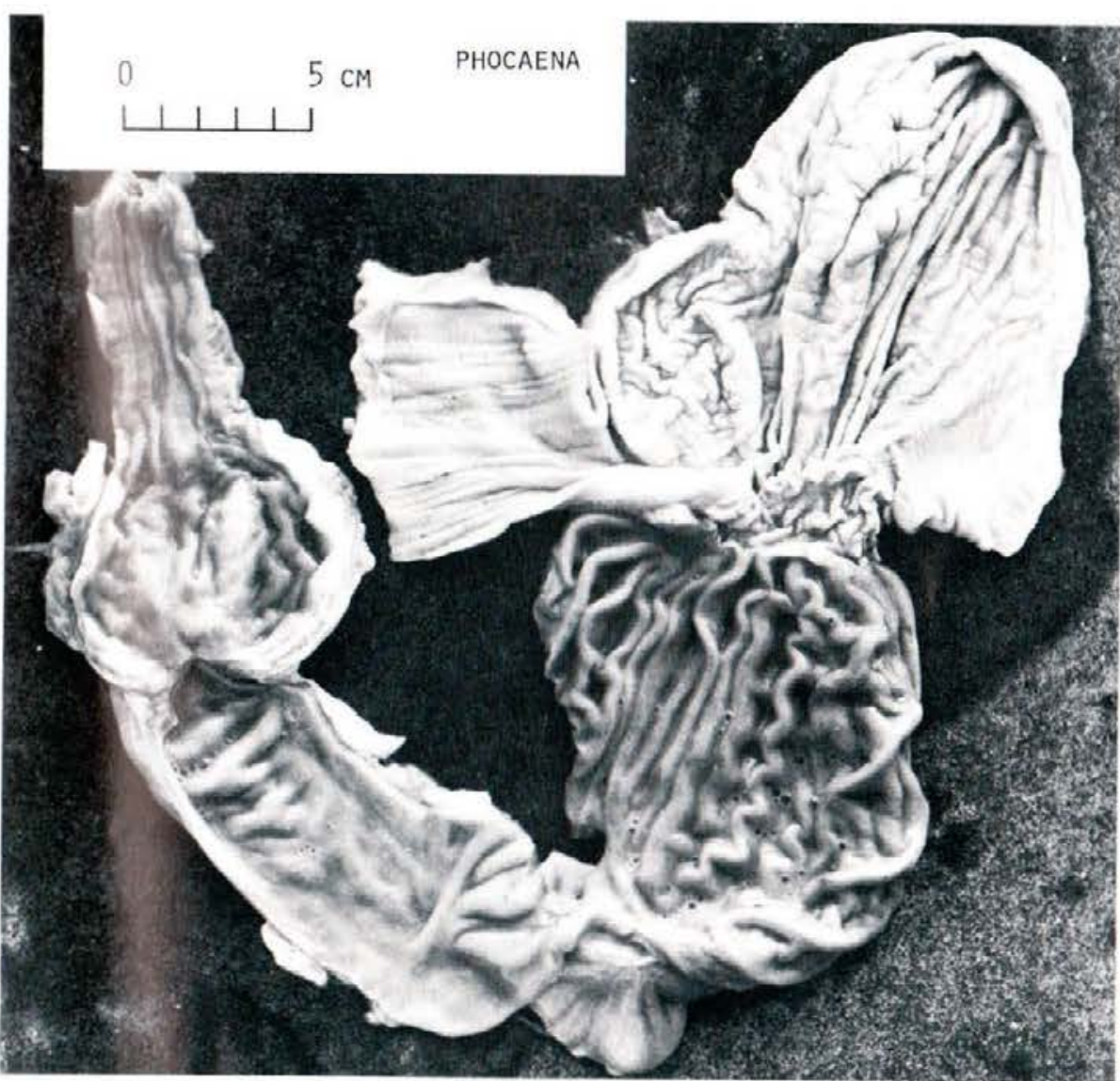

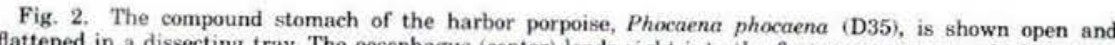
opens into the glandular chamber (lower). the first leads right into the first compartment, which in turn (lower center) leading up to the pyloric sphincter and thence into the duodenal diverticulum; the mucosal folds, Cambridge Univerth of the intestine, ean be seen (upper left). Photo by D.J.C. and Department of Anatomy, 

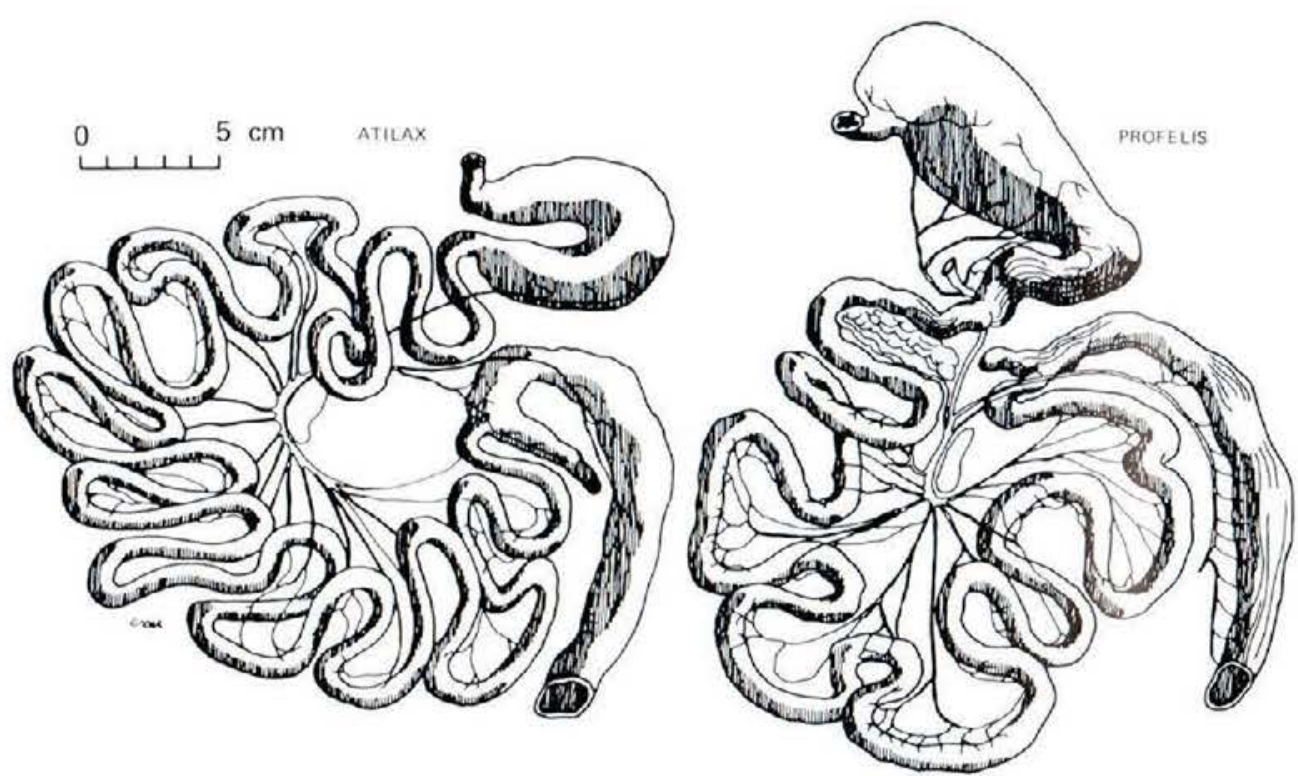

Fig. 3. Gastro-intestinal tract of Potamogale velox (MX) presented as in Figure 1, with the arrow marking the junction of small intestine and colon. In Poiana richardsoni (MS), to the right, the limit of the colon is clearly marked by a short caecun. Drawings by
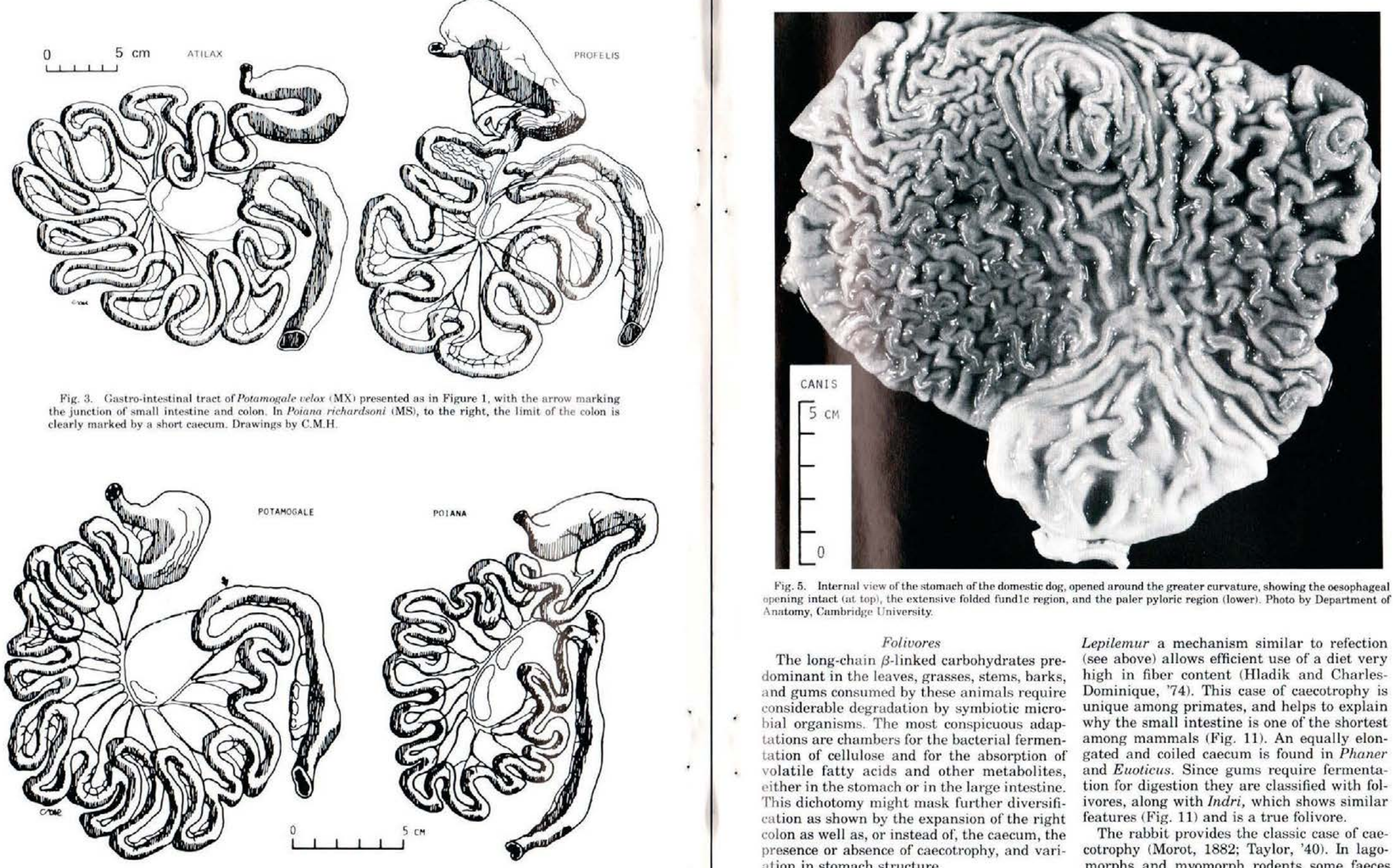

Fig. 5. Internal view of the stomach of the domestic dog, opened around the greater curvature, showing the oesophageal apening intact (at top), the extensive folded fundle region, and the paler pyloric region (lower). Photo by Department of

Folivores

The long-chain $\beta$-linked carbohydrates predominant in the leaves, grasses, stems, barks, and gums consumed by these animals require considerable degradation by symbiotic microbial organisms. The most conspicuous adaptations are chambers for the bacterial fermentations are chambers for the bacterial fermenvolatile fatty acids and other metabolites, volatile fatty acids and other metabolites, This dichotomy might mask further diversifcation as shown by the mask further diversification as shown by the expansion of the right colon as well as, or instead of, the caecum, the presence or absence of caecotrophy, and variation in stomach structure.

The large intestine is enlarged in those prosimians which feed on leaves or gums.
Lepilemur a mechanism similar to refection (see above) allows efficient use of a diet very high in fiber content (Hladik and CharlesDominique, '74). This case of caecotrophy is unique among primates, and helps to explain why the small intestine is one of the shortest among mammals (Fig. 11). An equally elongated and coiled caecum is found in Phaner and Euticus. Since gums require fermentation for digestion they are classified with folivores, along with Indri, which shows similar features (Fig. 11) and is a true folivore.

The rabbit provides the classic case of caecotrophy (Morot, 1882; Taylor, '40). In lagomorphs and myomorph rodents some faeces are reingested after fermentation in the capacious caecum, so that metabolites from the 


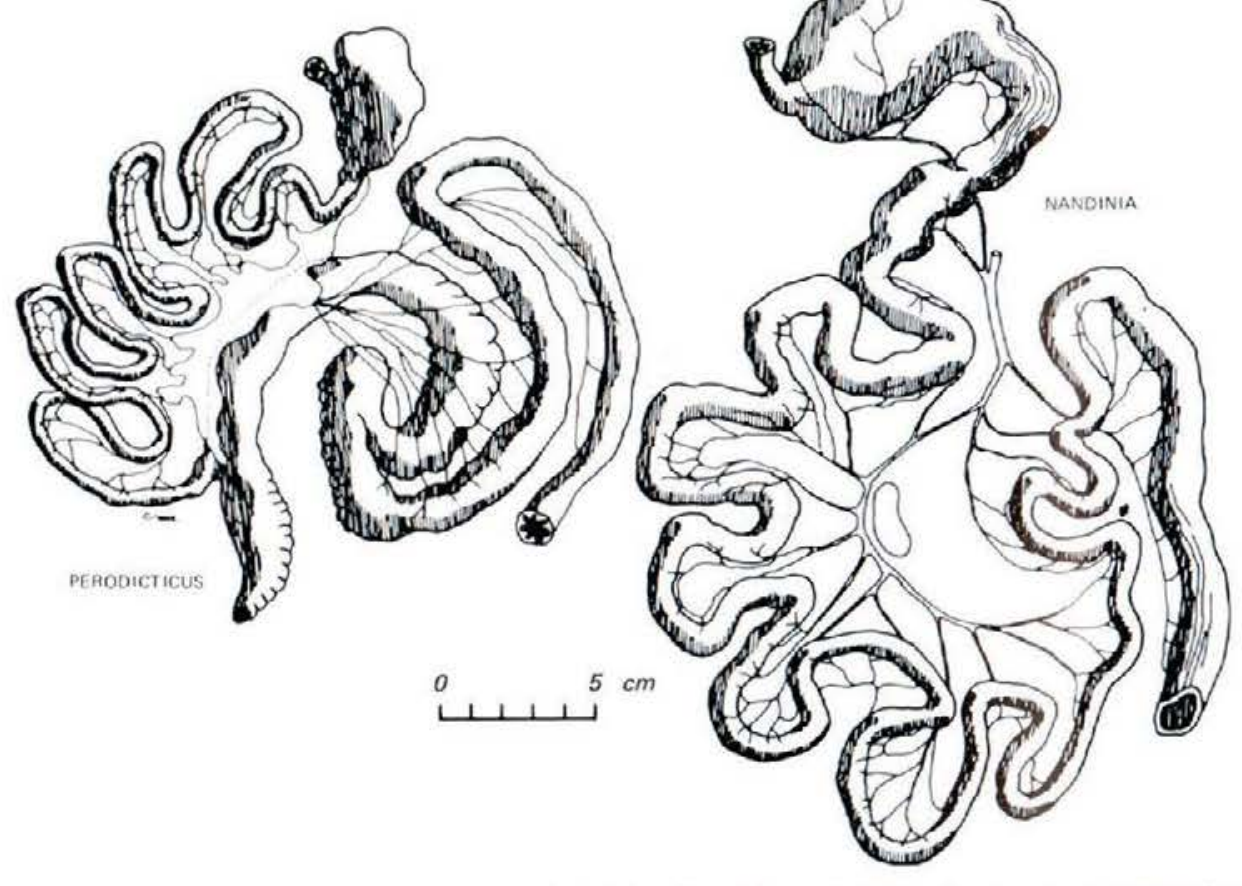

Fig. 6. Gastro-intestinal tracts of frugivores. On the left, from Perodicticus potto (FM), a frugivorous prosimian feedin

partly on animal matter. On the right, the palm civet, Nandinia binotate (MY) is a carnivore feeding

herbivorous diet can be absorbed in the small intestine.

The caecum is very coiled and elongated in "Thecialized folivores, such as the "Blidin" squirrel Anomalurus (Fig. 11) - even more so than in Lepilemur. The most complex large intestine is found in Dendrohyrax (Fig. 12) where the first caecum is followed by two more after about $20 \mathrm{~cm}$ of colon.

With enlargement of the colon in mammal the migration of the ileo-caeco-colic junction can be traced from the left cranial part of the abdominal cavity round to the right caudal aspect, so that the caecum comes to point caudally rather than cranially (Hill, '58). In those species with a voluminous caecum, how ever, cranial rotation has occurred so that it comes to occupy the ventral part of the abdomen, as in the horse (Fig. 13). Perissodactlys and proboscids have large colic loops in addi- tion to the huge sacculated caecum for the breakdown of their fibrous diet. As in other mammals which cope with this kind of diet the horse has a large area of keratinized epithelium in its stomach, which, however, remains simple (Fig. 14). Carleton ('73) suggests that the variable cornification of the stomach lining in different species of cricetine rodents might be correlated with the amoun of cellul might be corre in the diet.

In contrast to perissodactyls, proboscid have contrast to perissodactyls, proboscid have a large folded stomach and a short smal intestine of large internal area. Sirenians, such as the dugong, have a complex two-chambered stomach, with one part fulfilling the wide caecum (Grassé, th5

The most elaborate tracts are found in those folivores, usually subsisting almost entirely on grasses, with complex stomachs for bacte-

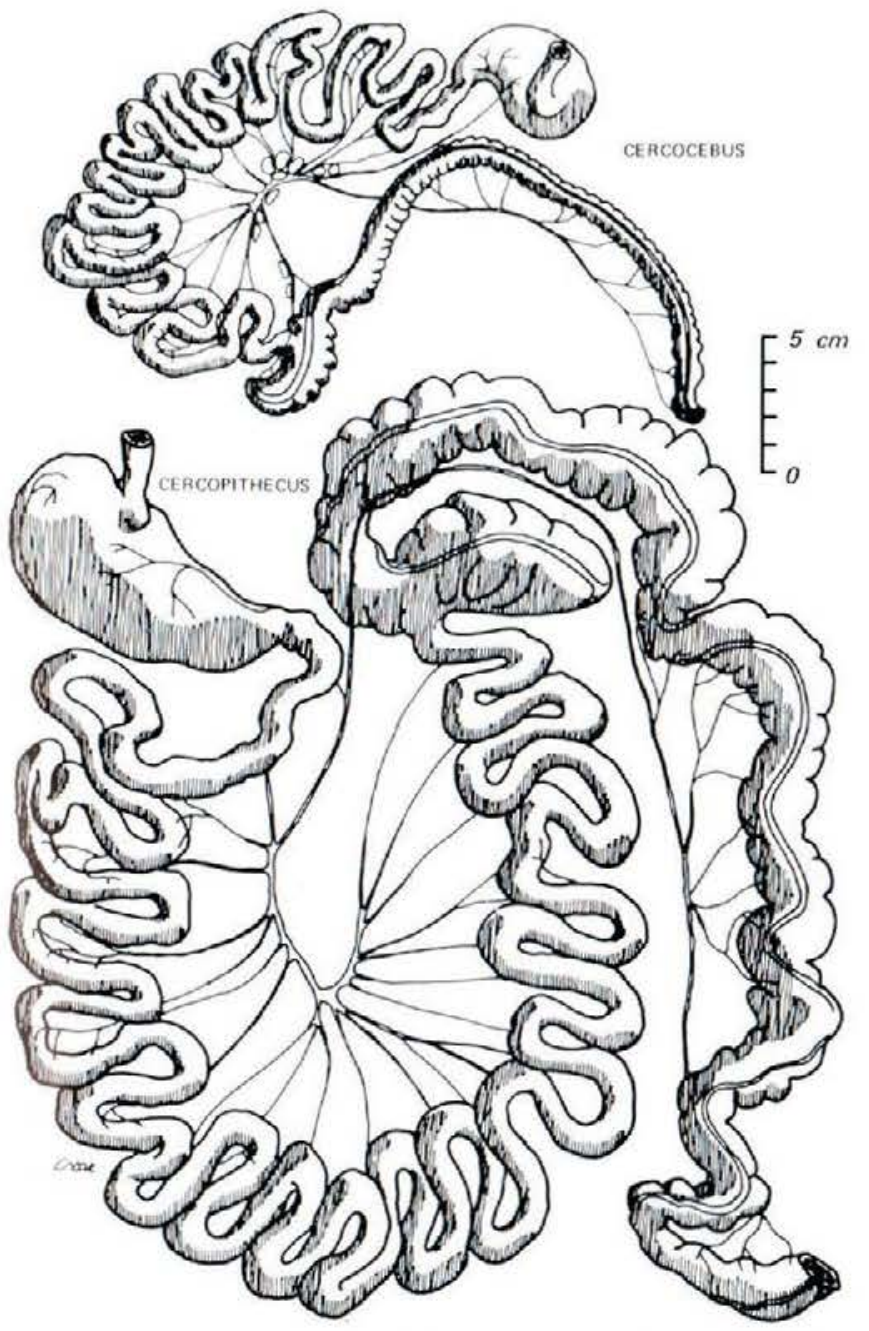

Fig. 7. Gastro-intestinal tracts of frugivorous monkeys. Above, the mangabey Cercocebus

rial fermentation, as exemplified by the artiodactyl ruminants. Macropod marsupials, some edentates, hippopotami, camels, and colobine monkeys show evolutionary converas Cephalophus and Hyemoschus (chevrotain) of Axis and pure types such as the spotted deer tomach structure for folivory (Moir, '68). In pure herbivores, such as the buffalo Symus, these groups there is actually a continuum of (G. Dubost, pers, comm.). These extremes diets from frugivore to folivore, as shown in the continuum are the most specialized form the preceding section for pigs and peccaries Macropod marsupials have a long tubula whose stomachs show some similarity to stomach, 


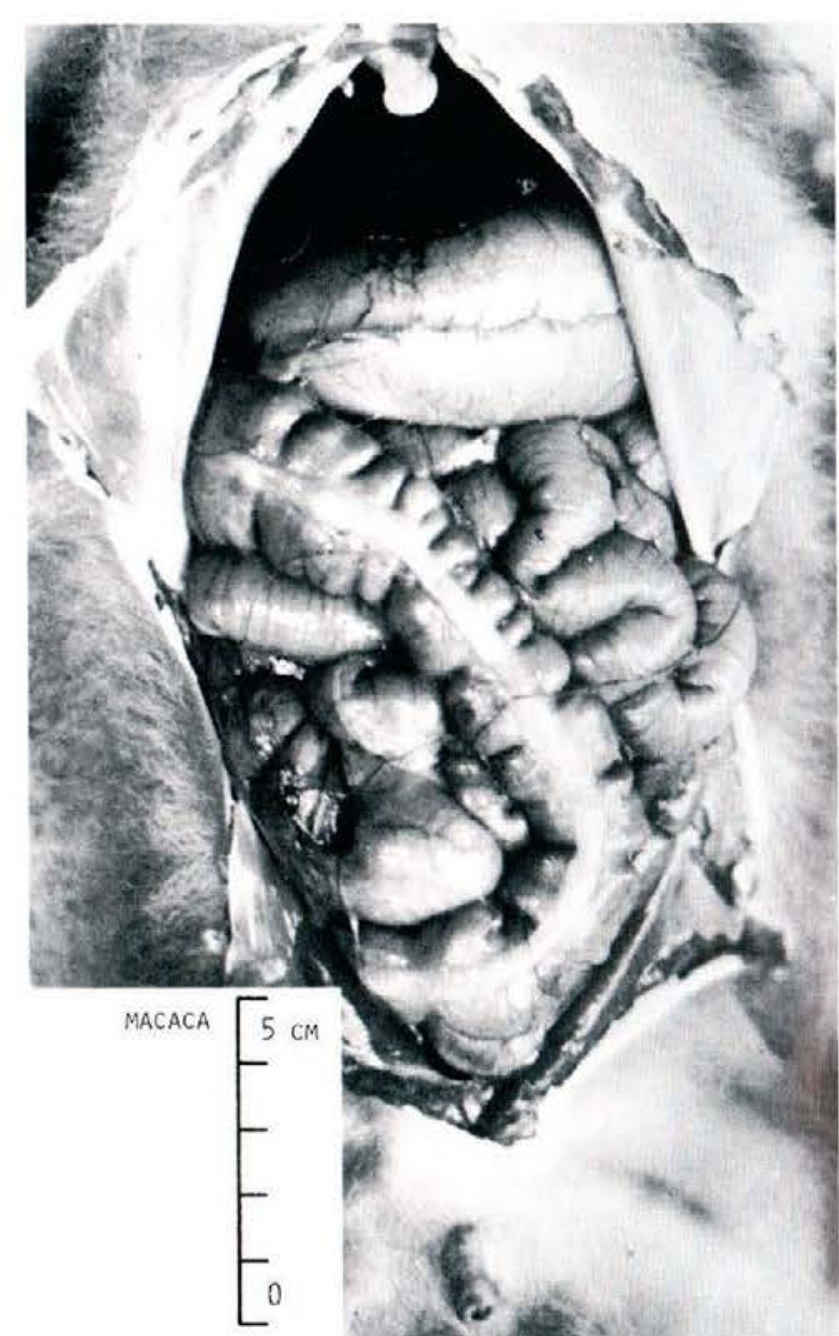

Fig. 8. The disposition of the gastro-intestinal tract within the abdomen of the long-tailed left), and loops of colon, with taenia coli (center). Photo by D.J.C.

curvature, with an oesophageal groove (ruminant feature linking oesophagus with omasum) (Grasse '55). The stomach leads into a long intestine with a wide caecum. Among folivorous edentates, such as the sloth Bradypus, there is a keratinized cardal region, a " small " with two diverticula and an oesophageal groove, and an "abomasum" with an expanded pyloric region with a very thick muscular wall.

The hippopotamus has the oesophagus opening into a vestibule, into which open two unequal diverticula, and which leads into a third tubular chamber; all three chambers have stratified epithelium thrown into proecting folds with numerous papillae. There very long intestine, but no caecum. Camel have a stomach that is smooth and ovoid in

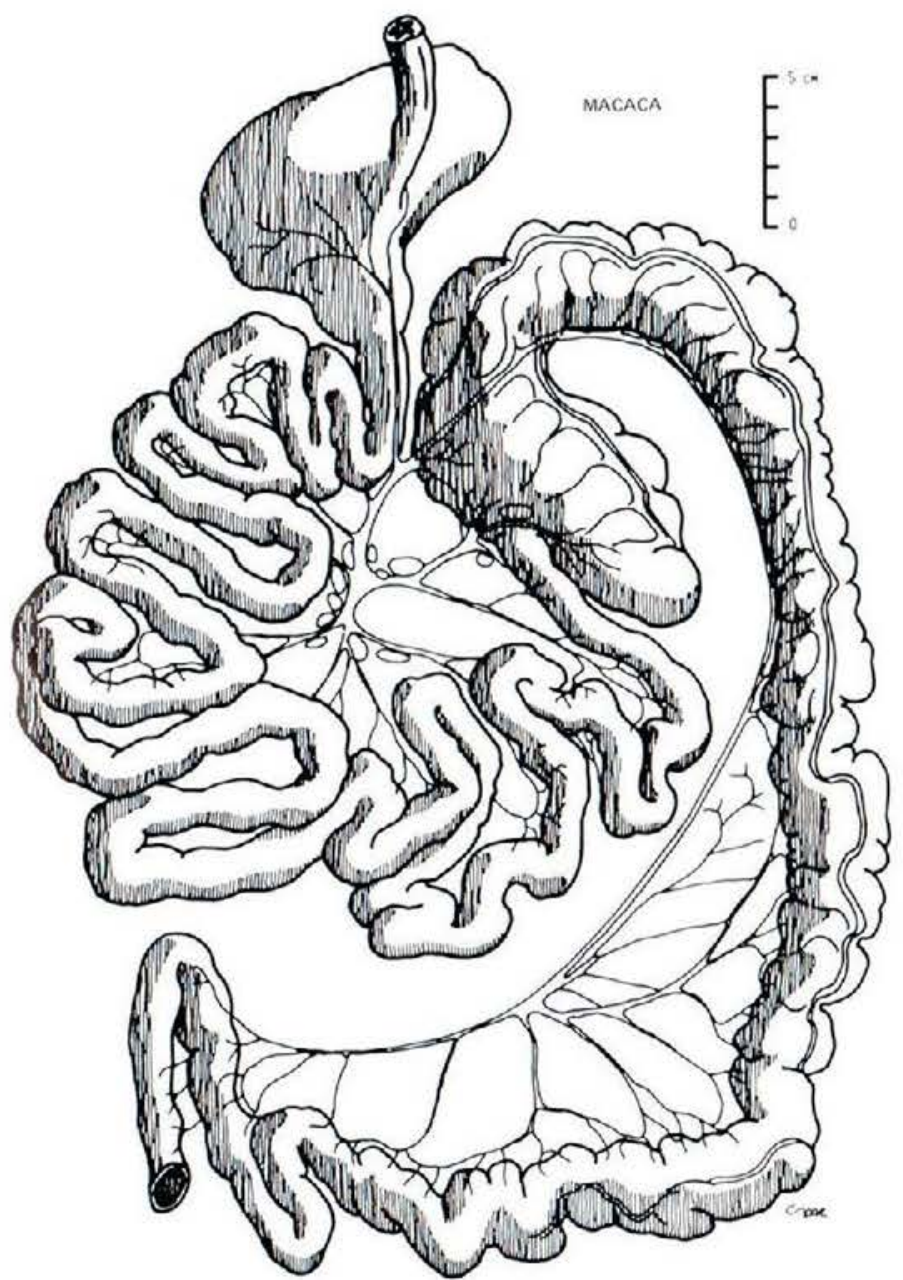

Fig. 9. Gastro-intestinal tract of the barbary macaque, Macaca sylvana (FO), showing a rather larger or than occurs in other irugivorous

shape, composed of two glandular sacs; the the sac, than in Asian colobines, where the omasum and a single tube. Colobine m and complex stomach, with much distension other Old World primates.

and sacculation proximally and a Ushaped The artiodactyl ruminants are well known all part of the oreater curvature (Hill, '58). These al., '68), which is dominated by the vast sacculations are produced by the reduction of men, divided into dorsal and ventral sacs by longitudinal muscle into two or more bands muscular pillars, and covered by keratinized more elongated, with the tube bent back on size and shape (Fig. 16). The oesophagous 

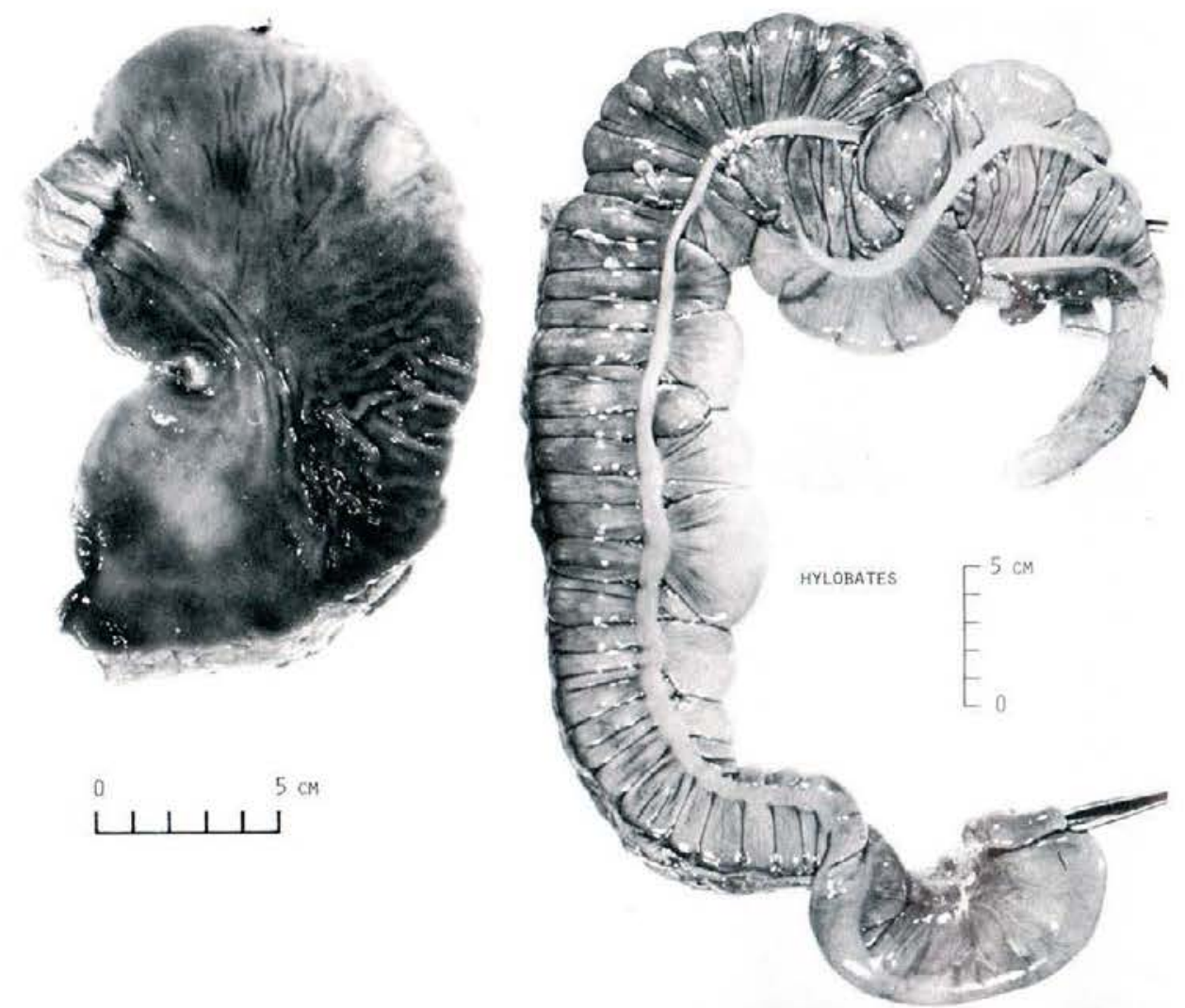

Fig. 10, On the left, an internal view of the stomach of the siamang, Hylobates syndactylus (P27), opened around lesser ito left) and greater curvatures and laid out in a dissecting tray; the oesophagus opens at the upper left, with a dark region of cardial glands, and the pyloric sphincter is at the lower let. On the right, an external view of the siamang' in the uper riph where the verifi, pally dis is a d with, and inmersed in, water; the ileum is clamped by forcep colon is elamped in the lower right. The large volume relates to the large intake of leaves in its diet. Photos by the Department of Anatomy, Cambridge Unviersity

opens into a much smaller reticulum, which has a distinctive honeycomb pattern of ridges (hexagonal in cow and sheep, pentagonal in goats) and is covered by small conical papillae. The rumen connects with the glandular part of the stomach through the small ovoid omasum, which is partitioned by many leaves of varying size for water absorption. The internal surface of the glandular abomasum is thrown into folds throughout the fundic region (Fig. 16). The intestine is again very long, the caecum is relatively short, and the colon is long and elaborately flexed and coiled.

Efforts at demonstrating homologies with

limited success. For example, the stomach of New World ments, with the ventricular groove from the firs to the last; only the reming fifth of the thind tubular com the terminal true fundic and pyoric tor 71). cor while this chamber has mucosal pleats the first two sac-like compartments have areas of large thandular saceules, which not only contain considerable amounts of ingesta, but are capable of frequent eversion. Thus, they seem more likely to contribute secretions to buffer stomach contents, rather than to absorb the ruminant stomach of bovids have had water. It is claimed that such structures aid

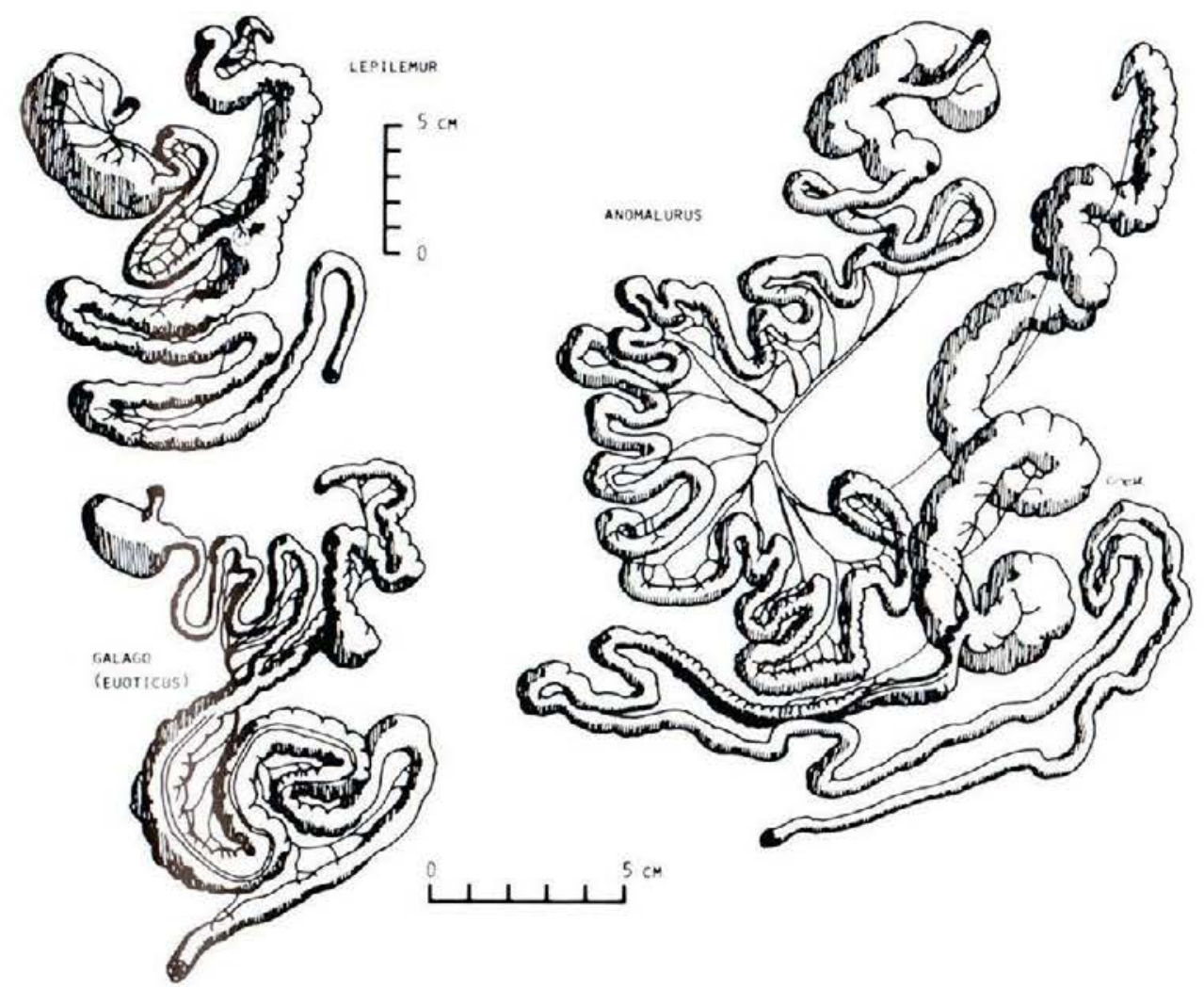

Fig. 11. Gastro-intestinal tracts of folivorous prosimians (left) and a rodent with extreme development of the caecum related to their specialized diets. The sportive lemur, Lepilemur leucopus (DO), upper left, has the shortest small intestine of all primates, il is the only genus in which caecotrophy occurs and the ileo-caeco-colic "plate" (arrowed) probably plays Euoticus eleganulus (DV), lower len, hows a similar morphology adapted to the digestion of gums, composed of lag hain carbohydrates, that also require fermentation. The flving squirrel, Anomalurus fraseri (MT) has a similar gut morphology related to a diet known to be mainly leaves. Drawings by C.M. H.

in a greater efficiency of digesting poor-quality vegetation at high altitudes, where cattle and goats cannot graze.

Janis (76) suggests that horses also have an advantage over cattle in their ability to use a more fibrous diet of low protein by taking in larger quantities which pass

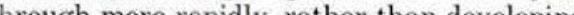
more efficient digestion of cellulose. In discussing the evolutionary strategy of in terms of physiology and ecology, trast their digestive system with the she inants, and refers to the greater extension of bivores that do not practice caecotrophy.
In conclusion, this review of the principal distinguishing features in the mammalian gastro-intestinal tract has emphasized the simple stomach and long small intestine of mammals known to subsist mainly on animal matter, and the elaboration of the stomach and or amall intestine in leaf - or grass-eating forms, with frugivores showing an intermediate m, wh the of cialized, occur among primates, wich unspecilize form at tain the extro tained the extreme adaptations found in other 


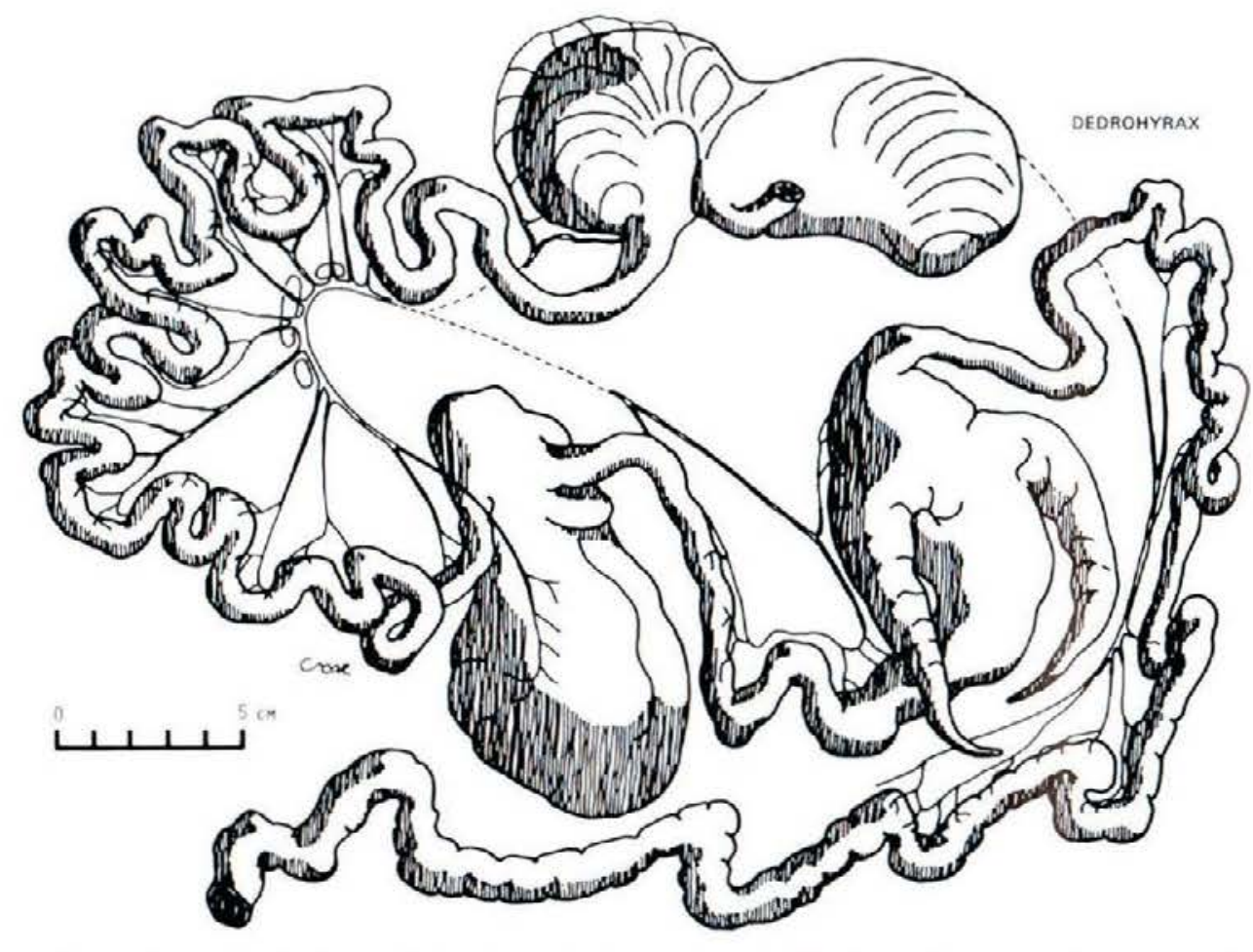

Fig. 12. Gastro-intestinal tract of the tree hyrax, Dendrohyrax dorsalis (MU), showing
of caeca and colon, the exact funetions of which are not yet known. Drawing by C.M.H.

order. Didelphia marsupials, adapted to a similar range of diets, show even less morphological specialization than lorisid and cheirogaleid primates (Charles-Dominique and Hladik, unpubl, observ,); this supports the idea that the gastro-intestinal supports the idea that aspects of mammalian evolution.

asp of mammalian evolution. It has been seen how variations in proportions of different parts of the tract, with certain structural peculiarities, can often be related to different aspects of diet. In some cases the correspondence is not obvious; references quate for a full functional interpretation. A fuller quantitative analysis is necessary to investigate the relationships within and between dietary groups. Having set the scene and illustrated the problems in this survey, we can now proceed with this more detailed evaluation.
QUANTITATIVE ANALYSIS OF GUT MORPHOLOGY Methods

Gastro-intestinal tracts were taken from 180 individuals of 78 mammalian species in England, France, Morocco, Gabon, Madagascar, Sri Lanka, Malaysia, and Panama. There are 117 primates of 48 species, 13 temperate mammals of 7 species ( 2 aquatic), and 24 tropical nonprimate mammals of 17 species. One-hundred forty-eight specimens were caught in their natural habitat by hunters during pest control operations or by local people for captivity, from illness or old age. In addition, 26 domestic mammals of six species were put down during routine marketing, research, or teaching operations.

Larger samples of certain species indicate the level of intraspecific variation, and the food; 29 animals, mostly primates, died in
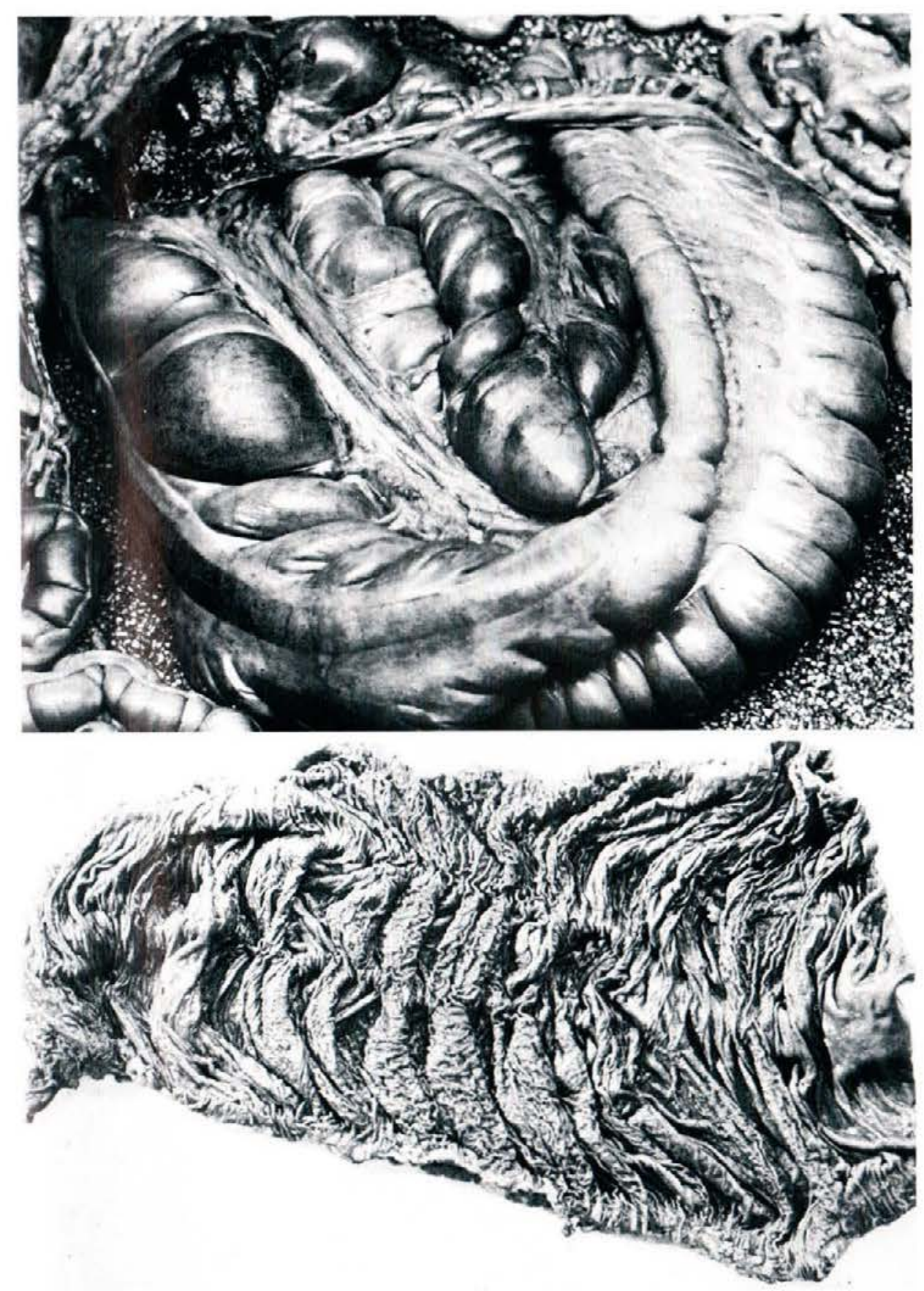

Fig. 13. The large intestines of the domestic horse (D14) showing, above, external shape and large size of the caecum (center) surrounded by dorsal and ventral loops of the primitive right colon, with sternal and diaphragmatic flexures (lower)
and the smaller size of the transverse and left colons, also with taenia coli (lower left corner). Below, the internal appearance of the caecum after opening and washing, before cutting the taenia coli, which increases the length from 80 to $240 \mathrm{~cm}$. Photos liy the Department of Anatomy, Cambridge University. 


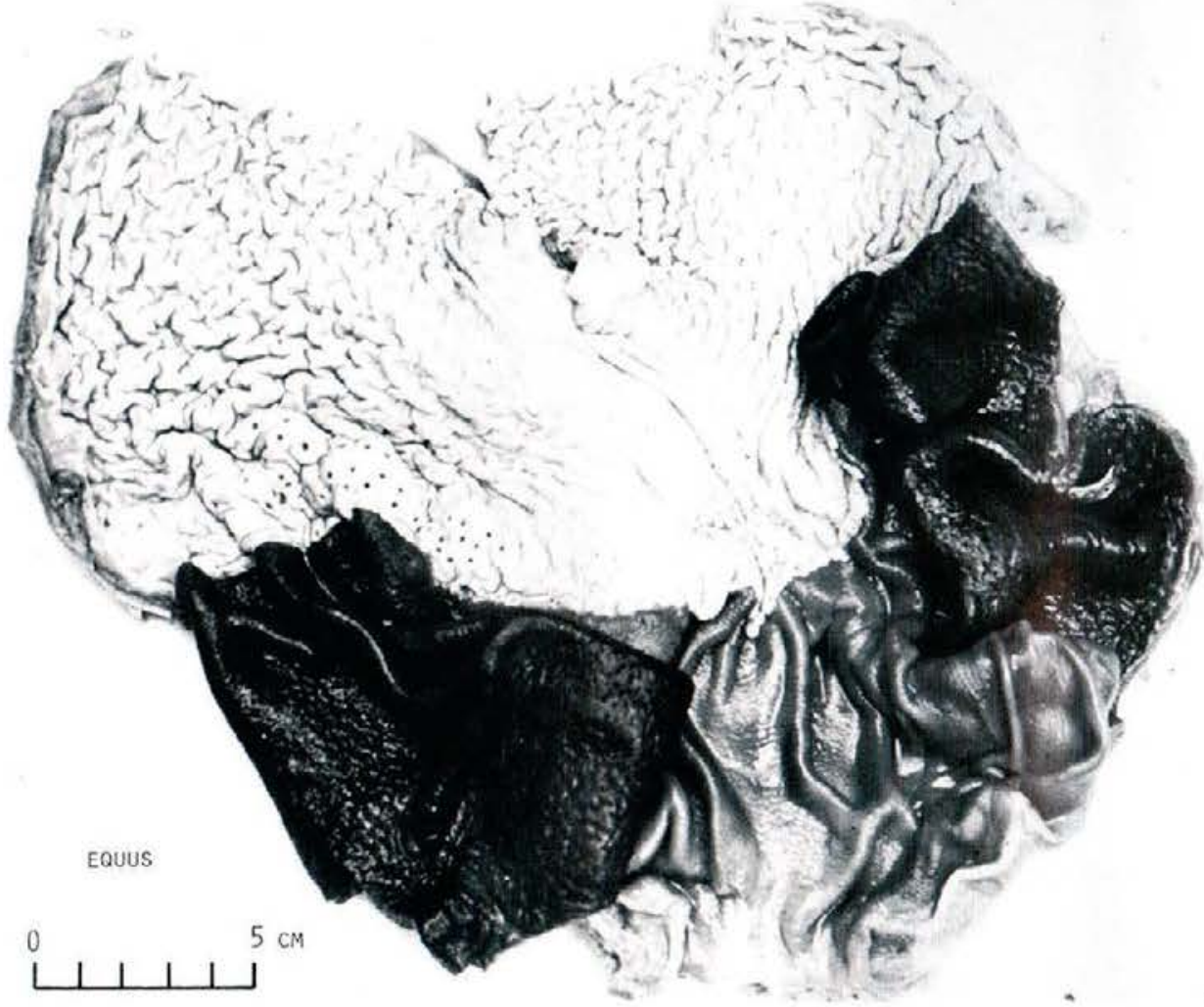

Fig. 14. Internal aspect of the stomach of the domestic horse (P14), opened around the greater curvature to show the large extent of folded, keratinized mucosa around the oesophagus (cf. Figure 2) and up into the saccus caecus (above), the larvae an be Department of Anatomy, Cambridge University.

reliability of small samples. Thirty-seven of analysis, because of the distortion introduced the 78 species are represented by only one by varying lengths of muzzle, especially when specimen, 15 species by only two, and 10 contrasting primates with other mammals. specinen, the sindividuals. There are four The guts of most specimens were examined species by the ser specimen the G. alleni, G. demidovit, Alouatta pallata, Cer- preserved in a saturated saline and then copithecus cephus, $C$. nictituns, Prestix scura, and the domes later study in $10 \%$ formol saline, but measof Arctocebus, Cheirngaleus, Miopithecus, urements under these conditions are affected Vulpes, and Dendrohyrax, six specimens of adversely by contraction at the time of fixaPresbytis melatophos and the domestic cat; tion. Many specimens were examined, drawn, and nine domestic dogs.

Specimens were weighed intact, which was displayed under water in a large dissecting not always possible in the field, and their tray. The dimensions of each region were then lengths were measured from bregma to is- measured, for calculations of area and volume, chium and from tip of nose to base of tail. The and weighed after the removal of excess moislatter measure of length was not used in this ture.
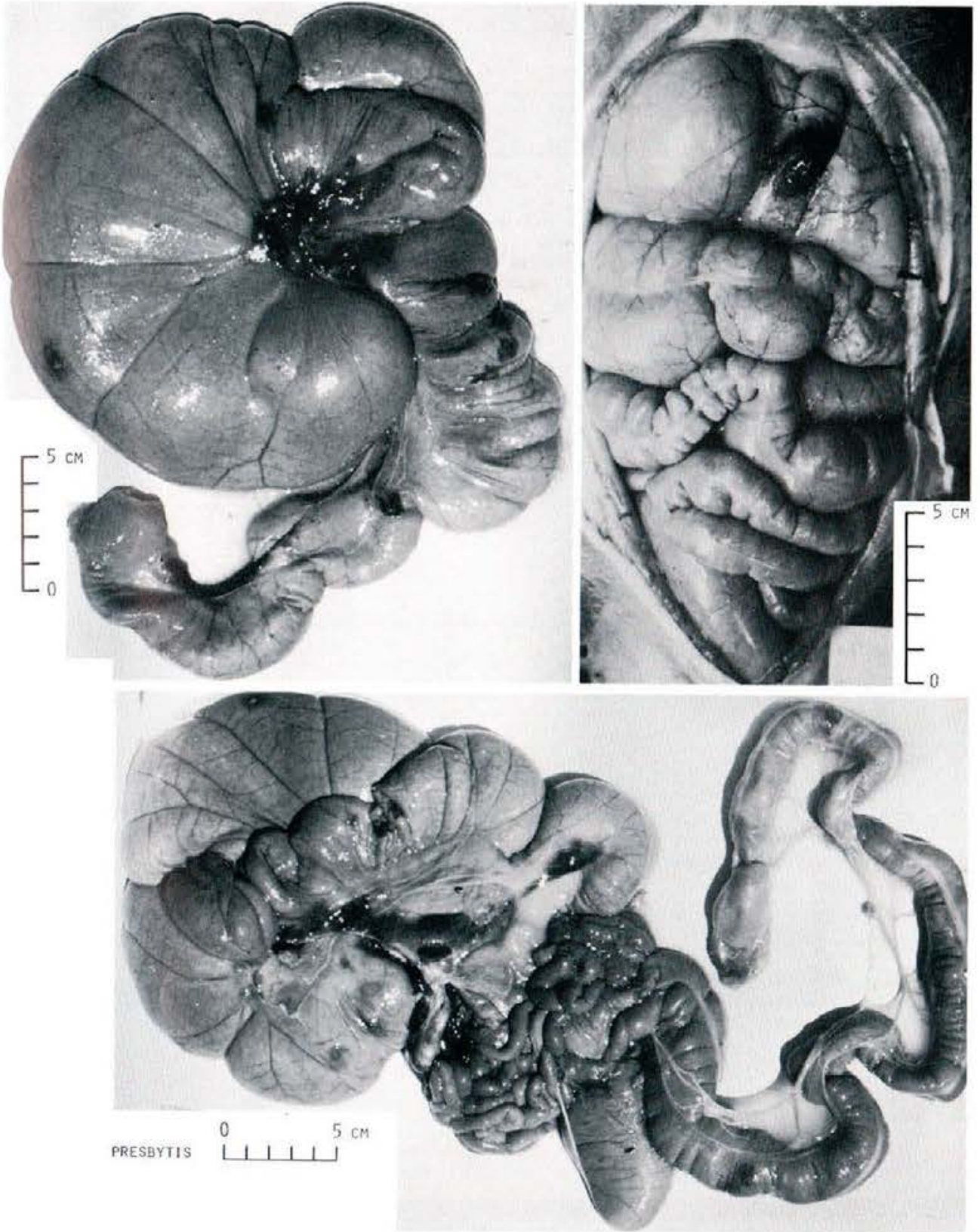

Fig. 15. The gastro-intestinal tract of the dusky leaf monkey, Presbytis obscura (P19). Upper right, the disposition within the abdominal cavity; note the large size of the stomach occupying the upper half of the view, and the coils of colon below (cf. right), and the pylorus (lower left). Below, the complete abdis water displayed to show the large sac, the gastric tube (on the the left, and the coils of small intestine, caecum (directed downwards), and colon leading around into the rectume smach on to the right. Photos by D.J.C. 

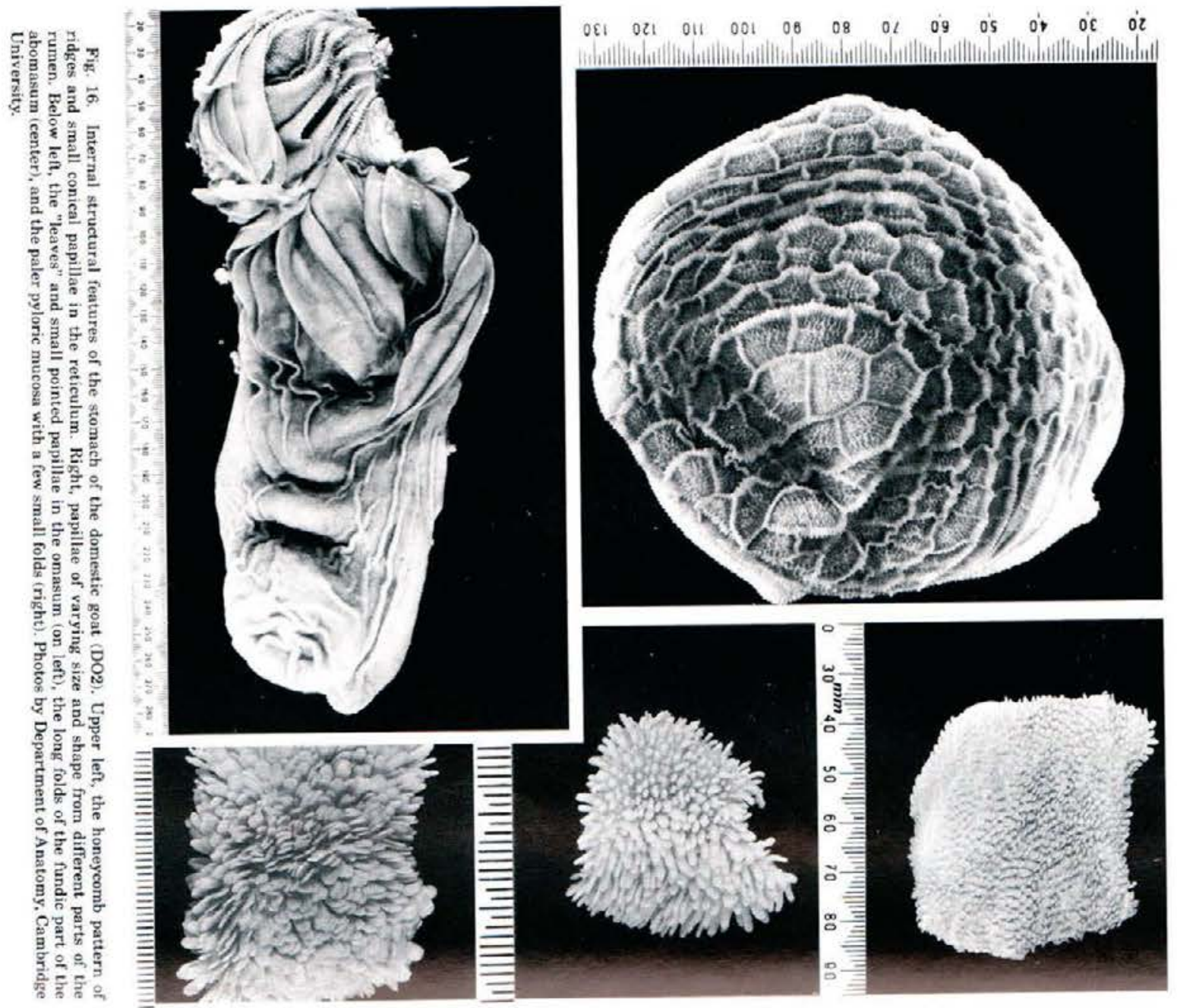
or leaves in their diet

\begin{tabular}{|c|c|c|c|c|c|c|}
\hline \multirow{2}{*}{$\begin{array}{l}\text { Dietary } \\
\text { Category }\end{array}$} & \multirow[b]{2}{*}{ Mammalian Order } & \multicolumn{5}{|c|}{ Features of Gastro-intestinal Tract } \\
\hline & & General & Stomach & Small Intestine & Caecum & Colon \\
\hline \multicolumn{7}{|l|}{ Faunivores } \\
\hline & Insectivora & $2 \%-7 \times B L$ & simple & very short & none & \\
\hline & Chiroptera & $-4 / 5 \mathrm{BL}$ & blind-ending tube & & & very short \\
\hline & Primates & & simple, globular & tortuous & short, conical & $\begin{array}{l}\text { simple, smooth- } \\
\text { walled }\end{array}$ \\
\hline & Carnivora & & simple & $4-6 \times B L$ & small or absent & reduced \\
\hline & Edentat & $7 \times \mathrm{BL}$ & "muscular tooth". & & none & \\
\hline & Pholidota & & $\begin{array}{l}\text { "muscular tooth," cornified, } \\
\text { stones }\end{array}$ & & & \\
\hline & Cetacea & & 3 chambers, 2 sphincters & very long & none & very short \\
\hline & Rodentia & & gastric gland changes & & Frugivores & \\
\hline Frugivores & Chiroptera & & rel. complex, distinct & & small or absent & \\
\hline & & & $\begin{array}{l}\text { cardial region, long } \\
\text { pyloric divertic., lat. } \\
\text { 'caecum' }\end{array}$ & & 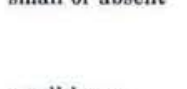 & \\
\hline & Primates & & simple, globular & $\begin{array}{l}\text { C-shaped duodenum } \\
\text { retroperitoneal }\end{array}$ & small-large & $\begin{array}{l}\text { elongated, folded, } \\
\text { taenia }\end{array}$ \\
\hline & Carnivora & & & & none & reduced \\
\hline & Artiodactyla & & zones, even chambers & very long & large & rel. complex \\
\hline & Rodentia & & $\begin{array}{l}\text { extensive cardial glands. } \\
\text { separated from fundus by } \\
\text { fold }\end{array}$ & & none & \\
\hline \multirow[t]{16}{*}{ Folivores } & & & & & & \\
\hline & Marsupalia, macropod & & $\begin{array}{l}\text { long, tubular, sacculated, } \\
\text { grooved }\end{array}$ & long & wide & \\
\hline & Primates & & & & & \\
\hline & $\begin{array}{l}\text { lemurid } \\
\text { colobine }\end{array}$ & caecotrophy & $\begin{array}{l}\text { simple } \\
\text { sacs and tube }\end{array}$ & very short & elongated, coiled & \\
\hline & Proboscidea & & large, folded & short, capacious & huge, saccul. & large loops \\
\hline & Sirenia & & 2-chambered & & very wide & \\
\hline & Hyracoidea & & & & 3 caeca & most complex \\
\hline & Perissodactyla & & cornified area & & huge, saccul. & large loops \\
\hline & Artiodactyla & & & & & \\
\hline & hippopotamid & & 3 chambers & very long & none & \\
\hline & NW camelid & & 3 chambers & & & \\
\hline & OW camelid & most elaborate & 2 sacs, smooth, ovoid & long & Jarge & \\
\hline & & most elaborate & & long & large & $\begin{array}{l}\text { long, folded and } \\
\text { coiled }\end{array}$ \\
\hline & Edentate & & $\begin{array}{l}\text { cornified cardia, 'rumen', } \\
\text { groove, 'abomasum' }\end{array}$ & & & \\
\hline & Rodentia & caecotrophy & cornified variably & & $\begin{array}{l}\text { capacious } \mathrm{v} . \\
\text { coiled, long }\end{array}$ & \\
\hline & Lagomorpha & caecotrophy & & & & \\
\hline
\end{tabular}


Techniques were standardized throughout between the two authors, on occasions when they worked together, so as to obtain comparable accuracy. Several hours were allowed to elapse after the death of the individual to permit complete relaxation of muscle tone in the gut wall. Measurements of length and breadth of stomach, small intestine, caecum, and colon were then made without stretching, after opening and flattening the gut wall, usually under water in a dissecting tray (except for the larger specimens). Because different parts of the gut can be fully contracted or relaxed, simultaneously or sequentially, this seems to be the best compromise in functional terms for measuring, for comparative purposterms for measuring, for comparative
es, what is a very malleable system.

es, what is a very malleable system.
The surface areas of small and large intesThe surface areas of small and large intesof breadths; sometimes it was more appropriate to treat the caecum as a triangle rather than an elongated rectangle. The irregular shape of the stomach required summing the area of its parts, usually arranged to cover the different compartments or division into fundus and pylorus. The areas of such nontubular parts were also measured by cutting pieces of aluminum foil to the exact shape of the part(s) immersed under water, and then weighing for

calculation from the weight of unit area; this provided a means of checking the accuracy of length and breadth measurements. Error re sulting from the different methods, or from repeated measurements, amounted to les than $5 \%$.

Little merit was placed on measuring volumes by distending parts of the gut with wate even if the pressure could be controlled), if only because of the possible distortion of subsequent measurements of area. Latterly, however. an a d a d in ind for the calculation of volumes (V) fy政

$$
\mathrm{V}=\pi\left(\frac{\mathrm{b}}{2 \pi}\right)^{2} 0.1=3.142\left(\frac{\mathrm{b}}{6.283}\right)^{2} 0.1,
$$

and stomachs were treated as spheres,

$\mathrm{V}=\frac{4}{3} \pi\left(\sqrt{\frac{\mathrm{A}}{4 \pi}}\right)^{3}=4.19\left(\sqrt{\frac{\mathrm{A}}{12.57}}\right)^{3}$ (Table 3).

For stomachs, similar results were obtained in a few cases by calculating the volume from the greater curvature, assuming its length (L) to be the circumference of a sphere,

$$
\mathrm{V}=\frac{4}{3} \pi\left(\frac{\mathrm{L}}{2 \pi}\right)^{3}=4.19\left(\frac{\mathrm{L}}{6.283}\right)^{3} \text { (Table 3). }
$$

Volumes calculated from surface area are bout $12 \%$ less on average than those from reater curvature or water-filing (Tables and 3).

While all species can be compared against common standard (calculating volumes from sheres of equivalent surface area), distortion occur in the case of species with a complex

stomach, where the whole clearly does not approximate a sphere. While some compartments resemble spheres (the ruminant reticlum, rumen and omasum, and the colobine presacus and and onst others anproxime prom the ruminat abomasum and the thders the ruminant abomasum and the coumes gastric and pyloric tubes). Thus, volTable 4) yielding values one-thind les on Table 4), yielding values one-third less on average. Even the calculations or volumes of of length of greater curvature) give variable
TABLE 3. Estimation of stomach volumes: considering the stomach as a sphere, and calculating volume from (a) length of greater curvature ( $L$ ), equivalent to circumference and (b) surface area (A)

\begin{tabular}{|c|c|c|c|}
\hline Species & Greater curvature & Surface area & $\begin{array}{l}\text { latter of. } \\
\text { former }\end{array}$ \\
\hline \multicolumn{4}{|l|}{ Prosimians } \\
\hline Arctocebus calabarensis & 9 & 5 & \\
\hline \multirow[t]{2}{*}{ Atahi laniger } & 12 & 19 & + \\
\hline & $\begin{array}{l}23 \\
46\end{array}$ & $\begin{array}{l}39 \\
62\end{array}$ & $\stackrel{t}{+}$ \\
\hline \multirow[t]{3}{*}{ Cheirogaleus major } & $\begin{array}{r}80 \\
9\end{array}$ & 10 & \\
\hline & 9 & 14 & + \\
\hline & 5 & 9 & + \\
\hline \multirow[t]{3}{*}{ Galago alleni } & $\begin{array}{l}17 \\
17\end{array}$ & 24 & \\
\hline & 17 & 9 & $\overline{-}$ \\
\hline & 4 & 6 & + \\
\hline \multirow{3}{*}{ Galago demidovii } & 2 & 2 & \\
\hline & 2 & 1 & - \\
\hline & $\begin{array}{l}1 \\
3\end{array}$ & $\begin{array}{l}1 \\
2\end{array}$ & - \\
\hline Lepilemur mustelinus & 17 & 28 & + \\
\hline \multicolumn{4}{|l|}{$\begin{array}{l}\text { New World monkeys } \\
\text { Norter }\end{array}$} \\
\hline Leontocebus midas & 4 & 4 & \\
\hline \multirow[t]{2}{*}{ Cebus griseus } & 37 & 53 & + \\
\hline & 29 & 31 & + \\
\hline Alouatta seniculus & 205 & 227 & - \\
\hline $\begin{array}{l}\text { Ateles paniscus } \\
\text { Olys }\end{array}$ & 264 & 212 & - \\
\hline \multirow{3}{*}{$\begin{array}{l}\text { Old World monkeys } \\
\text { Miopithecus talapoin }\end{array}$} & 29 & 27 & - \\
\hline & 46 & 42 & - \\
\hline & 23 & 32 & + \\
\hline Cercopithecus neglectus & 264 & 163 & \\
\hline \multirow[t]{2}{*}{ Cercopithecus nietitans } & 135 & 93 & - \\
\hline & 57 & 59 & + \\
\hline \multirow{2}{*}{ Cercopithecus uethiops } & $\begin{array}{r}297 \\
29\end{array}$ & $\begin{array}{r}221 \\
19\end{array}$ & $=$ \\
\hline & 6 & 5 & \\
\hline \multirow[t]{3}{*}{ Cercocebus albigena } & 135 & 130 & \\
\hline & 12 & 15 & + \\
\hline & $\begin{array}{r}135 \\
29\end{array}$ & 82 & - \\
\hline $\begin{array}{l}\text { Macaca sylianus } \\
\text { Papio papio }\end{array}$ & $\begin{array}{r}29 \\
9\end{array}$ & $\begin{array}{r}20 \\
8\end{array}$ & \\
\hline Papio sphinx & 9 & 7 & - \\
\hline \multicolumn{4}{|l|}{ Ape } \\
\hline \multirow{2}{*}{ Pan troglodytes } & 1079 & 965 & - \\
\hline & 135 & 72 & - \\
\hline Pan gorilla & 116 & 88 & - \\
\hline
\end{tabular}

Volume, $\mathrm{cm}^{3}$
TABLE 2. Estimation of gut volumes: filling stomach with water without

\begin{tabular}{|c|c|c|c|c|}
\hline \multirow[b]{2}{*}{ Species } & \multicolumn{4}{|c|}{ Volumes, $\mathrm{cm}^{x}$} \\
\hline & water-filled & surface : & area & greater curvature \\
\hline \multicolumn{5}{|c|}{ Apes } \\
\hline \multicolumn{5}{|c|}{ Hylabates syndactylus } \\
\hline stomach & $\begin{array}{l}240 \\
350\end{array}$ & $\begin{array}{l}1566 \\
385\end{array}$ & t & $\begin{array}{l}264 \\
296\end{array}$ \\
\hline \multirow{2}{*}{ intestine } & 950 & 697 & - & \\
\hline & 550 & 461 & - & \\
\hline \multirow[t]{2}{*}{ colon } & 1150 & 941 & - & \\
\hline \multirow{2}{*}{\multicolumn{5}{|c|}{ Hylobates pileatus }} \\
\hline & & & & \\
\hline \multicolumn{5}{|c|}{$\begin{array}{l}\text { Hylobates spleatus } \\
\text { stomach }\end{array}$} \\
\hline intestine & 500 & 596 & + & \\
\hline \multirow{2}{*}{\multicolumn{5}{|c|}{$\begin{array}{l}\text { Wild mammals } \\
\text { Won }\end{array}$}} \\
\hline & & & & \\
\hline \multicolumn{5}{|l|}{ Vulper vulpes } \\
\hline \multirow[t]{3}{*}{ stomach } & 270 & 538 & + & \\
\hline & 600 & 621 & + & \\
\hline & 300 & 392 & + & \\
\hline \multirow[t]{3}{*}{ intestine } & 480 & 329 & - & \\
\hline & 410 & 302 & - & \\
\hline & 470 & 340 & - & \\
\hline \multirow[t]{3}{*}{ colon } & 50 & 100 & + & \\
\hline & 180 & 151 & - & \\
\hline & 150 & 136 & - & ef. water-filled \\
\hline
\end{tabular}
with comparative data from the small intestine and colon, treated as cylinders 
results, apparently according to the degree of elongation of the stomach spindle.

\section{Results}

The data collected, and resulting basal calculations, are displayed in tables 5-8 for prosimians, New World monkeys, Old World monkeys (cercopithecine and colobine), apes, domestic mammals, and wild mammals (temperate and tropical). Emphasis is placed on adult animals taken from their natural habitat, since considerable changes in tat, since considerable changes in gross dimensions may occur in captivity, even after short periods, e.g., from a s3r reduction to an 100 increase in the surface area of the small intestine in some in the sithe mmature individuals are particularly suscep tible to dietary effects on gut proportions, and their measurements should be treated with caution; the stomach and colon are relatively reduced in young folivores, and may be in creased in faunivores. Fixed specimens are also liable to distortion from the functional state.

Gut Differentiation. The sizes of stomach and large intestine relative to small intestine, in terms of surface area, weight, and volume, provide a simple quantitative index of gut differentiation, without regard to the size of the animal. These coefficients of gut differentiation vary considerably in the mammals studied, from tracts that are dominated by small intestine in faunivores to those that are dominated by stomach and/or large intestine in folivores.
Considering surface areas, the coefficients of gut differentiation show considerable overlap between species of the three main dietary categories (Fig. 17). This overlap is explained to some extent by intermediate diets. The plots on a logarithmic scale represent species means, with the range of variation marked for those species with four or more specimens. While the values of the coefficients appear generally to represent structural adaptations indicative of the relative proportions of animal and plant matter in the diet, only those below 0.2 can be regarded as true faunivores and only those above 3.0 as exclusive folivores.

Interspecific variation may be appreciated more clearly by comparing coefficients within (and between) the varing coefficients within logical the a the wast stret are separated, albeit in dinerent ways, with values for frugivores clustered primates. This is especially maked among primates, with higher values reflecting a tract dominated by stomach and/or large intestine (for digesting leaves), and the few lower ones, among prosimians and ceboids, where the small intestine predominates (for digesting animal matter). The categories of "faunivore," "frugivore," and "folivore" are established according to structural discontinuities, and at this stage they can be no more than suggestive of diet. The overlap between them would seem to result from interspecific variation in the degree of admixture of animal, fruit, and leaf foods, which would be especially variable among frugivores.

TABLE 4. Estimation of stomach wolumes: complex stomachs, treated ( $a$ ) as a single sphere and (b) as a combination of spheres and cylinder:

\begin{tabular}{|c|c|c|c|c|}
\hline \multirow[b]{2}{*}{ Species } & \multicolumn{4}{|c|}{ Volume, $\mathrm{cm}^{3}$} \\
\hline & Single sphere & $\begin{array}{c}\text { Spheres } \\
\& \\
\text { Cylinders }\end{array}$ & $\begin{array}{l}\text { \% reduction } \\
\text { of latter }\end{array}$ & $\mathrm{n}$ \\
\hline \multicolumn{5}{|l|}{ Domestic mammals } \\
\hline Capra (goat) & 17,776 & 11,365 & 36 & 4 \\
\hline \multirow{2}{*}{\multicolumn{5}{|c|}{ Colobine monkeys }} \\
\hline & & & & \\
\hline Presbytis cristata & 5,171 & 3,259 & 37 & 2 \\
\hline Presbytis obseura & 4,124 & 2,767 & 33 & 4 \\
\hline Presbytis melalophos & 3,917 & 2,313 & 41 & 5 \\
\hline Presbytis rubicunda & 3,547 & 2,259 & 36 & 1 \\
\hline Nasalis larvatus & 8,270 & 6,523 & 21 & 1 \\
\hline \multirow[t]{2}{*}{ Pygathrix nemaeus } & 4,605 & 3,199 & 31 & 2 \\
\hline & & & $\overline{\mathrm{x}}=33$ & \\
\hline Colobus polykomas & 3,147 & 2,108 & & 2 \\
\hline Presbytis senex & 3,856 & 2,584 & & 2 \\
\hline Presbytis entellus & 5,532 & 3,706 & & 2 \\
\hline
\end{tabular}

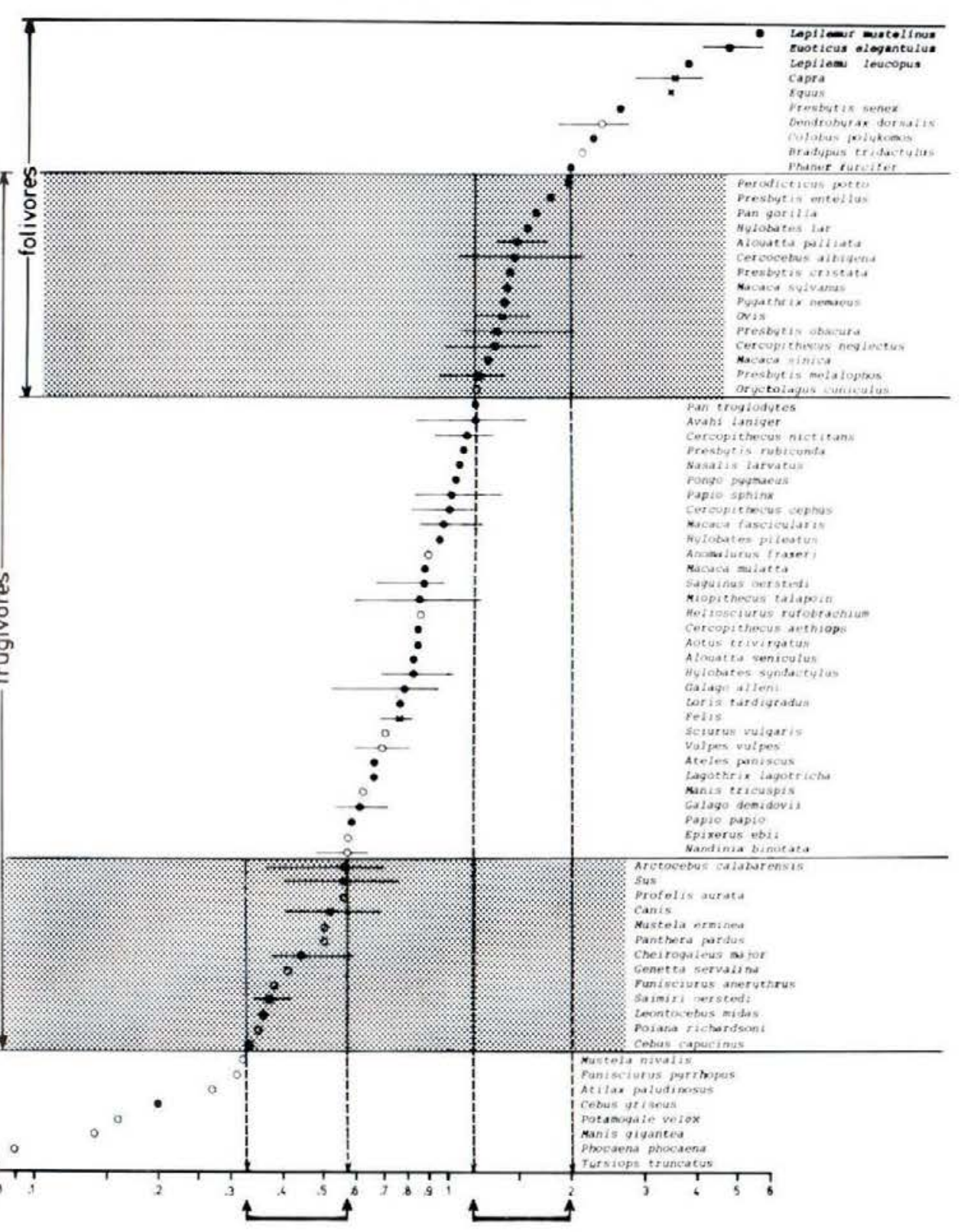

COEFFICIENT Of GUT DIFFERENTIATION

surface area of stomach + caecum+colon surface area of small intestine

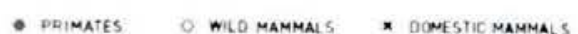

Fig. 17. Coefficients of gut differentiation from surface area plotted in order of magnitude (smallest values below) on a logarithmic scale, indicating by arrows and stippling the three main morphological dietary categories and the overlap

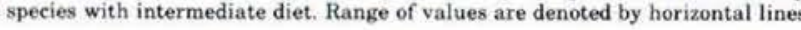
for species with more than one specimen. 


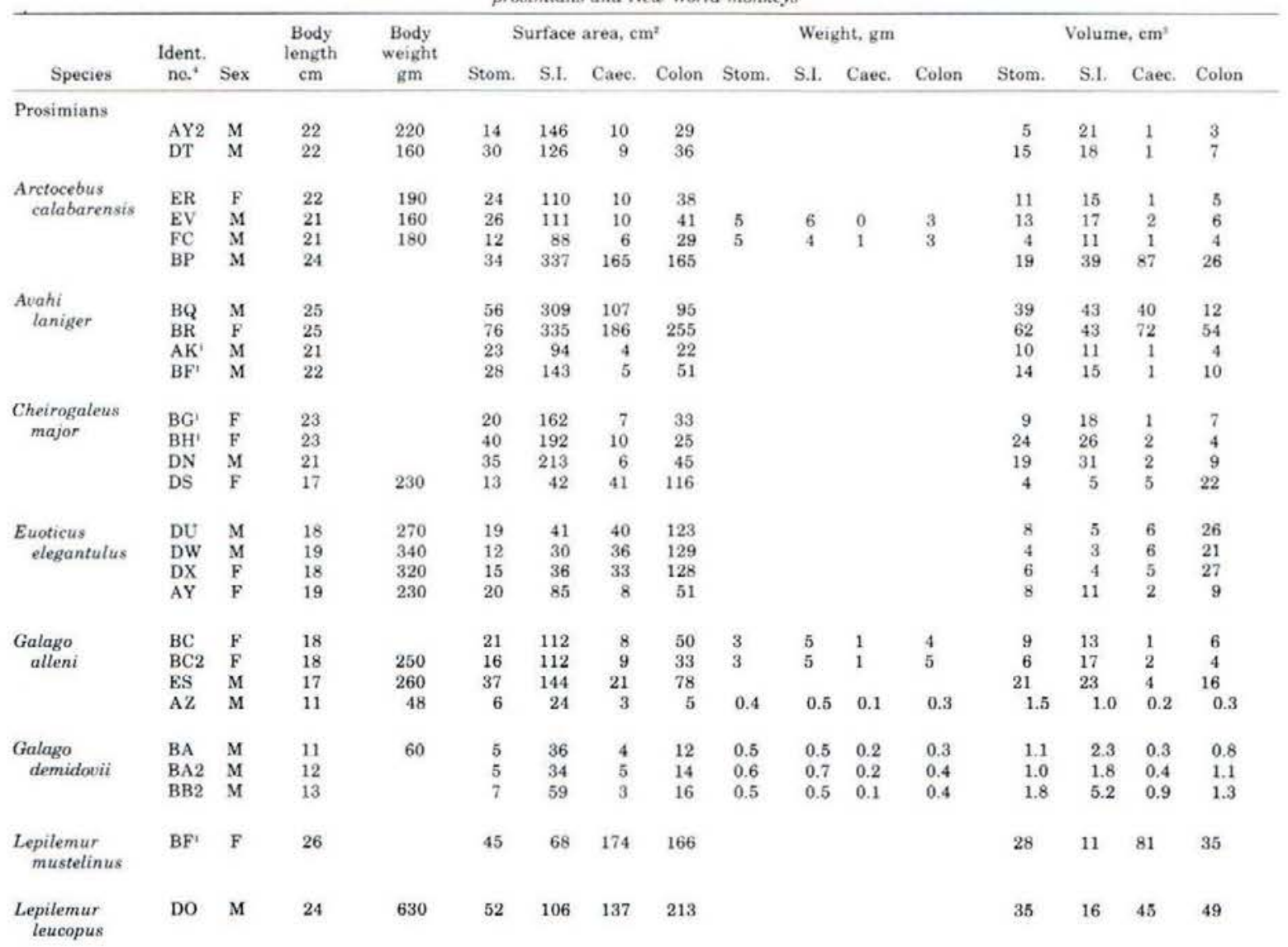

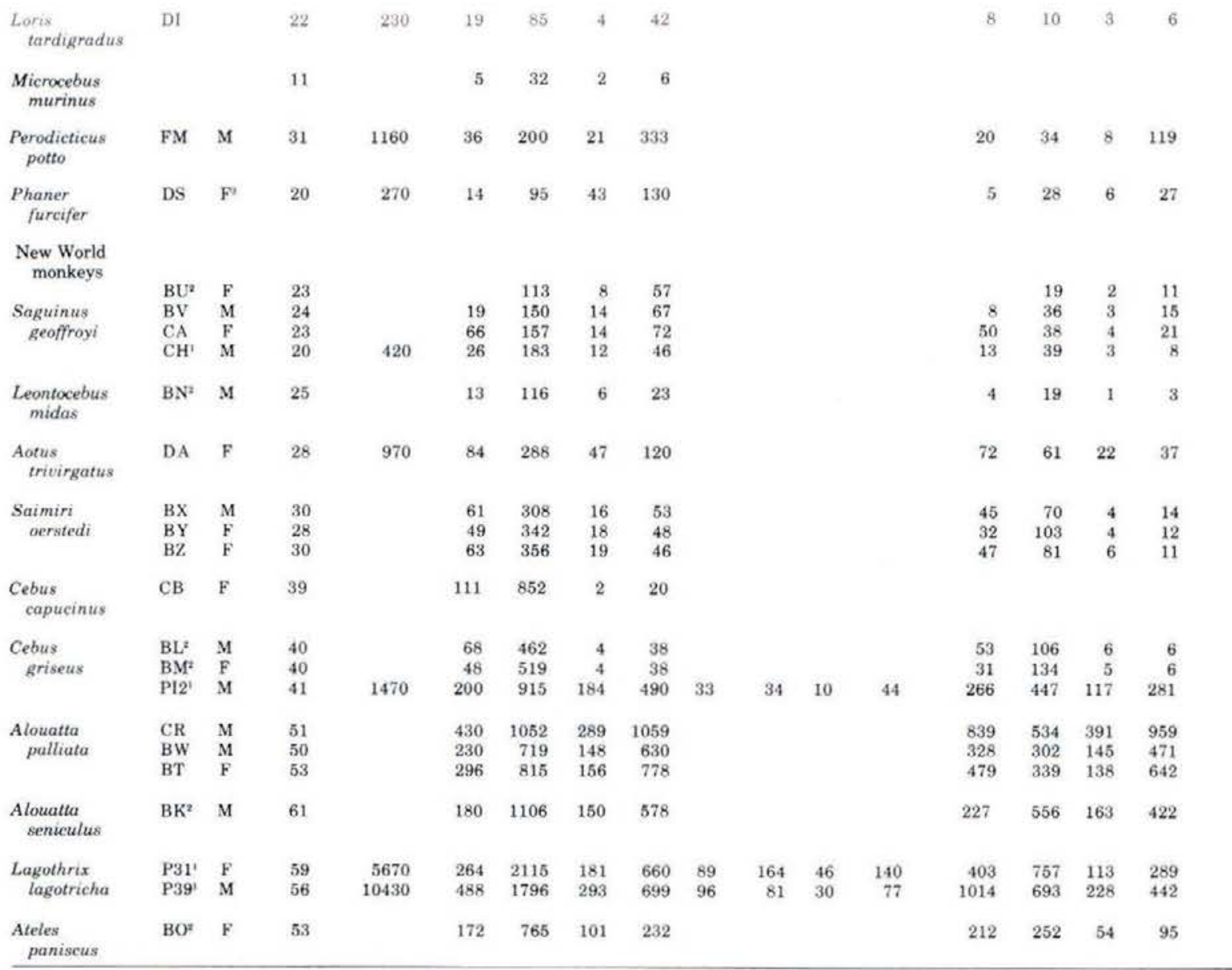




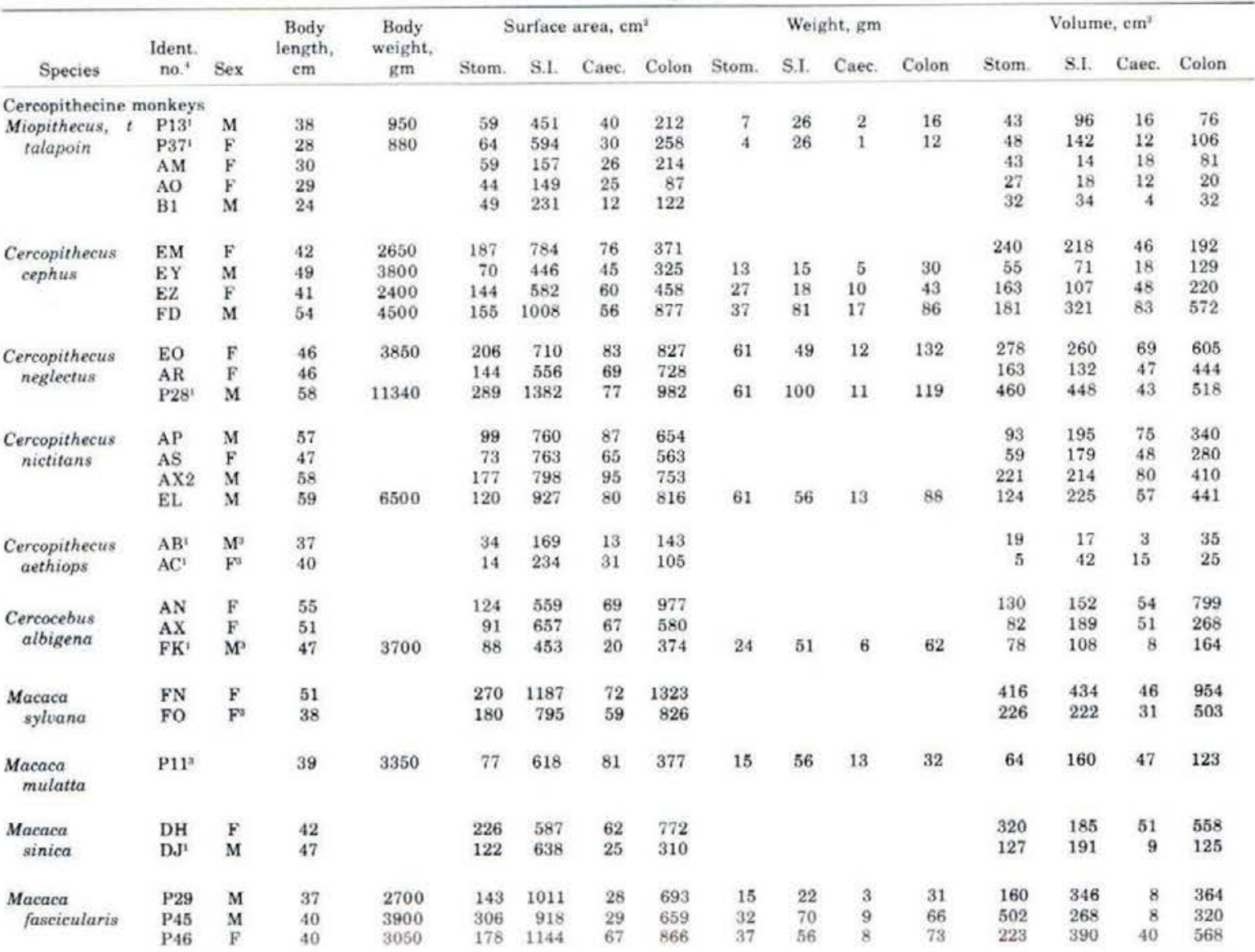

\begin{tabular}{|c|c|c|c|c|c|c|c|c|c|c|c|c|c|c|c|c|}
\hline Papio & FK & M & 72 & 16600 & 402 & 2854 & 64 & 1894 & & & & & 760 & 1596 & 47 & 1518 \\
\hline $\operatorname{sphin} x$ & EP & F & 51 & 6100 & 250 & 1143 & 50 & 1228 & 76 & 97 & 13 & 163 & 372 & 409 & 33 & 1395 \\
\hline & FR & F & 63 & 12300 & 322 & 2435 & 70 & 2240 & 123 & 296 & 13 & 332 & 543 & 968 & 195 & 1782 \\
\hline
\end{tabular}

\begin{tabular}{|c|c|c|c|c|c|c|c|c|c|c|c|c|c|c|c|c|}
\hline \multicolumn{17}{|c|}{ Colobine monkeys } \\
\hline \multirow{2}{*}{$\begin{array}{l}\text { Colobine monl } \\
\text { Colobus } \\
\text { polykomos }\end{array}$} & $\mathrm{AQ}$ & F & 56 & & 1021 & 556 & 26 & 549 & & & & & 2055 & 107 & 13 & 218 \\
\hline & $\mathrm{FB}$ & F & 58 & 6500 & 1056 & 925 & 15 & 630 & 154 & 149 & 5 & 72 & 2162 & 184 & 6 & 301 \\
\hline \multirow{2}{*}{$\begin{array}{l}\text { Presbytis } \\
\text { entellus }\end{array}$} & DF & M & 63 & & 1585 & 1673 & 105 & 978 & & & & & 3974 & 633 & 80 & 845 \\
\hline & DL & M & 65 & 10000 & 1439 & 1167 & 140 & 760 & & & & & 3438 & 330 & 104 & 505 \\
\hline \multirow{2}{*}{$\begin{array}{c}\text { Presbytis } \\
\text { senex }\end{array}$} & DG & F & 48 & & 938 & 740 & 139 & 548 & & & & & 1814 & 181 & 77 & 275 \\
\hline & DM & M & 59 & & 1416 & 687 & 139 & 548 & & & & & 3357 & 162 & 96 & 336 \\
\hline \multirow{2}{*}{$\begin{array}{l}\text { Presbytis } \\
\text { cristata }\end{array}$} & P30 & F & 50 & 6850 & 1694 & 1929 & 90 & 966 & 265 & 60 & 9 & 99 & 4831 & 604 & 64 & 645 \\
\hline & P33' & F & 53 & 5440 & 1175 & 1329 & 30 & 607 & 182 & 65 & 5 & 59 & 2209 & 385 & 12 & 285 \\
\hline \multirow{4}{*}{$\begin{array}{l}\text { Presbytis } \\
\text { obscura }\end{array}$} & P18 & $\mathrm{M}$ & 50 & 7960 & 1363 & 1953 & 64 & 670 & 180 & 77 & 8 & 66 & 3237 & 699 & 41 & 343 \\
\hline & P19 & $F^{3}$ & 45 & 4230 & 956 & 1311 & 52 & 558 & 105 & 53 & 4 & 42 & 1788 & 397 & 27 & 264 \\
\hline & P26 & M & 53 & 7200 & 1351 & 1969 & 88 & 902 & 154 & 62 & 6 & 76 & 2974 & 734 & 51 & 588 \\
\hline & P32 & F & 56 & 6350 & 1282 & 1129 & 90 & 869 & 211 & 45 & 8 & 50 & 3139 & 327 & 64 & 546 \\
\hline \multirow{6}{*}{$\begin{array}{l}\text { Presbytis } \\
\quad \text { melalophos }\end{array}$} & P14 & M & 51 & 6860 & 1020 & 1386 & 60 & 532 & 114 & 82 & 6 & 52 & 2072 & 336 & 34 & 156 \\
\hline & P16 & $\mathrm{M}^{3}$ & 44 & 5220 & 694 & 1075 & 23 & 369 & 109 & 76 & 3 & 44 & 1128 & 247 & 8 & 132 \\
\hline & P17 & $\mathrm{F}$ & 47 & 6410 & 1648 & 1796 & 60 & 552 & 145 & 107 & 6 & 63 & 3521 & 517 & 36 & 224 \\
\hline & P22 & M & 49 & 6510 & 1078 & 1389 & 42 & 695 & 90 & 50 & 4 & 42 & 2158 & 395 & 20 & 362 \\
\hline & P23 & F & 50 & 7340 & 1382 & 1695 & 68 & 848 & 124 & 71 & 8 & 50 & 3327 & 588 & 43 & 469 \\
\hline & P24 & $\mathrm{F}$ & 52 & 6880 & 1274 & 2021 & 38 & 612 & 150 & 60 & 7 & 71 & 2296 & 633 & 14 & 292 \\
\hline $\begin{array}{l}\text { Presbytis } \\
\quad \text { rubicunda }\end{array}$ & P381 & M & 56 & 6350 & 1125 & 1672 & 45 & 637 & 105 & 21 & 7 & 38 & 2259 & 505 & 20 & 329 \\
\hline $\begin{array}{l}\text { Nasalis } \\
\text { larvatus }\end{array}$ & $\mathrm{P} 25^{1}$ & M & 64 & 15880 & 1978 & 3120 & 100 & 1234 & 357 & 153 & 6 & 82 & 6523 & 1127 & 66 & 655 \\
\hline \multirow{2}{*}{$\begin{array}{l}\text { Pygathrix } \\
\text { nemaeus }\end{array}$} & P34 ${ }^{2}$ & F & 53 & 4540 & 1243 & 1512 & 36 & 578 & 137 & 63 & 5 & 50 & 2960 & 444 & 12 & 261 \\
\hline & P30 & F & 60 & 3630 & 1431 & 1601 & 80 & 854 & 200 & 47 & 4 & 45 & 3442 & 531 & 42 & 433 \\
\hline
\end{tabular}


TABLE 7. Measurements of body length and weight, and of surface area, weight, and volume of stomach, small intestine, caecum, and colon in apes, domestic mammals and temperate wild mammals

\begin{tabular}{|c|c|c|c|c|c|c|c|c|c|c|c|c|c|c|c|c|}
\hline \multirow[b]{2}{*}{ Species } & \multirow{2}{*}{$\begin{array}{l}\text { Ident. } \\
\text { no: }\end{array}$} & \multirow[b]{2}{*}{ Sex } & \multirow{2}{*}{$\begin{array}{l}\text { Body } \\
\text { length, } \\
\mathrm{cm}\end{array}$} & \multirow{2}{*}{$\begin{array}{c}\text { Body } \\
\text { weight, } \\
\text { gm }\end{array}$} & \multicolumn{4}{|c|}{ Surface area, $\mathrm{cm}^{2}$} & \multicolumn{4}{|c|}{ Weight, gm } & \multicolumn{4}{|c|}{ Volume, $\mathrm{cm}^{3}$} \\
\hline & & & & & Stom. & S.I. & Caec. & Colon & Stom. & S.L. & Caec. & Colon & Stom. & S.I. & Caec. & Colon \\
\hline \multicolumn{17}{|l|}{ Apes } \\
\hline Hylobates & $\mathrm{PO}^{2}$ & M & 40 & 5000 & 204 & 453 & 15 & 383 & 58 & 81 & 4 & 74 & 274 & 154 & 3 & 259 \\
\hline lar & PO6 ${ }^{2}$ & $\mathbf{F}$ & 40 & 5400 & 104 & 268 & 6 & 403 & 53 & 35 & 2 & 68 & 100 & 68 & 2 & 267 \\
\hline $\begin{array}{r}\text { Hylobates } \\
\text { pileatus }\end{array}$ & P41' & F & 47 & 7260 & 304 & 592 & 77 & 1128 & 56 & 77 & 17 & 144 & 499 & 596 & 34 & 920 \\
\hline Hylobates & P271 & $\mathrm{F}$ & 52 & 11340 & 457 & 2278 & 75 & 1557 & 146 & 150 & 10 & 230 & 919 & 1007 & 34 & 1891 \\
\hline syndactylus & $\mathrm{P} 40^{1}$ & M & 56 & 7250 & 140 & 1708 & 81 & 954 & 55 & 183 & 22 & 184 & 156 & 697 & 58 & 883 \\
\hline Pongo & P42' & M & 61 & 8620 & 256 & 1263 & 70 & 978 & 71 & 124 & 17 & 157 & 385 & 461 & 56 & 1071 \\
\hline pygmaeus & P35' & M & 95 & & 880 & 6564 & 155 & 5774 & 331 & 568 & 22 & 980 & 2457 & 4046 & 55 & 7800 \\
\hline Pan & $\mathrm{AD}^{\prime}$ & $\mathrm{F}$ & 83 & & 472 & 1700 & 162 & 1812 & & & & & 965 & 815 & 91 & 1451 \\
\hline troglodytes & EN & M & 72 & 34000 & 690 & 3761 & 286 & 2925 & & & & & 1705 & 1967 & 407 & 4335 \\
\hline $\begin{array}{l}\text { Pan } \\
\text { gorilla }\end{array}$ & EQ & M & 84 & 51000 & 1087 & 4018 & 590 & 4813 & & & & & 3370 & 1897 & 955 & 7006 \\
\hline
\end{tabular}

\begin{tabular}{|c|c|c|c|c|c|c|c|c|c|c|c|c|c|c|c|c|}
\hline \multicolumn{17}{|c|}{ Domestic mammals } \\
\hline Felis & D09 & $\mathrm{M}$ & 45 & 4000 & 144 & 345 & 8 & 125 & 24 & 104 & 1 & 17 & 163 & 60 & 2 & 48 \\
\hline \multirow[t]{5}{*}{ (cat) } & D12 & F & 40 & 2450 & 104 & 249 & 7 & 87 & 20 & 67 & 1 & 14 & 100 & 36 & 1 & 25 \\
\hline & D13 & $\mathrm{M}$ & 43 & 2730 & 120 & 372 & 9 & 123 & 16 & 84 & 1 & 17 & 124 & 71 & 2 & 40 \\
\hline & D18 & F & 42 & 2450 & 106 & 348 & 12 & 148 & 17 & 42 & 1 & 11 & 102 & 75 & 3 & 62 \\
\hline & D19 & F & 42 & 2700 & 132 & 374 & 11 & 130 & 21 & 43 & 1 & 11 & 143 & 86 & 3 & 52 \\
\hline & D20 & $\mathrm{M}$ & 46 & 4340 & 117 & 291 & 8 & 111 & 24 & 60 & 1 & 13 & 119 & 41 & 2 & 36 \\
\hline \multirow{6}{*}{$\begin{array}{l}\text { Canis } \\
\quad \text { (dog) }\end{array}$} & D03 & M & 78 & 13500 & 300 & 1030 & 40 & 225 & 133 & 263 & 8 & 42 & 490 & 238 & 16 & 90 \\
\hline & D04 & M & 59 & 7250 & 215 & 585 & 30 & 125 & 46 & 125 & 5 & 30 & 297 & 102 & 8 & 43 \\
\hline & D05 & F & 60 & 10680 & 426 & 992 & 37 & 208 & 109 & 198 & 8 & 42 & 826 & 253 & 11 & 75 \\
\hline & D06 & F & 58 & 9400 & 196 & 562 & 25 & 75 & 52 & 130 & 4 & 26 & 258 & 136 & 10 & 20 \\
\hline & D21 & F & 81 & 12550 & 344 & 1445 & 40 & 192 & 153 & 327 & 6 & 53 & 599 & 483 & 16 & 61 \\
\hline & D24 & F & 48 & 4750 & 162 & 776 & 20 & 135 & 48 & 170 & 7 & 24 & 194 & 196 & 5 & 54 \\
\hline
\end{tabular}

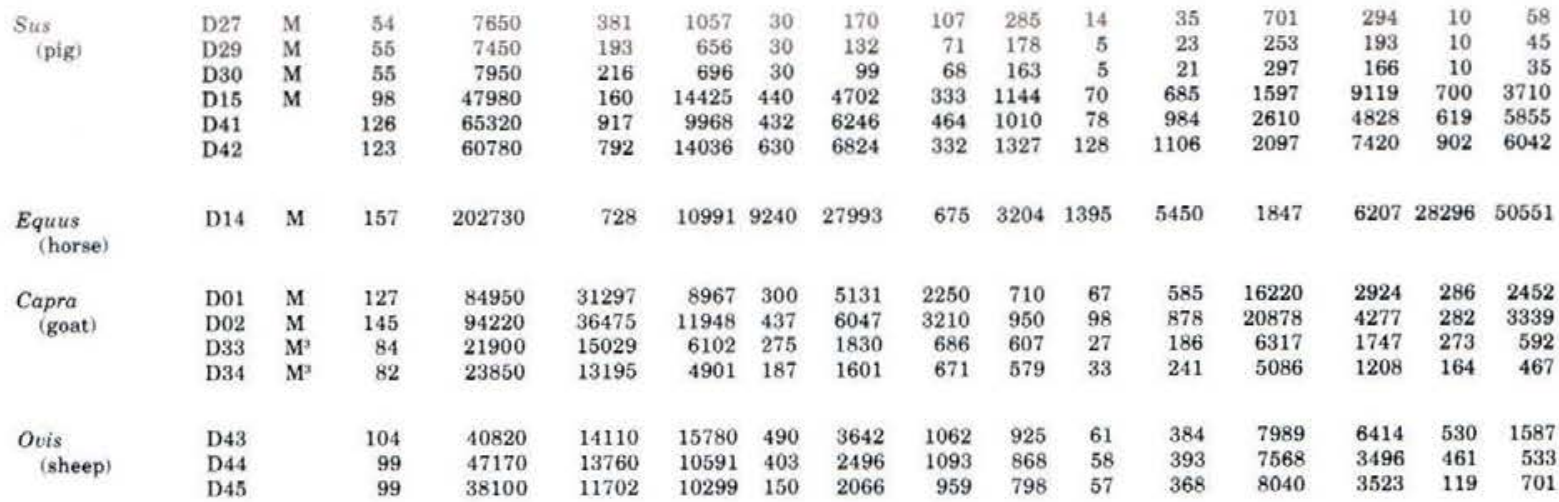

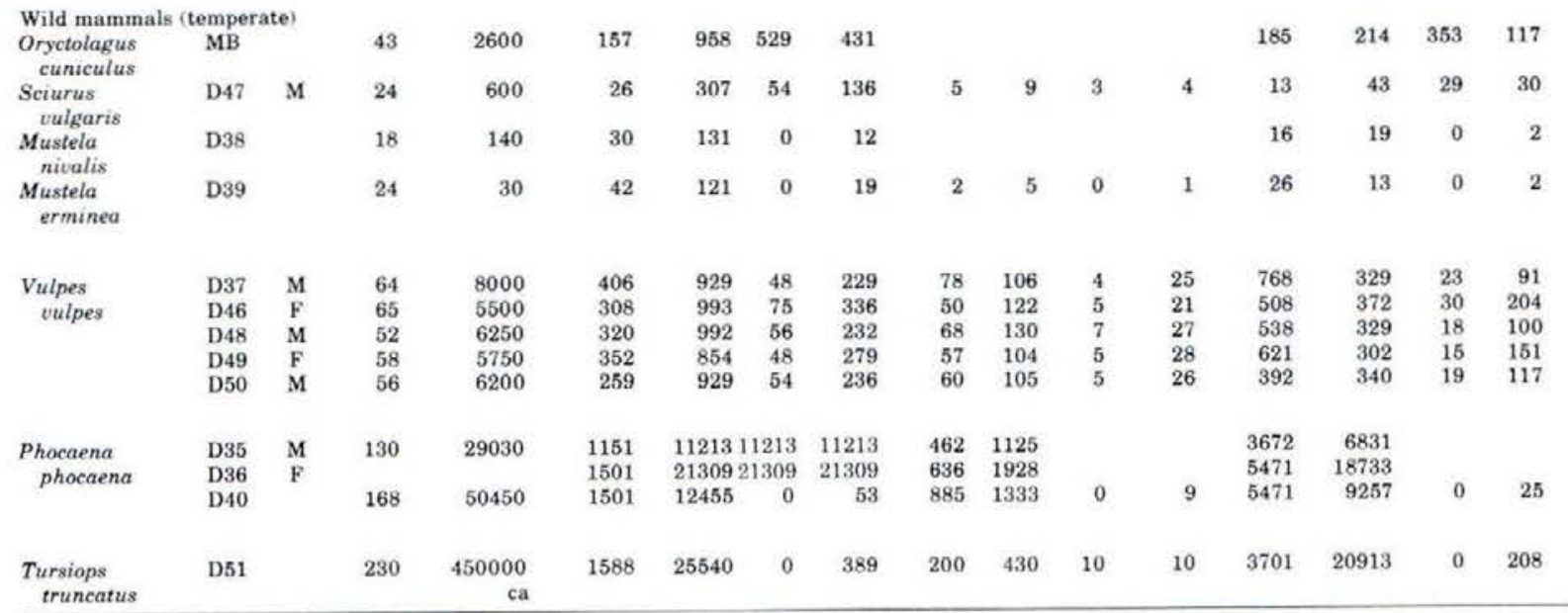

"Captive. ${ }^{\text {Fixed }}$ Immature.
'Nos, AA, BA, etc. C.M.H.; nos. P01, D01, ete, = D.J.C. 
TABLE 8. Measurements of body length and weight, and of surface area, weight, and volume of stomach, small intestine, caecum, and colon in

\begin{tabular}{|c|c|c|c|c|c|c|c|c|c|c|c|c|c|c|c|c|}
\hline \multirow[b]{2}{*}{ Species } & \multirow{2}{*}{$\begin{array}{l}\text { Ident. } \\
\text { no. }\end{array}$} & \multirow{2}{*}{ Sex } & \multirow{2}{*}{$\begin{array}{l}\text { Body } \\
\text { length. } \\
\mathrm{cm}\end{array}$} & \multirow{2}{*}{$\begin{array}{c}\text { Body } \\
\text { weight, } \\
\text { gm }\end{array}$} & \multicolumn{4}{|c|}{ Surface area, $\mathrm{cm}^{2}$} & \multicolumn{4}{|c|}{ Weight, gm } & \multicolumn{4}{|c|}{ Volume, $\mathrm{cm}^{2}$} \\
\hline & & & & & Stom. & S.L. & Caec. & Colon & Stom. & S.1. & Caec. & Colon & Stom. & S.I. & Caec. & Colon \\
\hline \multicolumn{17}{|c|}{ Wild mammals (tropical) } \\
\hline $\begin{array}{l}\text { Atilax } \\
\text { paludinosus }\end{array}$ & MW & $\mathrm{F}$ & 45 & 2380 & 70 & 575 & 9 & 74 & 31 & 86 & 3 & 19 & 55 & 124 & 4 & 21 \\
\hline $\begin{array}{l}\text { Potamogale } \\
\text { velox }\end{array}$ & MX & & 23 & 740 & 19 & 368 & 0 & 39 & 4 & 22 & 0 & 4 & 8 & 67 & 0 & 11 \\
\hline $\begin{array}{l}\text { Manis } \\
\text { tricuspis }\end{array}$ & ME & & 28 & 1550 & 189 & 517 & 0 & 134 & & & & & 245 & 85 & 0 & 55 \\
\hline $\begin{array}{l}\text { Manis } \\
\text { gigantea }\end{array}$ & MR & $\mathrm{M}^{3}$ & 23 & 1950 & 39 & 615 & 0 & 50 & 12 & 34 & 0 & 11 & 23 & 73 & 0 & 10 \\
\hline \multirow{2}{*}{$\begin{array}{l}\text { Epixerus } \\
\text { ebii }\end{array}$} & MG & $\mathrm{M}$ & 24 & 580 & 30 & 201 & 21 & 52 & 4 & 6 & 2 & 4 & 16 & 22 & 5 & 6 \\
\hline & MI & $F$ & 23 & 540 & 48 & 216 & 21 & 68 & 5 & 6 & 1 & 4 & 31 & 26 & 6 & 12 \\
\hline $\begin{array}{l}\text { Heliosciurus } \\
\text { rufobrachium }\end{array}$ & MH & M & 20 & 290 & 51 & 190 & 48 & 63 & 6 & 4 & 3 & 3 & 34 & 25 & 11 & 8 \\
\hline $\begin{array}{l}\text { Funisciurus } \\
\text { anerythrus }\end{array}$ & MK & & & & 16 & 161 & 15 & 30 & 3 & 5 & 1 & 2. & 6 & 18 & & \\
\hline $\begin{array}{c}\text { Funisciurus } \\
\text { pyrrhopus }\end{array}$ & ML & & & & 18 & 268 & 16 & 48 & 7 & 10 & 1 & 3 & 7 & 25 & 3 & 7 \\
\hline $\begin{array}{l}\text { Anomalurus } \\
\text { fraseri }\end{array}$ & $\mathrm{MT}^{2}$ & & 24 & & 10 & 216 & 90 & 93 & 5 & 9 & 7 & 5 & 3 & 34 & 22 & 11 \\
\hline $\begin{array}{l}\text { Eidolon } \\
\text { helvum }\end{array}$ & MF & $\mathrm{F}$ & 14 & 190 & & & & & 2 & 4 & 0 & 2 & & & & \\
\hline \multirow{5}{*}{$\begin{array}{l}\text { Dendrohyrax } \\
\text { dorsalis }\end{array}$} & MC & 3 & 40 & 1405 & 114 & 311 & 350 & 335 & & & & & 81 & 48 & 196 & 74 \\
\hline & Mo & F & 39 & 2323 & 140 & 456 & 482 & 572 & 54 & 25 & 61 & 43 & 110 & 73 & 331 & 169 \\
\hline & MP & & 38 & 2066 & 120 & 391 & 393 & 549 & 44 & 29 & 48 & 33 & 86 & 53 & & 129 \\
\hline & MU & $F$ & 31 & 1415 & 143 & 315 & 275 & 304 & 25 & 17 & 30 & 12 & 114 & 55 & & 80 \\
\hline & MV & M & 44 & 2720 & 126 & 588 & 362 & 594 & 54 & 40 & 60 & 44 & 94 & 131 & & 156 \\
\hline \multirow{3}{*}{$\begin{array}{c}\text { Nandinia } \\
\text { binotata }\end{array}$} & MD & $\mathrm{F}$ & 42 & 2400 & 143 & 481 & 0 & 150 & & & & & 160 & 142 & 0 & 53 \\
\hline & MY & M & 45 & 2250 & 105 & 420 & 0 & 98 & 34 & 65 & 0 & 23 & 101 & 100 & 0 & 27 \\
\hline & NA & M & 43 & 2440 & 60 & 209 & 0 & 73 & 22 & 38 & 0 & 16 & 43 & 37 & 0 & 15 \\
\hline $\begin{array}{l}\text { Bradypus } \\
\text { tridactylus }\end{array}$ & MA & & 46 & & 601 & 411 & 0 & 262 & & & & & 986 & 97 & 0 & 88 \\
\hline $\begin{array}{l}\text { Poiana } \\
\quad \text { richardsoni }\end{array}$ & MS & & 29 & 510 & 36 & 184 & 1 & 27 & 11 & 17 & 3 & 4 & 20 & 28 & 1 & 6 \\
\hline $\begin{array}{l}\text { Genetta } \\
\text { servalina }\end{array}$ & MQ & & 50 & 1480 & 63 & 274 & 2 & 48 & 19 & 54 & 5 & 15 & 47 & 42 & 3 & 15 \\
\hline $\begin{array}{l}\text { Profelis } \\
\text { aurata }\end{array}$ & $\mathrm{MZ}$ & $F^{u}$ & 57 & 5230 & 134 & 404 & 2 & 92 & 58 & 130 & 1 & 26 & 120 & 88 & 1 & 32 \\
\hline $\begin{array}{r}\text { Panthera } \\
\text { pardus }\end{array}$ & MM & $\mathrm{M}$ & 84 & 15700 & 421 & 1580 & 22 & 342 & 131 & 392 & 4 & 61 & 813 & 593 & 10 & 163 \\
\hline
\end{tabular}

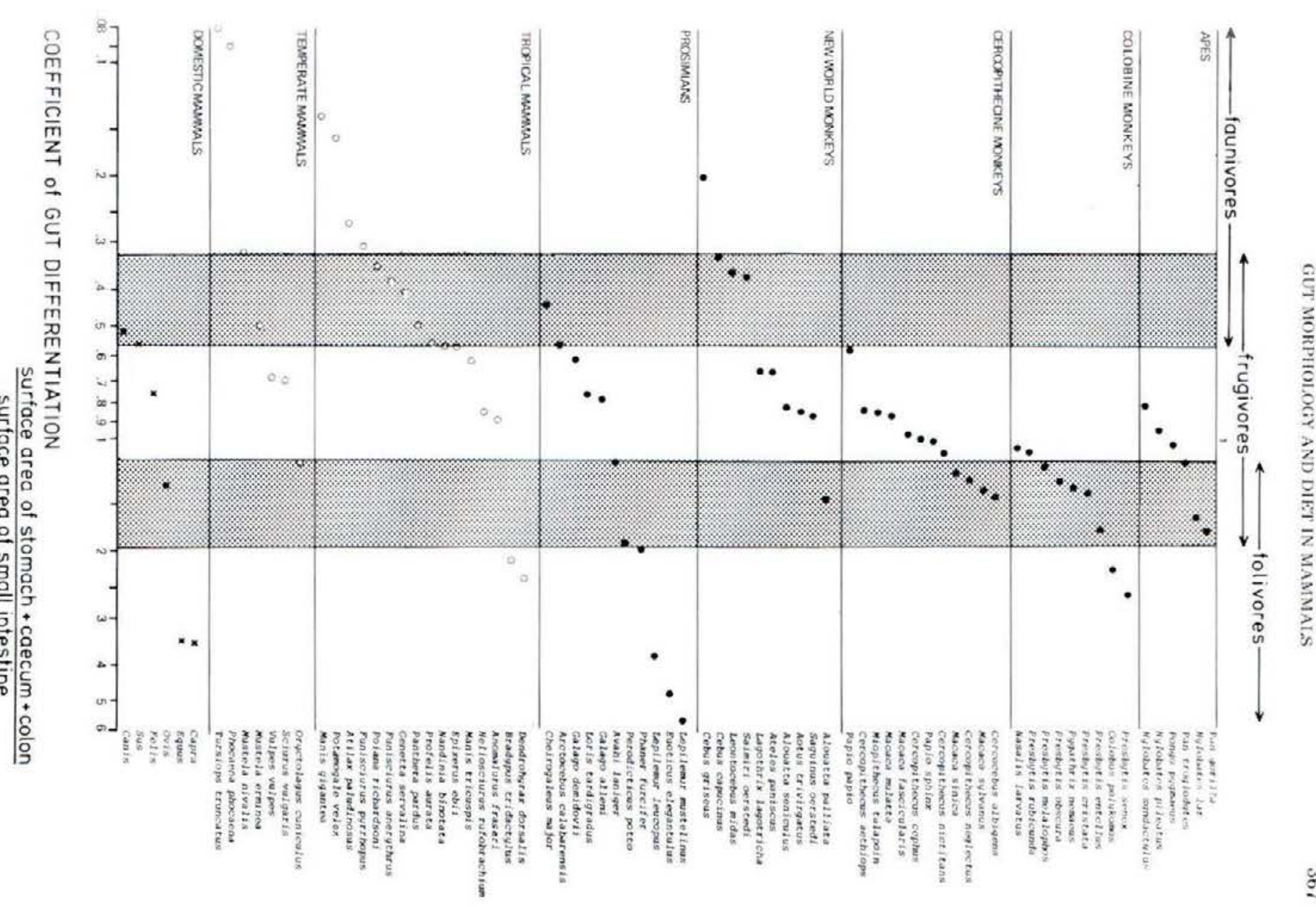




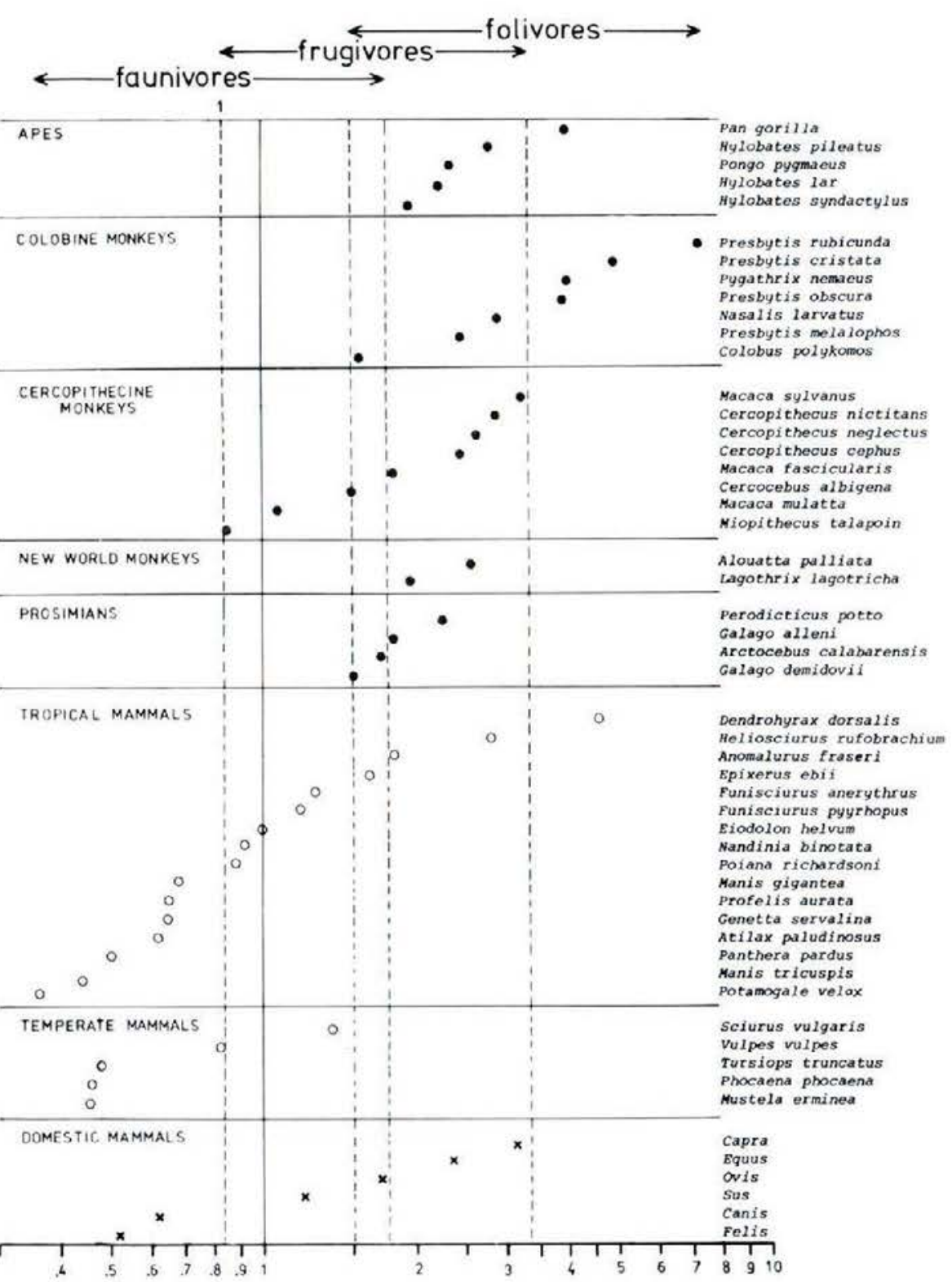

COEFFICIENT of GUT DIFFERENTIATION

weight of stomach + caecum + colon weight of small intestine

Fig. 19. Coefficients of gut differentiation from weight in each taxonomic group of primates, in other temperate and tropical mammals, and in domestic mammals, indicating the extent and overlap of the main morphological dietary categories
by vertical broken lines.

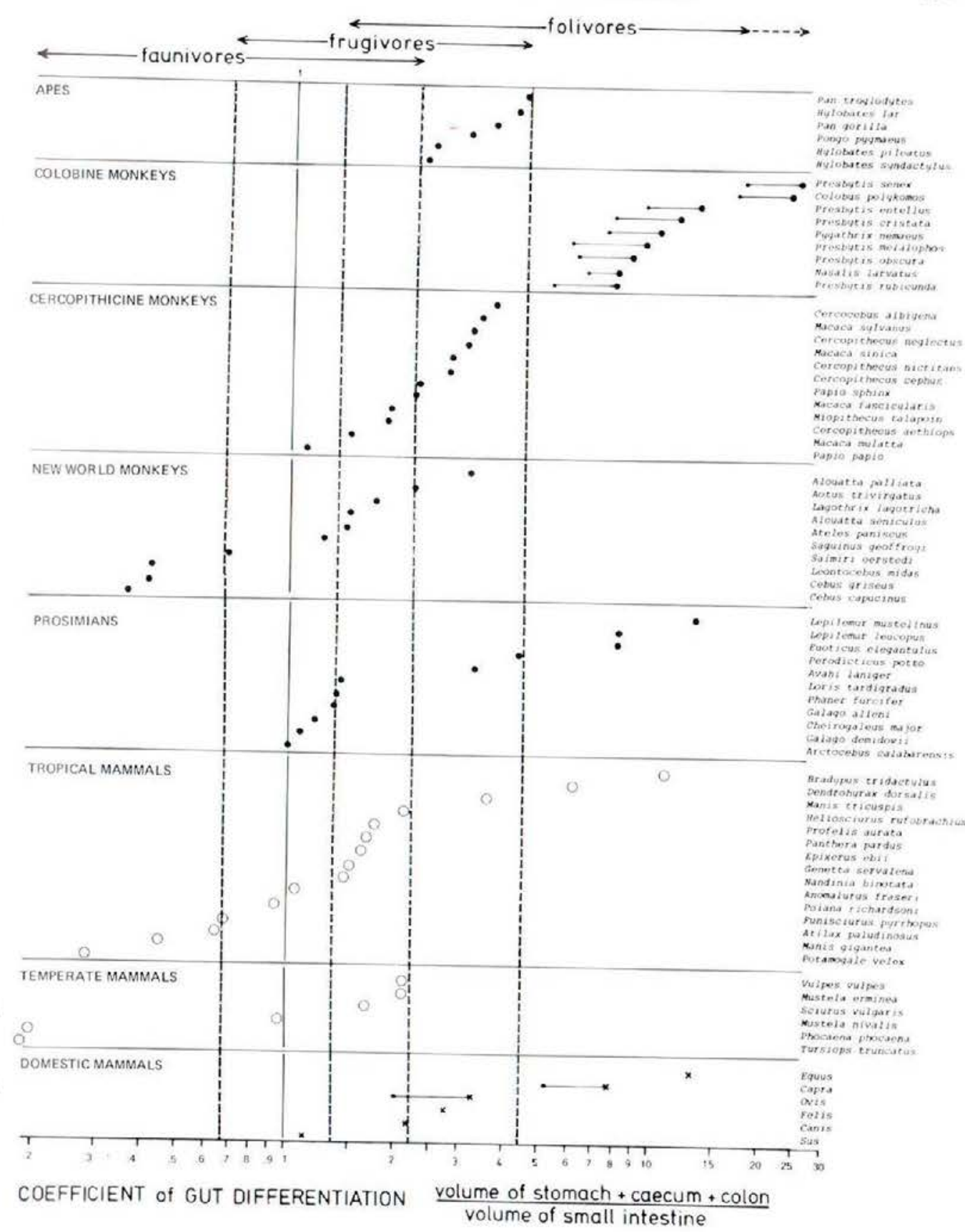

Fig. 20. Coefficients of gut differentiation from volume in each taxonomic group of primates, in other temperate and
tropical The distortion of values for costic mammals, indicating the extent and overlap of the main morphological dietary categories. spherical, is corrected as outlined in table 4 and plotted as a small closed circle to the teftandard treatment of stomachs as case of primates it leads to a closer relationship with other primates, but it disrupts the sequential pattern among don the 
While surface areas are taken as critical for pinpointing differences in digestive and absorptive functions between species, weights of each region provide an indication of the amount of muscle, and thus of physical activity in that region. In each mammalian group such data as are available provide a clear contrast between those faunivorous mammals with a relatively heavy small intestine, and those folivores with a heavy stomach and/or large intestine (Fig. 19). Comparing groups, however, we find different values for dietary boundaries (except for folivores), so that the overall spread of faunivores overlaps slightly with that of folivores, thereby obscuring frugivores as a group.

Volumes are most significant with reference to the capacity of those parts of the tract concerned with fermentation; it is presumed that the larger the volume, the more fermentation can take place. The extensive overlap of coefficients between dietary categories, re of coefficients between dietary categories, relecting wide variation in the rative volumes of diferent parts of the gut, may make thi. parameter the least accurate indicator of diet Fig. 20 . This would be because complexitie of function cannot be accounted for when commenting and mainly absorbing regions in this menting and mainly absorbing regions in this way.

Initially, stomachs were treated as sphere and volumes were calculated accordingly from surface areas, as described above, thereby standardizing interspecific comparison. Corrections according to the shape of each cham ber in complex stomachs gives a more accurate figure and a more precise indication of the dietary adaptation of the species concerned. Discrepancies between different methods of calculating stomach volume are small compared with the differences between species.

In a fermenting chamber the corresponding area for absorption should vary according to the two-thirds power of the volume. Since absorption is an important function irrespective of diet, there should be a compromise tive of diet, there should be a compromise between large volume and reduced surface area in the fermenting chambers of the more diffent consumers and leaves. In different species the presence of sacculations, folds, papillae, villi, and microvilli changes the relationship. In our measurements we could account only for the larger features; e.g., in ruminants such as the goat, papillae increase the surface area of the rumen eight fold, leaves" quadruple the area of the omasum, and folds double the area of the abomas um (Fig. 16). Such features also affect the weight of the organ. Similarly, villi increase weight intestine by similar proportions, although there is considerable interspecific variation there is considerable interspecific variation correction is the at her the studies are in progress. Nevertheless, these indicators of dietary adaptation.

Allometric Relationships. To compare the dimensions of the gastro-intestinal tract an its component parts between species, an allometric correction must be introduced in relation to body weight or some other measure of body size. In the field it was easier to measure accurately the length rather than the weigh of the specimen; in any case, the latter is more susceptible to changes in individual condition. The value of the constant of proportionality is determined by the shape of the body (McMahon, '73), which is fairly homogeneou among primates, and not very different in the ther terrestrial mammals. Furthermore, the of values derived from length are not distorted by nonmo no distorted by nom ast "72).

The volumes of potential fermenting chambers (the sum of values for stomach, caecum, and colon in each species are displayed on logarithmic scale in relation to body size (taken as the cube of body length, as a measure related directly to weight) (Fig. 21). The regression of these volumes (V) on body size $\left(\mathrm{L}^{3}\right)$ in 73 species, using the means for those with more than one specimen, is represented by the equation:

$\log \mathrm{V}=1.02 \log \mathrm{L}^{3}-2.69(\mathrm{r}$

$=0.83, \mathrm{p}<0.001$

The large scatter, reflected by the low value of $r$, is not surprising since species differin markedly in diet are grouped together. The slope of the regression equation is close to 1.0 which means that the volume for fermentation appears at first approximation to be proportional to body size. Parra (78), when comparing the size of fermenting chambers in reming the size of fermenting chamers in rumnants and non fernants, obtained a slope of fermenting chambers increased with body

The relationship between the volume of fer- menting chambers and body size can be illus trated by cubic models of animals of length $\mathrm{L}$. and volume $L^{3}$ (Fig. 24). The fermenting chambers are required to fill this volume with nutrients each day; this will be achieved if the size of the fermenting chamber is proportional to the size of the animal. However, this intake of nutrients relates to metabolic weight, which only increases to the threequarter power of body weight (Schmidt-Nielsen, 72 , that is, $L^{2-2}$ in our model. Furthermore, Tucker ( 70$)$ calculated that the energetic costs of movement in terrestrial mammals are relatively smaller in larger forms. In the arboreal environment of most primates, however, costs might be much higher for larger species, because they are theoretically proportional to actual body weight (or $L^{3}$ ) for all vertical movements. Thus the correcting factor for gut volume to account for eco-physiological needs in relation to body size should lie between $\mathrm{L}^{2.25}$ and $\mathrm{L}^{3}$, slopes of 0.75 and 1.00 respectively in the $\log / \log$ graph.

If animals with similar diets are considered together, the wide scatter of plots (Fig. 21) is resolved into meaningful components (Fig. 22). Thus, reliable data on the volumes of potential fermenting chambers from mature wild mammals are regressed linearly against body size in four groups:

1) in 30 faunivores of 14 species, from 11 to $230 \mathrm{~cm}$ body length,

$\log \mathrm{V}=0.95( \pm 0.11) \log \mathrm{L}^{3}-2.52(r=0.95$, $\mathrm{p}<0.001)$;

2) in 50 frugivores of 22 species, from 17 to $126 \mathrm{~cm}$ body length.

$\log \mathrm{V}=1.13( \pm 0.12) \log \mathrm{L}^{3}-2.94(\mathrm{r}=0.92$, $\mathrm{p}<0.001$ )

3) in 13 folivores of seven species, with large caecum and colon, from 17 to $157 \mathrm{~cm}$,

$\log \mathrm{V}=1.20( \pm 0.08) \log \mathrm{L}^{3}-2.95(\mathrm{r}=0.99$, $\mathrm{p}<0.001)$; and

4) in 14 folivores of six species, with large stomachs, from $44-145 \mathrm{~cm}$ body length.

$\log \mathrm{V}=0.78( \pm 0.09) \log \mathrm{L}^{3}-0.69(\mathrm{r}=0.97$ $\mathrm{p}<0.001)$

For each of these equations the $95 \%$ confidence intervals were calculated according to sta dard practice (Moore et al., '72); those for the different dietary groups are clearly separated Fig. 22). The differences between the slopes in the equations for folivores with large colon and faunivores are also significant $(\mathrm{p}<0.05$ ) In faunivores, where fermentation is minimal, the volumes of these parts of the gut are related mostly to actual body weight (expressed as $\mathrm{L}$ ). In frugivores and folivores with large caecum and colon the potential ferment ing chambers are relatively more voluminou. in larger animals, the wider scatter among frugivores seems to reflect the inclusion of species consuming significant amounts of either animal or plant matter in addition to fruit. The folivores with large stomachs are remarkable in that the sizes of potential fermenting chambers are relatively much smaller in larger animals; compared with the othe three groups, this represents a more efficient adaptation to metabolic needs, since the slope of regression is close to the theoretical 0.75 . Although there is a close correspondence between fermenting volume and body across the two types of folivore, as shown by the crosing and lack of much the crospetive regre ificant differ ent allo dific relations tive allotic relationships of the two distincin strategies fore-gut and mid-gut fermentation (in stomach and caecum/colon respectively). Structurally this is a matter of "sacs" (spheres versus "tubes" (cylinders). The "sac" is ideal for fermentation, but it must be kept relative$y$ small in the larger fore-gut fermenters, so as to provide adequate area for absorption; they have a relatively larger small intestine to complete this process (see below). In conrast, the larger mid-gut fermenters require an extended, thus more voluminous, "tube" for adequate absorption; area and volume do not diverge so rapidly with increasing size of cylinder, as they do with spheres.

This leads directly to a consideration of absorptive activity within the gastro-intestinal tract, which is concerned with surface aren rather than volume. It is our initial assumption, based on evidence from man, rhesus ton, based on evidence from man, rhesus mont ret region for absorbing the products of digestion. Thus, to seek allometric relationships, the values for the surface area in each species are plotted against body size on a logarithmic scale (Fig. 23). The linear regression of these surface areas $(A)$ in relation to body size $\left(L^{3}\right)$ using means for those of the 76 species for
which there is more than one specimen, is 


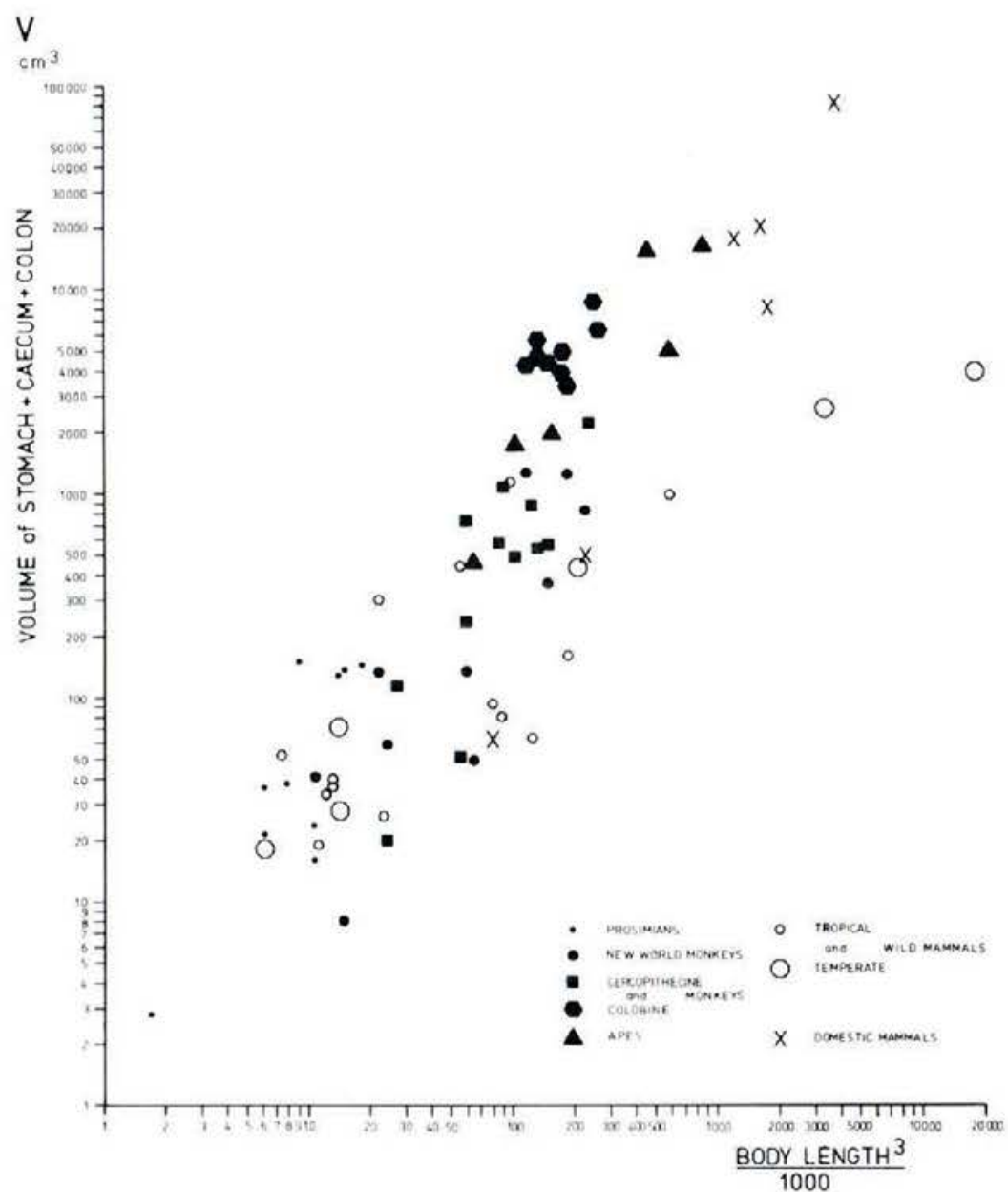

Fig. 21. Volumes of potential fermenting chambers plotted against body size (from body length, $\mathrm{cm}$ ) for each species, using mean values where there is more than one specimen.

represented by the equation:

$\log \mathrm{A}=0.76 \log \mathrm{L}^{3}-0.96(\mathrm{r}=0.93, \mathrm{p}$ 0.001 .

The scatter is less than that for volume (Fig. 21). The slope of 0.76 would mean that the bolic rather than overall body size (see below for discussion of confidence intervals).
Returning to the cubic model of animals of varying length $\mathrm{L}$ and volume $\mathrm{L}^{3}$ (Fig. 24), relationships between surface area and absorption can be described. If flow across the mucosa occurs at a constant rate, because of similar histology, the surface area of gut re. quired to fill the animal at a rate of $1,000 \mathrm{~cm}^{3}$ day $/ \mathrm{cm}^{2}$ will be $0.001,1$, and $1,000 \mathrm{~cm}^{2}$ respectively for the three animals. Because an imals of different sizes have different basal

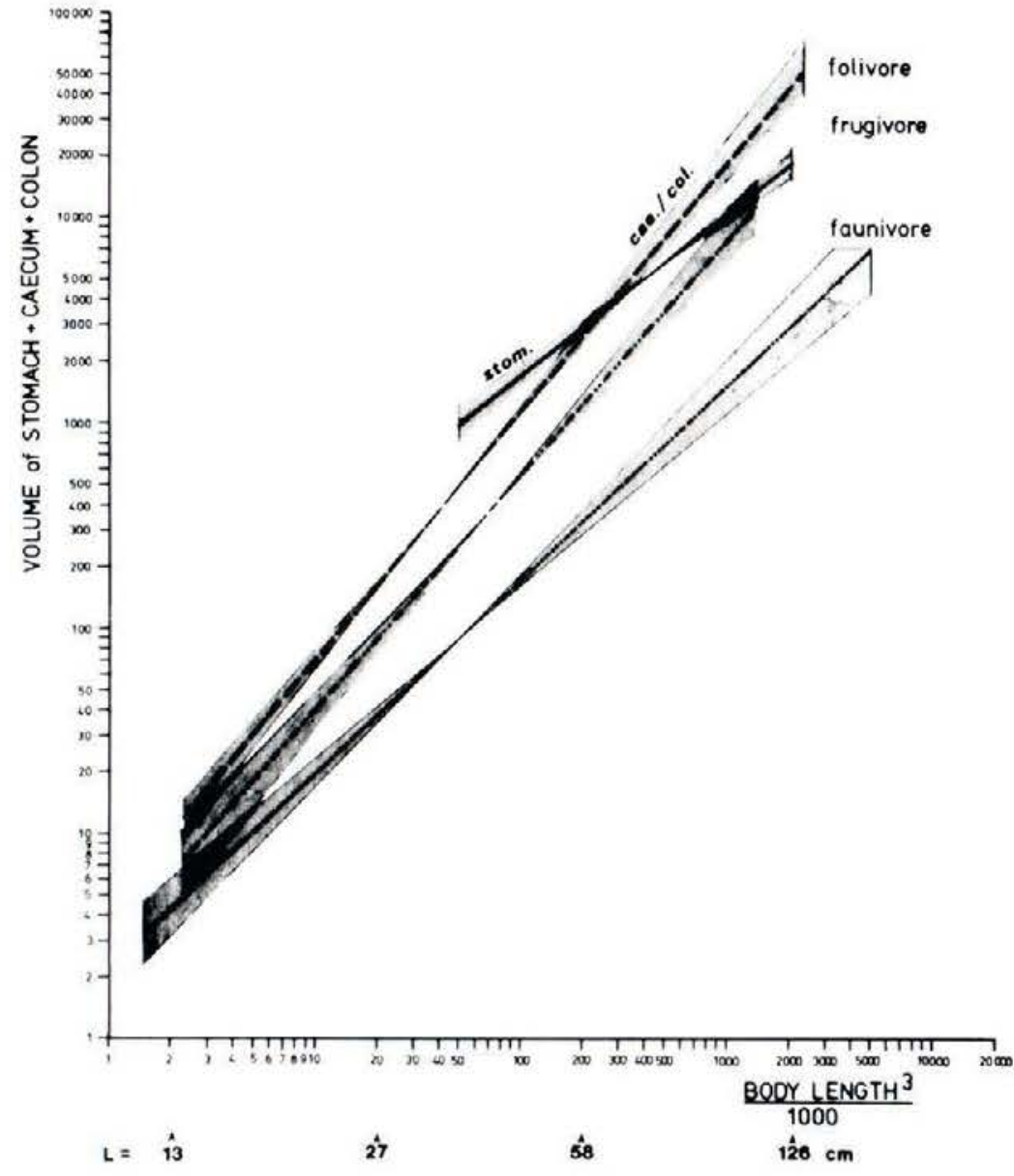

Fig. 22. The relationship between the volume of potentinl fermenting chambers and body size in faunivores, (rrugivores, folivores with large stomachs (stom.), and folivores with large caecum and colon (cae.col.), in the form of regressions derived from individual data, with the shaded areas demareating the $95 \%$ confidence limit
for the slopes,

metabolic rates (BMR), however, the volumes to be filled are proportional to the three-quarter power of body weight- $\mathrm{L}^{2.25}$ in our modeland the volume of nutrients absorbed in 1 day will be such that areas of $0.0056,1$ and 178 $\mathrm{cm}^{2}$ are required in the three animals respectively. It can be seen that there is a point beyond which further increase in body size is imposible, because of a prohibitive requireiment for vast intestinal area.

Allowance must also be made for activity, which as mentioned above costs relatively more in terms of energy in a larger animal, despite an improved output. Thus the flow across the gut wall depends on a surface area of gut that relates to a value of body size fomewhere correct factor to enertic cos to eneers to fall in the sure range a fore 
A

$\mathrm{cm}^{2}$

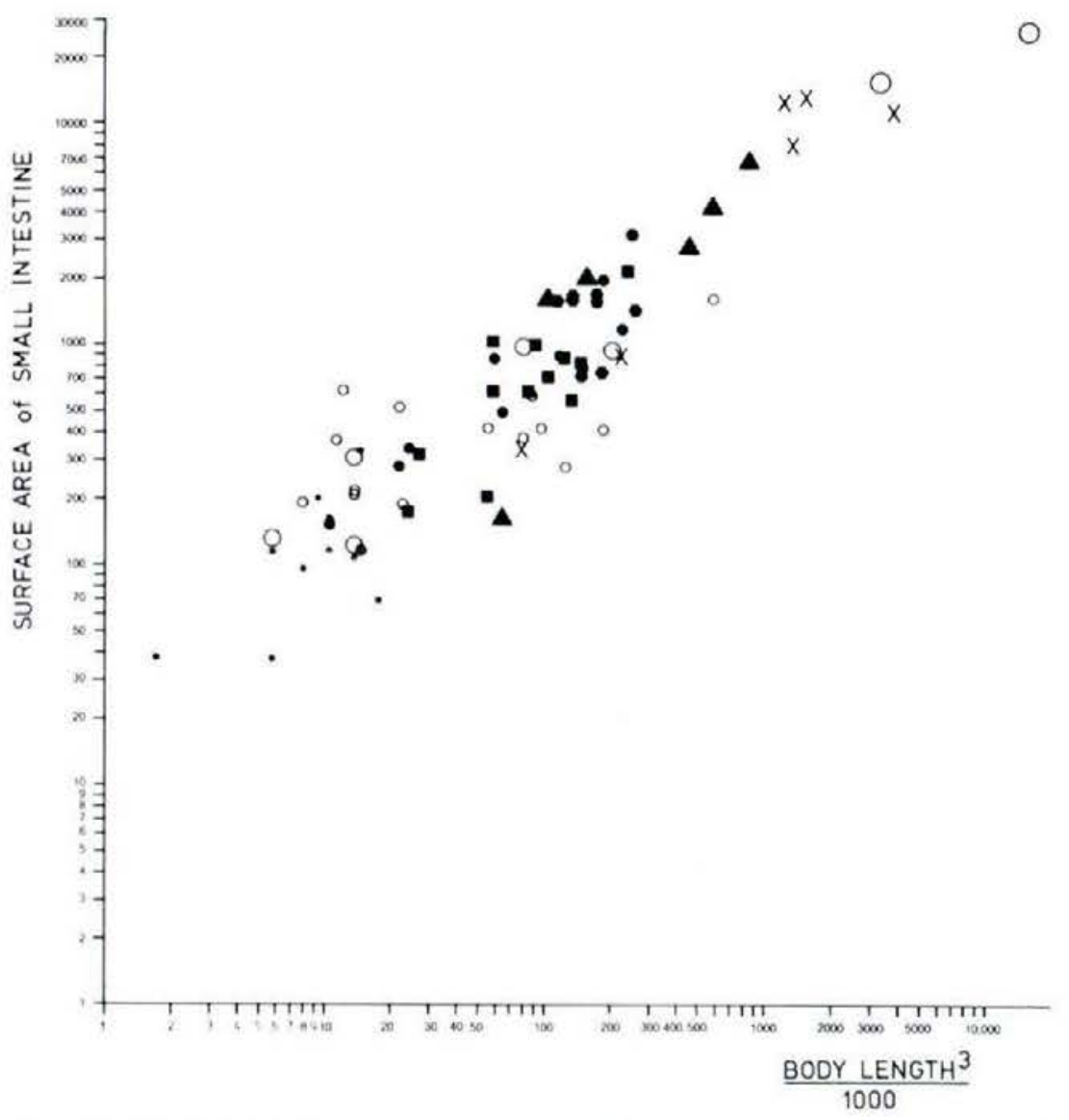
Fig. 23. Surface areas of the main absorbing region ismall intestine) plotted against body size (from body
length, $\mathrm{cm}$ ) for each species, using mean values where there is more than one specimen.

menting volume, the nature of the relationship is different.

The relationship between the surface area of the small intestine and body size is clarified by regressing data for mature wild individuals in four groups (Fig. 25):

1) in 31 faunivores of 14 species.

$\log \mathrm{A}=0.65( \pm 0.07) \log \mathrm{L}^{3}-0.54(\mathrm{r}=0.96$,

$$
\mathrm{p}<0.001)
$$

2) in 51 frugivores of 23 species,

$\log \mathrm{A}=0.75( \pm 0.08) \log \mathrm{L}^{3}-0.85(\mathrm{r}=0.92$, $\mathrm{p}<0.001)$;
3) in 14 mid-gut fermenting folivores of 8 species,

$\log \mathrm{A}=0.86( \pm 0.15) \log \mathrm{L}^{3}-1.46(\mathrm{r}=0.95$ $\mathrm{p}<0.001)$; and

4) in 14 fore-gut fermenting folivores of 6

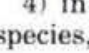

$\log \mathrm{A}=1.16( \pm 0.22) \log \mathrm{L}^{3}-3.09(\mathrm{r}=0.94$, $\mathrm{p}<0.001)$.

Thus, different patterns emerge; only frugivores follow the expectation of absorptive area being directly proportional to metabolic body

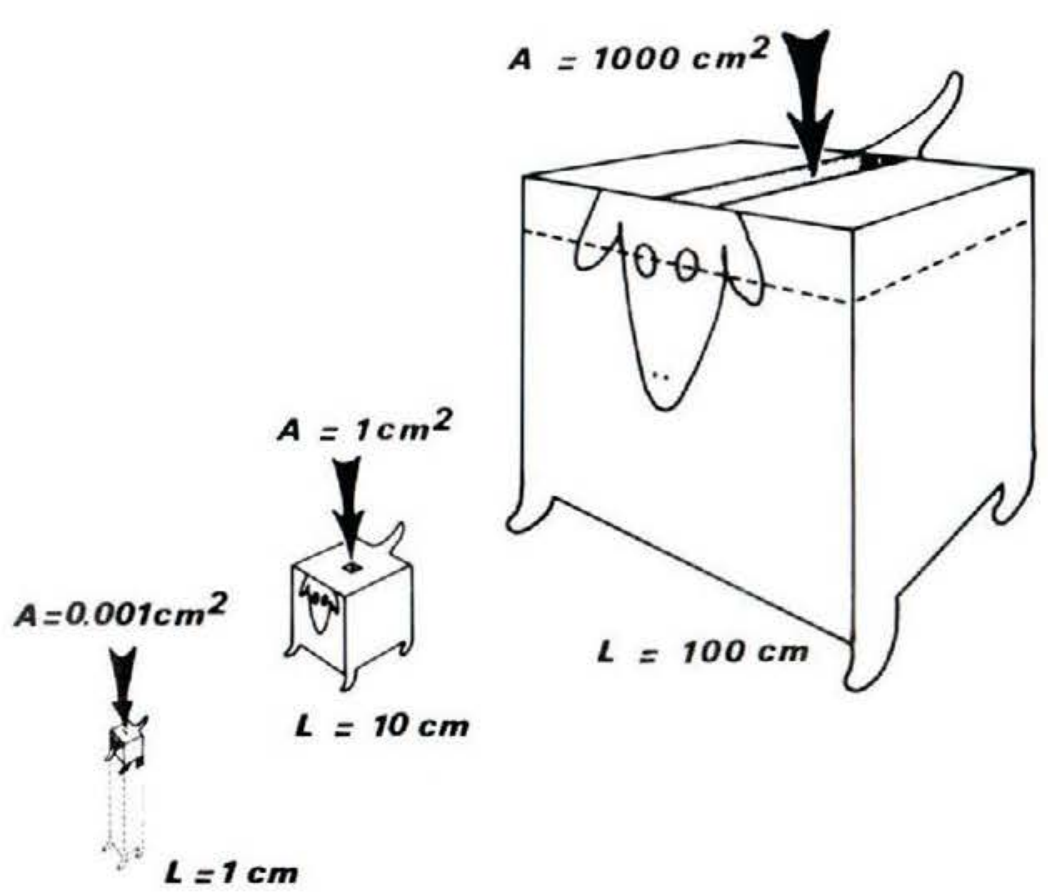

Fig. 24. Cubic models of body lengths 1,10 , and $100 \mathrm{~cm}$, and theoretical weights $.001,1$, and $1000 \mathrm{~kg}$. The areas necessary to fill these models in unit time by constant flow (shown by openings in top) are .001, 1 , and liters, but the "metaholic volumes", that actually have to be filled, with middle-sized model as referend 1000 $.0056,1$, and 178 liters ishown by broken lines on the smallest and largest modelsi). Thus, to maintain the constancy of the organism, and to fill the different volumes in the same time, the absorptive intestinal areas must be 0056,1 , and $178 \mathrm{~cm}^{2}$

size (in log values), but they have the widest scatter (for the reasons mentioned previously). Faunivores have relatively less small intestine when larger, whereas the larger the folivore, especially the fore-gut fermenters, the larger the small intestine relative to body size. Correlations within each Correlations within each group, however, are less close than in the analysis of volumes, and calculation of the $95 \%$ confidence intervals produces exten lines. The most obvio different regression tines. The most obvious explanation is that it is enroneous to assume that aboth inton of nutrients o frugivores with a significant intake of leaves.
There is a mounting body of evidence that the arge intestine in particular does much more than regulate water and electrolytes (Sineshchekov, 65; Giesecke, '69; Kay and Pfeffer, 69: Parra, '78).

Accordingly, after testing different combinations of areal proportions, so as to account to some extent for the absorption that osent in stomach, caecum, and colon, the best fit in was obtain by a dine combined area of these regions to the area of chall intestine. Since the actual the area of hall intestine. Since the actual efficiency of pecies, we have to rely measured in most choice. The resulting linear regressions of this 
$\mathrm{cm}^{2}$

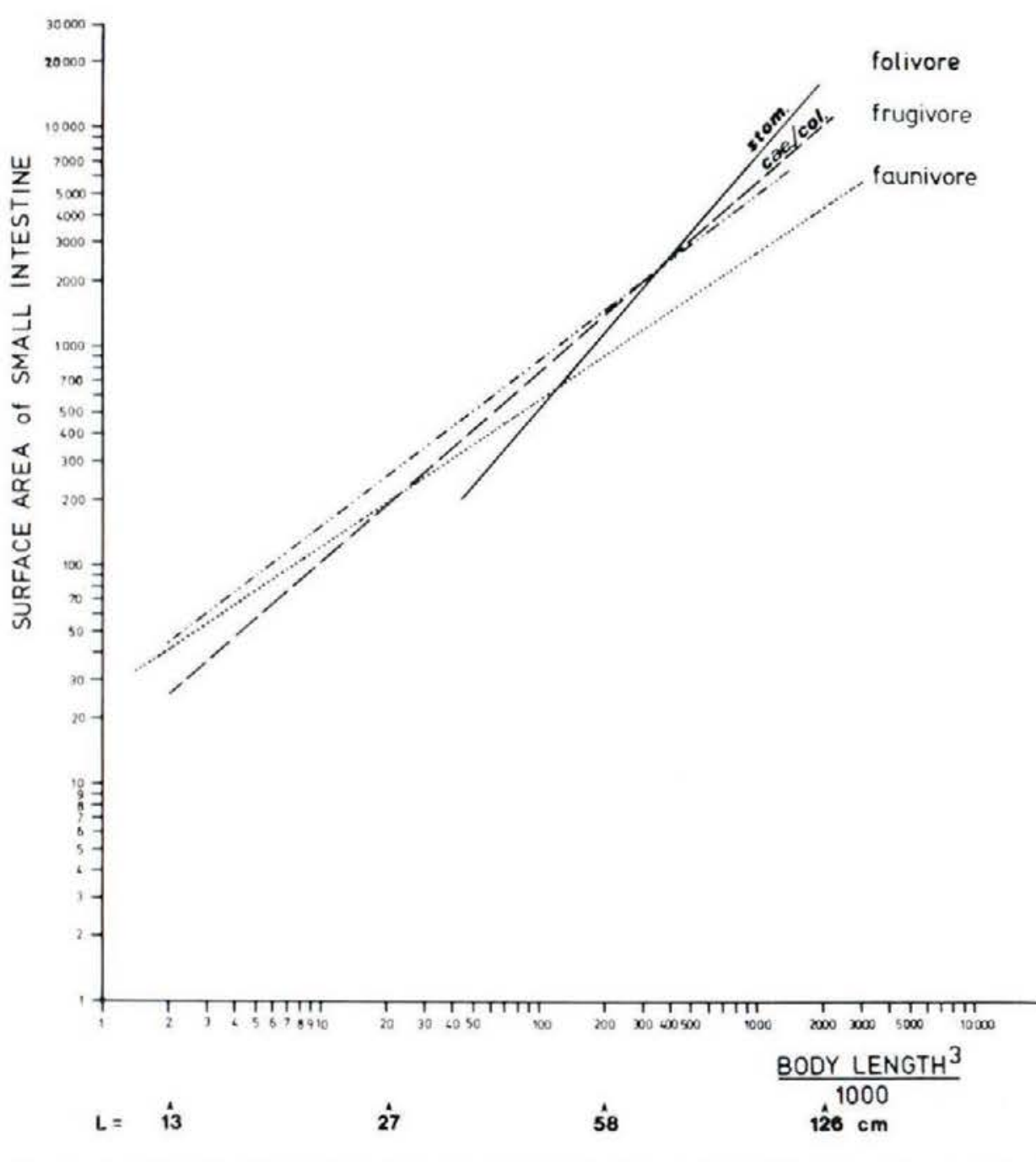

Fig. 25. The relationship between the surface area of the main absorbing region (small intestine) and body size (fror body length, $\mathrm{cm}$ ) in faunivores, frugivores, folivores with large stomachs (stom.), and folivores with large caecum and
colon (e/coli, in the form of regressions from individual data. The 95\% confidence intervals would show extensive overlap.

"absorptive area" $\left(\mathrm{A}^{\prime}\right)$ and body size $\left(\mathrm{L}^{3}\right)$ in the four groups are:

1) in 32 animalivores of 16 species,

$\log \mathrm{A}^{\prime}=0.66( \pm 0.06) \log \mathrm{L}^{*}-0.48(\mathrm{r}=$ $0.96, \mathrm{p}<0.0011 ;$
2 ) in 46 frugivores of 21 species,

$\log \mathrm{A}^{\prime}=0.79( \pm 0.09) \log \mathrm{L}^{3}-0.88(\mathrm{r}=$ $0.95, \mathrm{p}<0.001$

3) in 8 mid-gut fermenting folivores, $\log \mathrm{A}^{\prime}=0.86( \pm 0.15) \log \mathrm{L}^{3}-1.46(\mathrm{r}=$ $0.95, p<0.001)$; and

4) in 14 fore-gut fermenting folivores,

$\log \mathrm{A}^{\prime}=1.19( \pm 0.17) \log \mathrm{L}^{3}-2.97(\mathrm{r}=$ $0.96, \mathrm{p}<0.001$ )

These regressions now have a better fit (higher value of $r^{2}$ ). Since values for the two folivore groups overlap each other extensively, the regression was applied to the total set of data. Thus, for 38 folivores of 16 species,

$\log \mathrm{A}^{\prime}=0.88( \pm 0.06) \log \mathrm{L}^{3}-1.17(\mathrm{r}=0.97$ $p<0.0011$.

In the three dietary groups characterized by these equations (Fig. 26), the $95 \%$ confidence intervals have been calculated; they show no
overlap except for animals of very small body overlap except for animals of very small body
weight, because of the convergence of the weight, because of the convergence of the three lines. This latter feature suggests that
smaller animals show similar structural adsmaller animals show similar structural ad-
aptations for absorption, irrespective of diet. The maximum and minimum values of the slopes of these regressions have been compared in terms of $95 \%$ confidence intervals. They differ significantly between folivores and faunivores, but frugivores differ from these two extremes at only the $85 \%$ limit. This lack of high significance is not surprising, since the frugivore sample comprises species with rather different diets based on fruit. Both frugivores and folivores fall within the limits derived for metabolic plus energetic requirements (slopes between 0.75 and 1.00 ). Fauniveres, on the other hand with a slope of 0.66 less then 0.50 for a mall set of highly specialized fan 0.50 or a s a nivores, in the lare value expected for absorptive intestinal area. These large faunivores usually catch very large prey at inegular intervals, which prois digested during long periods of rest, and a is digested during long periods of rest, and a smaller intestine is adequate, because of the extra time available for absorption. Conversely, small faunivores, relying mainly on invertebrates, have access to a more regular supply of food, which corresponds to the eco-physiological patterns of the other dietary groups. The significant difference in the slopes of regression for each dietary category do not allow the use of a single allometric factor. Such a factor would have been invaluable in interspecific comparisons independent of body size, as was attempted above with indices of gut differentiation. The results of the relation between body size and the potential area for absorption (Fig. 26) show that this area must be divided by $\mathrm{L}^{1.25}$ in faunivores, by $\mathrm{L}^{2.37}$ in frugivores, and by $\mathrm{L}^{2.64}$ in folivores, in order to eliminate allometric factors and validate the comparison between species. The factor $\mathrm{L}^{2}$, used in earlier studies to compare gut surface areas (Hladik, '67), was a good approximation apart from being below the theoretical range from $L^{2-2}$ to $L^{3}$ ), but it can now be seen as valid only for faunivores and some frugivores. The ultimate aim in our studies of gut morphology has always been to seek correla tions with diet. The results presented in this section advance conserably our und in this ing of the morphological feares relevand liet in the different dietary groups, and show het in the different dietary groups, and show 列 ween adequate volume for fermentation the adequate surface area for absorption. Or the appochest ot yield conclusive ratios of gut diflerentiaion, probably through ignoring allometric actors, and the second, accounting for such actors, did not yield a single morphological ndex directly comparable with diet. So far we ave been considering diet from the morphol gical viewpoint, and before concluding the earch for a single morphological index, some eatures of diet and feeding behavior need first to be stressed.

DIET IN REI.ATION TO GUT MORPHOLOGY

The diets of most species, especially prinates, are composed of varying combinations of each major category of food-animal mater, fruit, and leaves. This is well known from field studies and partly explains the scatter of mots in the preceding analysis, . the specol somizing

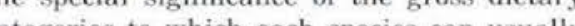
cate to which each species can usually e assigned, particularly the most specialized forms, we have tried to avoid any implication that a classification into faunivores, frugiores, and folivores reflects exclusive diets.

In comparing the diets of wild mammals, even among closely related forms, we immeiately encounter problems resulting from diflerent methods of both observation and anal ysis. Observations may be made continuously, or sampled at intervals of varying duration, over periods that vary from a few hours to everal days. Food intake may be assessed in ross terms or in fine detail, either from direct observation or even from analyzing stomach contents or faeces. The difficulties are compounded when such variable data are subject- 
$\mathrm{Am}^{\prime} \mathbf{c m}^{2}$

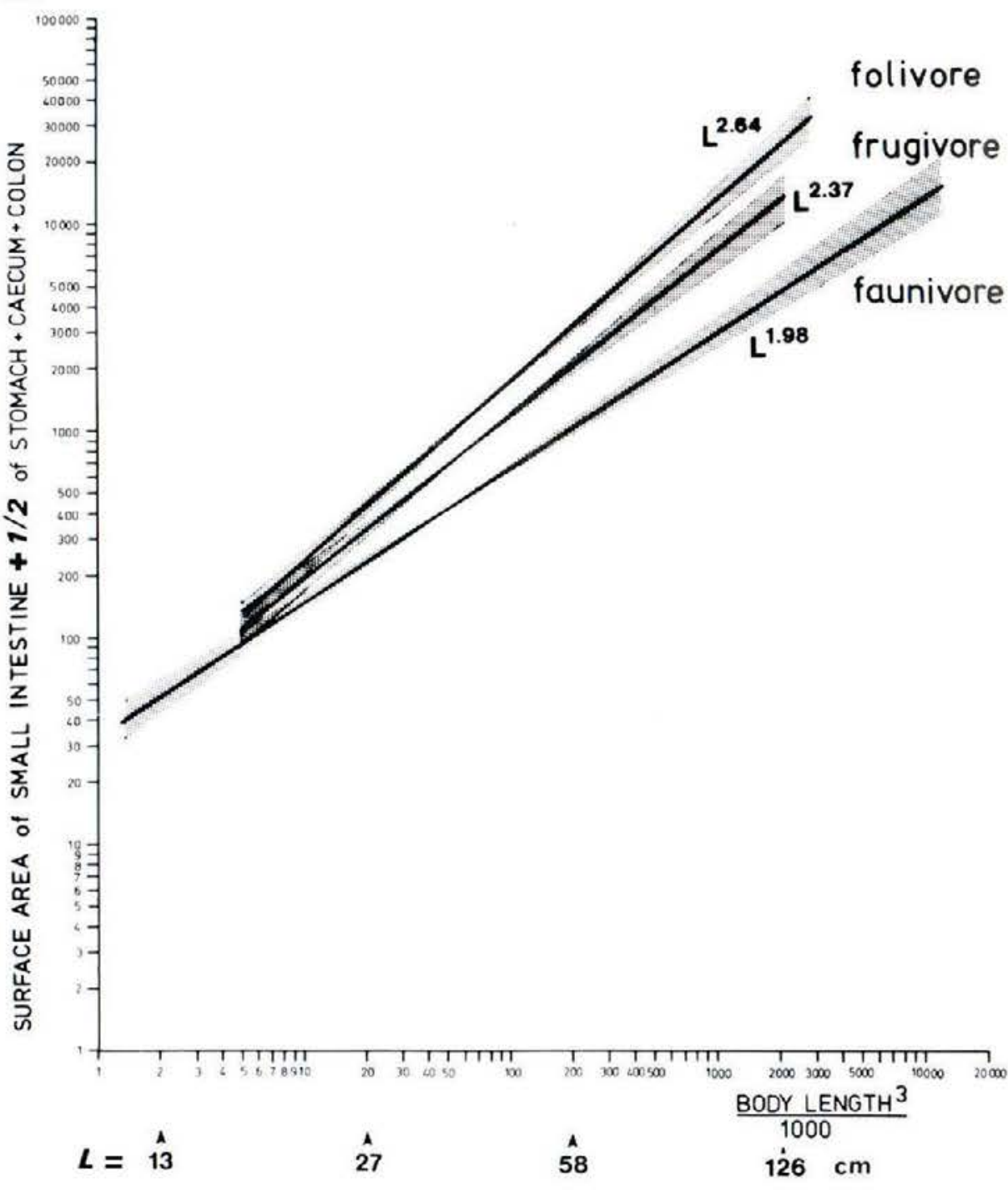

Fig. 26. The relationship between the potential area for absorption (surface area of small intestine and half the combined areas of stomach, caecum, and colon) and body size (from body length, $\mathrm{cm}$ ) in faunivores, frugivores and folivore (wo types combined), in the form of regressions derived from individual data. The correcting factors (L), accounting for the allometric relations in each group, are markedly different, because of the variations in slope. The stippled are ed to different kinds of analysis, according to the relatively narrow question to which the researcher may be addressing him/herself (Hladik and Chivers, '78).

It need not matter if different methods of observation are used, so long as their reliability can be assessed to yield results that are truly comparable. In seeking correlations with gut morphology it is amounts of different foods ingested, rather than the time spent feeding on each, which are of paramount im feeding It is relatively easy, in sampling im portance it is res wich are of parame in samg the the detail of foeding bout in ter accurately the details of feeding bouts in terms of time Chack, 74 , St but it is me Mackinnon, ' 8 , but it is much more difficult to measure the amounts ingested in terms of fresh (or dry weight over a reasonable length of time Hladik and Hladik 69,72 , Hladik, 73 ; Iwamoto, 74,78 , Raemaekers, 77 ) and to analyze food composition (Hladik et al., ' 71 ; Hladik, 77a,b; Goodall, 77). Data based on the analysis of stomach contents pose special problems, but may yield the kind of measures required (Gautier-Hion, '78).

While the amounts of leaves and other vegetative plant parts ingested can be deduced with sufficient accuracy from feeding times, fruits may be underestimated as much as fivefold, and insects may be overestimated as much as 15 times, compared with the actual amount by weight (Hladik, '77a,b). While such distortions may fortuitously cancel each other out (Raemaekers, '77), data based on time are obviously inappropriate for our purposes; mixing data based on time and weight should be treated with circumspection.

Different models have been proposed to represent the diets of wild primates, so as to account for the average intake of an individual and its variation over time (e.g., Hladik and Hladik, '69, '72: Suzuki, '65: Kay, '73; MacKinnon and MacKinnon, '781. The most effecive method for representing a system containing three variables - animal matter, fruit,
and leaves - is a tri-rectangular projection (or

and leaves - is a tri-rectang
three-dimensional graph).

This approach involves plotting values for the three major categories of food in the diet within a three-dimensional system of converging axes (Fig. 27, right upper). Since the three variables are not independent (their sum is always $100 \%$ ), the projection of any combined dietary value will fall within the triangle $\mathrm{AFL}$, where point $\mathrm{A}$ represents a diet of $100 \%$ animal matter, point $\mathrm{F}$ a diet of $100 \%$ fruit, and point $\mathrm{L}$ a diet wholly of leaves. In this triangle (Fig. 27), any point close to A represents a diet rich in animal matter, close to $F$ rich in fruit, and close to $L$ rich in leaves. Because of the construction of the triangle $\mathrm{AFL}$, the dietary values (in terms of per cent of animals, fruit, and leaves) are plotted more conveniently along the perpendicular axes $\mathrm{Ox}$ and $\mathrm{Oy}$. If $\mathrm{OL}=+100$ and $\mathrm{OA}=-100$, then $x=(\%$ leaves $)-(\%$ animals $)$, and $y=\sqrt{3}(\%$ fruit), for any point within the triangle.

In addition to pinpointing an average diet for addition to pinpointing an average diet its range of these these patrie species, it may not bo at the same time of year, but, nore importantly, this similarity of gross categories obscures important differences in food choice (species and its different parts), and thus in biochemical composition. identify and this analysis is sufficient to identify and quantify significant differences between species, even those which have been regarded previously as similar, e.g., the "omnivorous," more properly frugivorous, primates such as Cebus, Macaca, and Pan. Although these three primates eat mostly fruit, the overlap represents but a small part of their dietary ranges; for the means $(x=-5$, $+15,+26$ respectively), accounting for differences in the supplement of plant and animal matter, provide good diagnostic dietary indices.

To amplify the interspecific comparison, the mean diets of as many as possible of the mammalian species studied morphologically are plotted in Figure 28. This inevitably means adapting data based on time measures, but all values are derived from studies lasting, but allo more than 1 year (see, for example, CluttonBrock, bastine of the triangle is conspicuous, and is not a consequence of inadequate sampling of species. No mammal mixes large quantities of animal matter and leaves without including fruit in its diet. Since, as has been shown previously, faunivory and folivory represent contrasting, and incompatible, adaptations, the quantity of fruit in such a mixed diet should always be considerable. From the demonstration by Hladik et al. (72) that fruit is an adequate source of carbohydrate for the energetic requirements of most primates but inadequate in protein, Kay ('73) argues that those primates securing this protein from insects are necessarily much smaller than those obtaining it from leaves.

Thus, as exemplified by primates, there are 
PAIMATE DIETS

$\Rightarrow M E A N S$

AND RANGES

$\mathrm{x}=(\%$ Leaves $)-(\%$ Animals $)$

$y=1.732(\%$ Fruits $)$

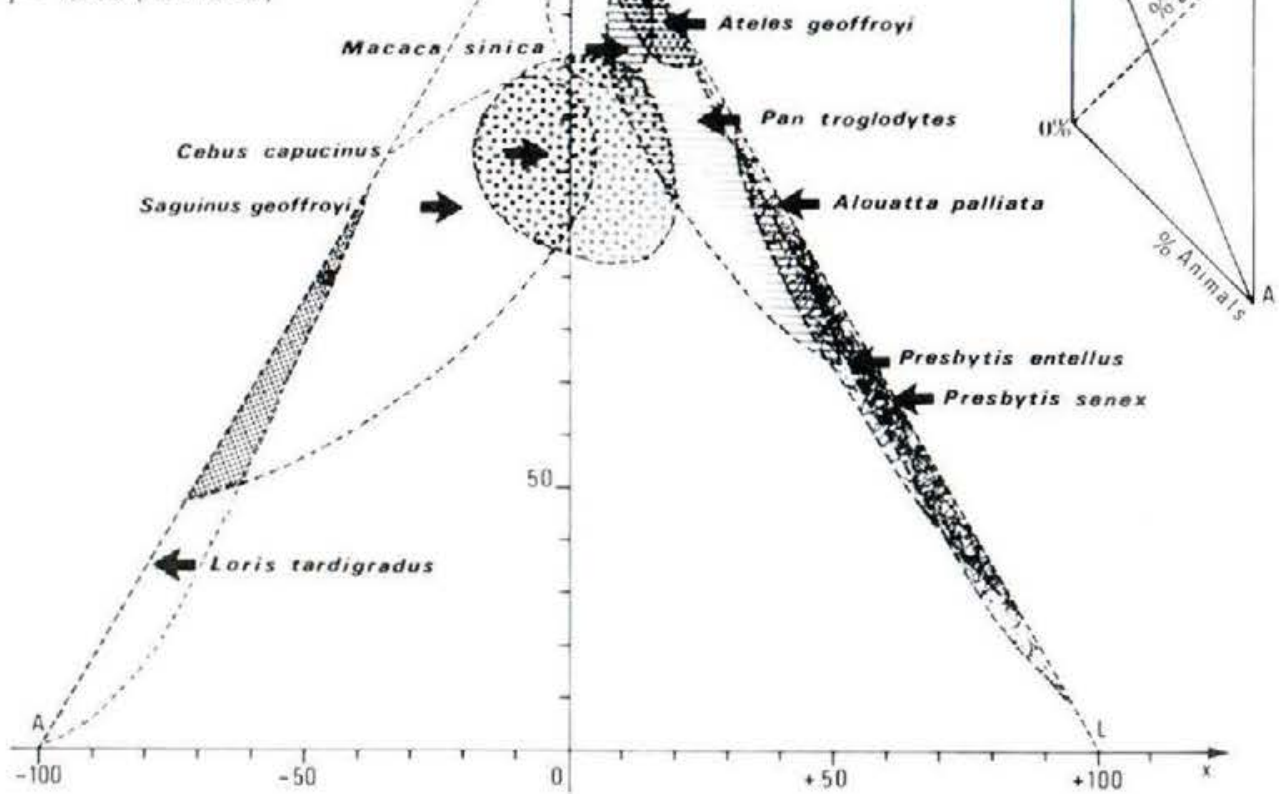
Fig. 27. Annual means and ranges of the diet of nine primate species from Panama, Gabon, and Sri Lanka idata from
Hladik and Hladik, '69, $72 ;$ Hladik, 73) represented within a triangle Isee text for explanation of its derivation from trirectangular projection, and its applications. The composition of the mean annual diet, in terms of proportions of animal matter, fruit, and leaves, is pinpointed by an arrow: most data, collected over 24-hour periods at all times of year, are included in the shaded area conly daily records which differ markedly from the previous or following days are excluded.

optimum body sizes corresponding to the different feeding strategies:

\section{Body size}

kg (Kay, 73)

Faunivores

$$
0.4
$$

Frugivores

$$
4.0
$$

\section{Biomass$$
\mathrm{Kg} / \mathrm{km}^{2}
$$$$
\text { (Hladik, '78a) }
$$

Folivores

300

We have arrived independently at conclusion. similar to those of Kay (73), who shows that primate species each specialize on either antmal matter, or fruit or leaves, althou h my maliatter, or fruil or low dependence) and secondarily on another (
$20 \%$ dependence); for reasons given above, no species exceeds $20 \%$ for both animal matter and leaves.

Returning to Figure 27, it is not possible from the data available to predict a central minimum $y$-value, the lowest proportion of fruit taken by a frugivore. It is likely to be quite high, since the data are clearly distributed along a crescentic path from $\mathrm{A}$ to $\mathrm{L}$ via the vicinity of $F$, with the greatest range of $y$ values around the zero $x$-yalues. This repre values around the zero $x$-values. This reprepath from the anclutionary path from the ancestral insectivorous forms (Ripley, 79) through three ecological grades
(Hladik, '78b).

The geometrical arrangement of the data,

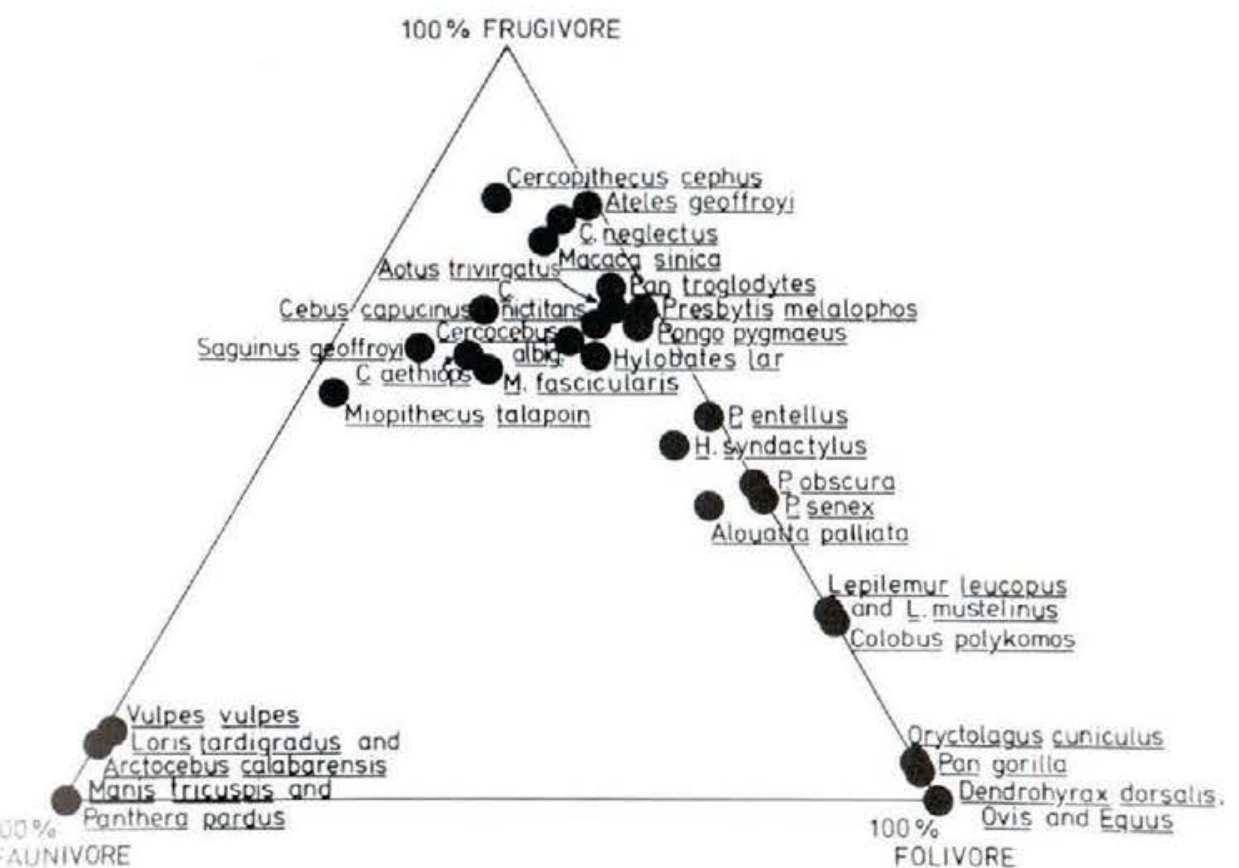

EAUNIVORE

FOLIVORE

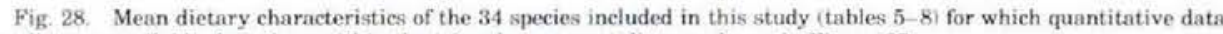
Mean dietary characteristics of the 34 species included in this study (tables $5-814$.

cators of diet, varying from -100 (pure faunivores) to +100 (pure folivores). The final task the

Considering first the potential volumes for fermentation, the data for faunivores and fol ivores (excepting those with large stomachs have been linearly regressed separately against body size (Fig. 22) These regressions are used to represent the structural limits for coping with the two extremes of diet (Fig. 29). Most primates fall within these limits, but the concentration of within these limits, but the sented by the third regression line, closer t the upper line, reflects their greater similarit to folivores than to faunivores. In order to derive a morphological index for comparison with the dietary one, we need a scale of negative and positive values to reflect thei direction and degree of adaptation to either faunivory or folivory respectively. To account for the asymmetry in the relative positions of the regression lines, it is more appropriate to take the line of the regression for frugivores as the zero, rather than a line midway between the regressions for folivores and fauni.

Thus the morphological location of any species can be described as the distance $D$ above or below this zero line, by the following conditional formula:

$$
\begin{aligned}
& \text { if } \mathrm{V}>\mathrm{V}_{\mathrm{f}}, \mathrm{D}=+\frac{\mathrm{V}-\mathrm{V}_{\mathrm{f}}}{\mathrm{V}_{\mathrm{f}}-\mathrm{V}_{\mathrm{f}}} \\
& \text { if } \mathrm{V}<\mathrm{V}_{f}, \mathrm{D}=-\frac{\mathrm{V}_{\mathrm{f}}-\mathrm{V}_{\mathrm{f}}}{\mathrm{V}_{\mathrm{f}}-\mathrm{V}_{\mathrm{i}}}
\end{aligned}
$$

where $V, V_{u}, V_{f}$ and $V_{1}$ represent the potential volumes for fermentation in the subject, and in faunivore, frugivore, and folivore of the same size, respectively; these latter are calculated from the regression equations relating to Figure 22, where body size is derived from the length $\mathrm{L}$, the distance between breoma and ischial callosity. Since body weight $\mathrm{W}$ is 
the more widely used measure of body size the regression equations were recalculated according to the approximation, $W=\frac{\mathrm{L}^{3}}{30}(\mathrm{~L}$ in $\mathrm{cm}, \mathrm{W}$ in $\mathrm{gm}^{1}$ ), which fits most of our speci mens, yielding the same results:

for faunivores,

$\log \mathrm{V}=0.95( \pm 0.11) \log \mathrm{W}-1.07$ for frugivores,

$\log \mathrm{V}=1.13(+0.12) \log \mathrm{W}-1.25$; and for folivores,

$\log \mathrm{V}=1.20( \pm 0.08) \log \mathrm{W}-1.18$.

As shown in Figure 29, the asymmetry creates a discrepancy in the size of units above and below the zero line, since the extremes represented by the outer lines have values of -1 and +1 . To attain a homogeneous distribution of the units, and thus the desired index of gut specialization, the distances D are transformed mathematically into the values $\mathrm{TR}_{\mathrm{u}}$. The conditional formula used (Fig. 291

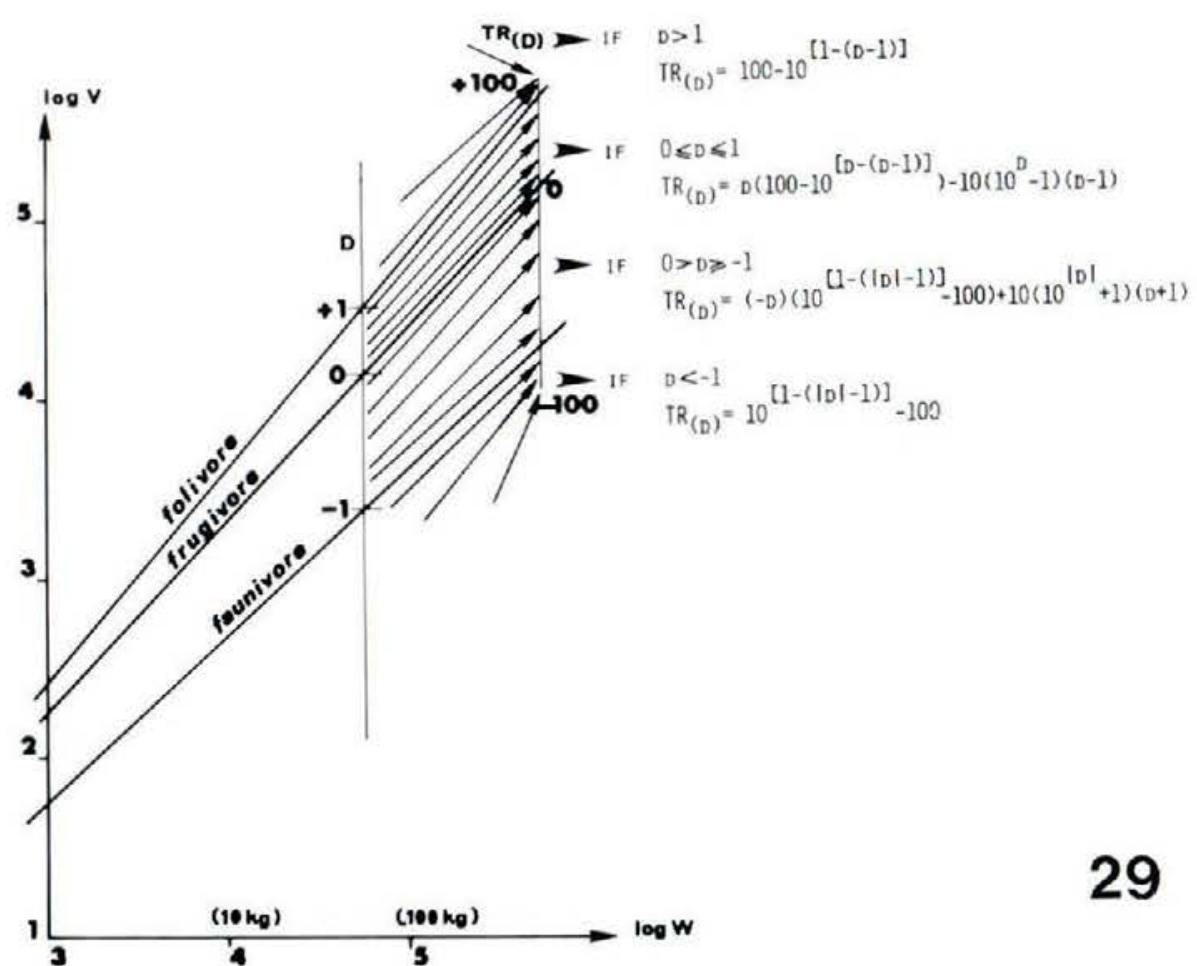

is based on antilogarithms; although appearing very complex, on the small programmable calculator, now in wide use, it is almost as

This nonlinear transformation not only renders comparable scores above and below the the never exces ero line, but yields values that never exceed

17in 29. The conditional formula is designed Fig. 29 . The conditional formula is designed o produce values of -90 and +90 on the resession lines for animalivores and foliche reatter to assume that the upper one accounts for 'A regression of all data available in Tables 5-8 gives a relation,
$W=0.041 \times 12=\left(r=0.98\right.$ or $W=\frac{1}{24.4}$. The approximation $W$ 12. in preferred, since it yields a better fit for most wild arborea rimates.

20n the HP 25 calculator the program is: $g x \geqslant 0$ GTO $07 \mathrm{I} C \mathrm{CH}$ TO $x$ y $y$ ABS $17 x$ G $x$ GTO $36 x \geq y$ STO $x \geq y-1 x=$ - $x$ - GTO $44-1 x \geq y-$ g 10 RCL $3 x \geq y-$ RCL $1 \times 1$ STO $x=y$ GTO 06. After storing the values 1,10 , and 100 in register TR easy to use as the ordinary logarithm diets including more than $90 \%$ of leaves, and ter

Such a method of nonlinear interpolation between two diverging repression lines, can be used a an approximation of the percentage "tenden" for any biotion the percentage "tendency" for any birlo varying between two opposite poles. In this case, we are indicating the extent to which each species is tending toward one dietary extreme or the other, having resolved the special allometric problems encountered. These indices of gut specialization, derived from potential fer menting volumes for all species except those with complex stomachs, are very similar to the dietary indices (see below).

The same method is applied to the potentia absorbing area (including half the area of stomach and large intestine together with the area of small intestine) in all species. The regressions of these areas ( $\left.\mathrm{A}^{\prime}\right)$ are those of Figure 26. The asymmetry of the regression for frugivores in relation to the other two is even more marked; thus the conditional formula is used to locate each species, accordin to body size, at distance $\mathrm{D}$ above or below this zero line:

$$
\begin{aligned}
& \text { if } \mathrm{A}^{\prime}>\mathrm{A}_{\mathrm{f}}^{\prime}, \mathrm{D}=+\frac{\mathrm{A}^{\prime}-\mathrm{A}_{\mathrm{f}}^{\prime}}{\mathrm{A}_{\mathrm{t}}^{\prime}-\mathrm{A}_{\mathrm{f}}^{\prime}} \\
& \text { if } \mathrm{A}^{\prime}<\mathrm{A}_{\mathrm{f}}^{\prime}, \mathrm{D}=-\frac{\mathrm{A}_{\mathrm{f}}^{\prime}-\mathrm{A}^{\prime}}{\mathrm{A}_{\mathrm{f}}^{\prime}-\mathrm{A}_{\mathrm{a}}^{\prime}}
\end{aligned}
$$

where $\mathrm{A}^{\prime}, \mathrm{A}_{\mathrm{a}}^{\prime}, \mathrm{A}_{t}^{\prime}$, and $\mathrm{A}^{\prime}$, represent the potential absorbing areas in the subject, an in faunivore, frugivore, and folivore of the same size, respectively. As in the precedin case, the regression equations were recalculated with references to body weight, rather than length: for faunivores,

$\log \mathrm{A}^{\prime}=0.66( \pm 0.06) \log \mathrm{W}-0.49$ for frugivores,

$\log \mathrm{A}^{\prime}=0.79(+0.09) \log \mathrm{W}-0.33 ;$

and for folivores,

$\log \mathrm{A}^{\prime}=0.86( \pm 0.15) \log \mathrm{W}-0.15$.

The asymmetry again creates a discrepancy in the size of units above and below the zero line, so the transformation $\mathrm{TR}_{\mathrm{im}}$ is performed as shown in Figure 29. This yields indices of gut specialization, in terms of area, which are also very similar to the dietary indices.

In these operations we are locating each species in relation to all others, according to the gross dietary classification derived previously. Thus, it is not surprising, with the large samples, that there is samples, that there is good correspondence The problem The problem of scatter is not easy to resolve, because or the difnculties in measuring such a malleable morphological system, and in The variation within species.

The major advance resulting from this ap proach is that, having resolved the complex allometric problems, mammalian species following different adaptive strategies may be compared quantitatively. It is possible to de limit the "ecophysiological tendency" for each species, especially for primates, whose body sizes fall in the central part of the range investigated. For example, among the socalled "omnivorous" primates, which feed on variable amounts of fruit, insects, and leaves, the significant differences in diet which have been demonstrated recently follow those between the various indices:

\begin{tabular}{|c|c|c|c|}
\hline & & \\
\hline & by area, $\mathrm{A}^{\prime}$ & by volume, $\mathrm{V}$ & \\
\hline $\begin{array}{l}\text { Miopithecus talapoin } \\
\text { Ceropithecus cephus }\end{array}$ & $\begin{array}{l}-85 \\
-27\end{array}$ & -2 & $\begin{array}{l}-40 \text { estimate, Fig. } 28 \\
-10 \text { estimate, Fig. } 28\end{array}$ \\
\hline Papio sphinx & +9 & 0 & \\
\hline Cebus capucinus & +11 & & -5 \\
\hline Macaca sinica & +16 & +22 & +15 \\
\hline Alouatta palliata & +40 & +31 & +40 \\
\hline Macaca syluana & +45 & +85 & \\
\hline Presbytis melalophos & +82 & & folivore \\
\hline
\end{tabular}

Gut specialization index Dietary index (Fig. 27)

Fig. 29. Method for comparing the potential volume of fermentation in the gastro-intestinal tracts of various primates with contrasting diets. The log of volume (of stomach, caecum, and colon) is plotted against the log of body weight (taking $\frac{L^{3}}{30}$ as a good approximation for body weight), so as to eliminate allometric parameters. The resulting regressions from a large sample of faunivores and folivores (Fig. 22) are used again here, and considered as showing the structural limits for coping with diets containing $90 \%$ of animal matter and $90 \%$ of leaves, respectively. Most primates fall within these limits, and the distance $\mathrm{D}$ from the regression line for frugivores can be regarded as an indicator of the morphological tendency towards faunivory or folivory. The conditional formula presented allows a transformation of $\mathrm{D}$ into the index $\mathrm{TR}_{\mathrm{p}}$, which, in most cases, is the same number as the dietary index, $x$, as defined from the tri-rectangular projection (Fig. 27). 
The similarities between indices for each species are pleasing, considering that morphological indices refer to single individuals, and the dietary indices are derived separately from data of variable quality. The success of
this approach depends on a) obtaining adethis approach depends on a) obtaining adequate gut samples that are truly representative of the population from which dietary data are obtained, b) obtaining adequate dietary data, in terms of weight of each food ingested, and c) defining in which species morphological adaptations may confer greater dietary flexibility, e.g., variations across the geographic range and feeding behavior in captivity.

Reference has been made to the convergence of the regression lines for potential absorbing area, $A^{\prime}$ (Fig. 26), which renders this model inapplicable to species smaller than $27 \mathrm{~cm}$ inapplicable to species smaller than $27 \mathrm{~cm}$ body length. otential fer. is quite satisfactory for small species. Figure for folivores with large stomachs, however, are not included in Figure 29. To derive in dices of gut specialization (Gsl) for such forms either the A model should be used, or the model revised using the regression line folivores with large stomachs (Fig. 22 .

The specialized seed-eaters have not been included in these models, if primates eat seed. they usually do so in small quantities and when they are unripe. Certain frugivorou squirrels of Gabon also consume some insect. Emmons, 75) and Eptxerus ebu, for example see Table 8), has a GSI from V of -16. Gut specialization indices of other rain-forest squirrels have been calculated from data collected recently in Malaysia (Payne, '79). The small Sundasciurus tenuis, of length $13 \mathrm{~cm}$, which eats mostly bark, sap, and seeds, and some insects, has an index of +100 . The fruiteating species Callosciurus notatus and $C$. prevosti have indices of +97 and -22 respectively, with the latter eating considerably more soft fruit in contrast, the seedreating more son fruit, in contrast, the seed-eating Rets ich in protein and fat seem to -93. seeds rich in protein and fat seem to need processing more like animal matter than the vegetative parts of plants. An unusual primate, Cercopithecus neglectus, whose diet is known to include large quantities of seed. Gautier-Hion, 78), also has low indices. Thus further research is needed on the composition, consumption, and assimilation of seeds ingested by mammals.

In the search for a full physiological expla nation of the relationships between morphology and diet, that we have quantified, two main lines of research should be followed. There needs to be more extensive analysis and quantification of the biochemical compositio of foods, in relation to diet, and of the fin structure and cellular populations of the gastro-intestinal mucosa, in relation to morphology. At the same time, the quantity and comparability of the kinds of morphological and dietary data discussed herein must be im proved, if we are to understand the real significance of "sacs" and "tubes."

\section{ACKNOWLEDGMENTS}

We thank the Smithsonian Institution, especially Dr. Martin Moynihan, who obtained funding for $\mathrm{C}$. M H at the Smithsonian Tropical Research Institute from 1966 to 1968 C.M.H. was also funded in 1969-1970 by the Smithsonian Biological Program in Ceylon, inini me the the y the Centre National de la kecherche Scientificte ( Five employed by the University of Cambridge; he acknowledges the facilities generously provided for his studies, and grants from the Department of Anatomy and University Travel ing Expenses Fund for 2 -month visits to Malaysia in 1972, 1974, and 1976, where loca travel was aided by a Royal Society Govern ment Grant-in-Aid

C.M.H. acknowledges gratefully the coop eration of the Panamanian authorities, the Wildlife Department of Sri Lanka, the Ga bonese authorities involved in the C.N.R.S. Station of Ipassa/Makokou, the Forest. Depart ment of Morocco, and the Service des Eaux et Forrets de Madagascar; and D.J.C. the Head Office of the Game Department (now the Department of Wildlife and National Parks), the State Game Wardens of Pahang and Perak and their staff, and the Institute for Medien Research in Kuala Lumpur, Malaysia Research in Kuala Lumpur, Malaysia. In France guts of primates were obtained from the Museum diristoire Naturelle in Paris, an in England from Miss Mary Brancker, veterinary surgeon to Twycross Zoo, and from the Zoological society of London. We are gratefu to Professor R.J. Harrison for the opportunity to include marine mammals in our survey, and to Mr. David Ellis of British mammals.

We are also indebted to those who assisted us in our unsavory labors, especially our wives, Sarah Chivers and Annette Hladik, and to the Visual Aids Unit, Department of
Anatomy, Cambridge, for their reproduction of the figures. Finally, we thank Donald Steven and R.D. Martin in particular among those who have given helpful advice during the course of this work; and Donald Steven, John Payne, Pierre Charles-Dominique, G. Cansela da Fonseca, and Gerard Dubost for their constructive comments on the manuscript.

\section{LITERATURE CITED}

Bolk, L., E. Göppert, E. Kallius, and W. Lubosch (1939) Handbuch der vergleichenden Anatomie der Wirbeltiere.
Band III. Darmsystem. Urban and Schwarzenberg, Berlin

and Vienna.
Bell, G.H., J.N. Davidson, and H. Scarborough (1963) Textbook of Physiology an

ingstone, Edin 1973) A survey of proses stomach morphot ogy, In: New World Cricetinae (Rodentia, Muroidea), with comments on functional interpretntions. Misc. Publ. Mus. Zool., University of Michigan, No. 146, pp. 1-43. Charles-Dominique, P, and C.M. Hladik (1971) le lep Charles-Dominique, P. (1978) Ecologie et vie sociale de Nandinia binotata (Carnivores, Viverridés): Comparison avec les prosin
$32: 477-528$

(1974) The Siamang in Malaya. Primatol. $4: 1-335$.
Chivers, D.J., and J. Herbert (1978) Recent Advances in Primatology. Vol. 1. Behaviour. Academic Press, London. Clutton-Brock, T.H. (1977) Primate Ecology. Studies of
Feeding and Ranging Behaviour in Lemurs, Monkeys reeding and Ranging Behaviour in Lemurs, Monkeys
and Apes. Academic Press, London. Comline, R.S., IA. Silver, and D.H. Steven (1968) Physiological anatomy of the ruminant stomach. In: Handbook of Physiology. Sect. 6 (alimentary canal). Vol. 5. Am. Physiol, Soc, Washington, pp. 2647-2671.

政,

Per, G. (1805) Lecons d'Anatomie Comparée, Crochard, Eillenberger, W., and H. Baum (1921) Handbuch der vergleichenden Anatomie der Haustiere. Hirschwald, Berlin.
Emmons, L. (1975) Behaviour and Ecology of African Rain Forest Squirrels. Ph.D. dissertation. Cornell University, Ithaca, New York

rooden, J. (1964) Stomach contents and gastro-intestinal proportions in wild shot Guianan monkeys. Am. J. Phys. Anthrop., n.s.. 22: 227-231.

Toes and coexistence in

- $\quad \begin{aligned} & \text { sympatric primates in Gabon. In: Recent Advances in } \\ & \text { Primatology. Vol. 1. Behaviour. D.J. Chivers and J. }\end{aligned}$ Herbert, eds. Academic Press, London, pp. 269-286.

Genest-Villard, H. (1968) Lestomac de Lophuromys si

pusi (Rongeurs, Muriedés). Mammalie, 32:639-656.
Giesecke, D. (1969) Comparative microbiology of the ali mentary tract. In: Physiology of Digestion and Metato-
lism in the Ruminant. A.T. Phillipson, ed. Oriel Press, Newcastle, pp. 306-318.

Goodall, A.G. (1977) Feeding and ranging behaviour of a mountain gorilla group in the Tshibinda-Kahuzi region
(Zaire) In: Primate Ecology: Studies of Feeding and Ranging Behaviour in Lemurs, Monkeys and Apes TH. Clutton-Brock, ed. Academic Press, London, pp. 449-479. Grassé, P. P. (1955) Traité de zoologie: Anatomie, systematique, biologie. Marmmiferes, fasc. 2:1646-1653. Masson,
Harrison, R.J., F.R. Johnson, and B.A. Young (1970) The us, Stenella. J. Zool., London, 160:377-390. and large intestine: Form and position. Primatologia

3:139-207.
ladik, C.M. (1967) Surface relative du tractus digestif de quelques primates, morphologie des villosités intestín. malia, $31: 120-147$.

Hladik, C.M. (1973) Alimentation et activité d'un groupe de chimpanzés reintroduit en forèt gabonaise. Terre e Vie, 27:343-41:

ladik, C.M. (1975) Ecology, diet and social patterning in Old and New World primates. In: Socio-ecology and
Psychology of Primates. R.H. Tuttle, ed. Mouton, The Hague, pp, $3-36$.

(1) Chimpanzes of Gabon and chimpan zees of Gombe. In: Primate Ecology. Studies of Feeding and Ranging Behaviour of Lemurs, Monkeys and Apes $595-601$.

Hladik, C.M. (1977b) A comparative study of feeding strat egies of two sympatric species of leaf monkeys. Presbytis senex and Presbytis entellus. In: Feeding and Ranging Brock, ed Academic Press, London, pp. 481-501. Hladik, C.M. (1978a) Adaptive strategies of primates in relation to leaf-eating. In: Ecology of Arboreal Folivores,
G.G. Montgomery ed. Smithsonian Institution Press, Washington. pp. 373-395.

The Study of Prosimian Behaviour G G A prosimians. In
Thyle and B.D. Martin, eds, Academic Press, New York, pp 307-357. Hladik, C.M., and P. Charles-Dominique (1974) The behav iour and ecology of the sportive lemur /Lepilemur mus telinuss in relation to its dietary peculiarities. In: Prosi-
mian Biology. R.D. Martin, G.A. Doyle, and A.C. Walker, Mladik, C.M., and D.J. Chivers (1978) Concluding discus. sion: Ecological factors and specific behavioural pattern determining primate diet. In: Recent Advances in $\mathrm{Pr}$ matology. Vol. 1, D.J. Chivers and J. Herbert, eds. Aca
demic Press, London, pp. 433-444.

vén Colorado (Panama). Terre et Vie, 26:25-11

C.M., and A. Hladik (1972) Disponisilité alimer taires et domaines vilt ix dr

Hladik, C.M., A. Hladik, J. Bousset, P. Valdebouze, G. aire des primates de l'ile de Barro Colorado (Panama) Résultats des analyses quantitatives. Folia Primatol, 16:85-122 troop of Japanese monkeys (Macaca fuscata) at Koshim Istet, Miyazaki. Primates, 15:241-262

(1) Food avallability as a limiting factor on poptape macaque and gelad Chivers and J. Herbert, eds. Academic Press, London, pp.

Janis, C. (1976) The evolutionary strategy of the Equida and the origins of rumen and caecal digestion. Evolution, 30: $757-774$

Kay, R.F. (1973) Mastication, Molar Tooth Structure and Diet in Primates. Ph.D. dissertation, Yale University,

Kay, R.N.B., and E. Pfeffer (1969) Movements of water an 
Physiology of Digestion and Metabolism in the RumiPhillipson, ed. Oriel Press, Newcastle, pp Kayser, C. (1963) Digestion et absorption. In: Physiologie. Vol. 1. C. Kayser, ed. Flammarion, Paris, pp. 247-406 Kuhn, H.J. (1964) Zur Kenntnis von Bau und Funktion des 2:193-221. MacKinnon, J.R., and K.S. MacKinnon (1978) Comparative feeding ecology of six sympatric primates in West Malay-
sia. In: Recent Advances in Primatolog y. Vol. 1. D.J. sia. In: Recent Advances in Primatology. Vol. 1. D.J.
Chivers and J. Herbert, eds. Academic Press, London, pp. Chivers and J. Herbert, eds. Academic Press, Lordon, pp.
305. Magnan, A. (1912) Le régime alimentaire et la longeur de l'intestin chez les Mammiferes. C.R. Acad. Sci. (Paris) 154:129-131.

McMahon, T. (1973) Size and shape in biology. Science, 179:1201-1204:

On the intestinal tract of mammals.

Moir, R.J. (1968) Ruminant digestion and evolution. In 5. Am. Physiol. Soc., Washington, pp. 2673-2694.

5. Am. P. of Do., Washington, pp. 2673-2694. Vol. dard Statistical Methods. Pitman, London. léporidés. Rec. Med. Vet., 59:635-646.

Parra, R. (1978) Comparison of fore-gut and hind-gut fermentation in herbivores. In. The Ecology of Arborea Press, Washington, pp. 205-229. Payne, J.B. (1979) On the Ecology of Malayan Rain-Forest
Squirrels. Ph.D. dissertation. University of Cambridge, Cambridge. Ecology of Siamang and lar Gibbons. Ph.D. dissertation University of Cambridge, Cambridge.

Ripley, S. (1979) Environmental grain, niche diversification ronment, Behaviour and Morphology: Dynam tions in Primates. H. Preuschoft and M.E. Morbeck, eds. Gustav Fischer, New York, pp. 37-74

Schmidt-Nielsen, K. (1972) How Animals Work. Cambridge University Press, Cambridge

(1965) Digestion and assimilation the stomach and intestines of ruminant. In Physiology of Digestion in the Ruminant. R.W. Dougherty, ed. Butterworths, London, pp. 254-261

Struhsaker, T.T. (19 in the Kibale Forest, Uganda. In: Recent Advances in Academic Press, London, pp 225-248.

Suzuki, A. (1965) An ecological study of wild Japanese focused on their food Primates, 7:481-487. coprophag y normally Tucker, V.A. (1970) Energetic cost of locomotion in animals Comp. Biochem. Physiol., 34: 841-846.

Vallenas, A., J.F. Cummings, and J.F. Munnell (1971) A gross study of the compartmentalised stomach of two New World ca $134: 399-424$.
Adresse de C.M. Hladik en 2013 :

Claude Marcel HLADIK

Directeur de recherche émérite

Eco-Anthropologie et Ethnobiologie

Muséum National d'Histoire Naturelle

4 avenue du Petit Château

91800 Brunoy (France)

cmhladik@mnhn.fr

<http://www.ecoanthropologie.cnrs.fr/IMG/pdf_Site-WEB-Hladik-2013.pdf>

\section{éco-anthropologie} ethnobiologie 